DEVELOPMENT OF A COMPUTER-AIDED DRAGLINE SELECTION PROGRAM

A THESIS SUBMITTED TO

THE GRADUATE SCHOOL OF NATURAL AND APPLIED SCIENCES $\mathrm{OF}$

MIDDLE EAST TECHNICAL UNIVERSITY

BY

SAYID AKHUNDOV

IN PARTIAL FULFILLMENT OF THE REQUIREMENTS

FOR

THE DEGREE OF MASTER OF SCIENCE

IN

MINING ENGINEERING

OCTOBER 2017 

Approval of the thesis:

\section{DEVELOPMENT OF A COMPUTER-AIDED DRAGLINE SELECTION PROGRAM}

Submitted by Sayid Akhundov in partial fulfillment of the requirements for the degree of Master of Science in Mining Engineering Department, Middle East Technical University by,

Prof. Dr. Gülbin Dural Ünver

Dean, Graduate School of Natural and Applied Sciences

Prof. Dr. Celal Karpuz

Head of Department, Mining Engineering Dept.

Assoc. Prof. Dr. Nuray Demirel

Supervisor, Mining Engineering Dept., METU

\section{Examining Committee Members}

Prof. Dr. Bahtiyar Ünver

Mining Engineering Dept., Hacettepe University

Assoc. Prof. Dr. Nuray Demirel

Mining Engineering Dept., METU

Prof. Dr. Celal Karpuz

Mining Engineering Dept., METU

Assoc. Prof. Dr. Hasan Aydin Bilgin

Mining Engineering Dept., METU

Assoc. Prof. Dr. Mehmet Ali Hindistan

Mining Engineering Dept., Hacettepe University

Date: 13. 10. 2017 
I hereby declare that all information in this document has been obtained and presented in accordance with academic rules and ethical conduct. I also declare that, as required by these rules and conduct, I have fully cited and referenced all material and results that are not original to this work.

Name, Last Name:

Signature 


\title{
ABSTRACT \\ DEVELOPMENT OF A COMPUTER-AIDED DRAGLINE SELECTION PROGRAM
}

\author{
Akhundov, Sayid \\ MS, Mining Engineering Department \\ Supervisor: Assoc. Prof. Dr. Nuray DEMIREL
}

October 2017,81 pages

Selection of appropriate machine and equipment is one of the most critical tasks required in surface mining. Since draglines are massive and expensive machines, their selection is of paramount concern to mining engineers and decision makers. The selection of appropriate dragline model requires simultaneous consideration of various parameters, such as geological properties of overburden material, stripping method, available fund and technology. Therefore, this is a complex and time-consuming process.

In this study, the dragline selection process was reviewed and a computeraided selection program, Draglayout, was developed to increase the efficiency in the selection process. The developed software suggests list of the commercially available dragline units based on its maximum suspended load and reach factor which are compatible to achieve the given stripping and production targets.

The selection process consists of four main stages as:

i. Initial estimations of dragline operation parameters (availability, dragline utilization, dragline operating hours, cycle time, ore production, ore recovery, etc.),

ii. Defining initial mine design geometry, 
iii. Available equipment geometry and mine design relations,

iv. Reviewing the above steps and selecting the dragline.

Developed Draglayout software is an easy and useable tool for selecting dragline equipment. Draglayout provides mining engineers and decision makers with an efficient and easy way to select the most appropriate dragline for the required stripping targets.

Keywords: Open cast, dragline, selection, side casting. 


\title{
$\ddot{\mathbf{O z}}$
}

\section{BİLGISAYAR DESTEKLİ ÇEKME KEPÇELİ YERKAZAR SEÇIM PROGRAMININ GELIŞTIRILILESI}

\author{
Akhundov, Sayid \\ Yüksek Lisans, Maden Mühendisliği Bölümü \\ Tez yöneticisi: Doç. Dr. Nuray DEMIREL
}

Ekim 2017, 81 sayfa

Açık maden işletmeciliğinde uygun makine ve ekipman seçimi en kritik işlerden biridir. Çekme kepçeli yerkazarlar büyük ve yatırım maliyeti yüksek makinalar olmaları nedeni ile bunların seçimi maden mühendisleri ve karar vericiler için büyük önem arz etmektedir. Çekme kepçeli yerkazar seçimi, üst örtü malzemesinin jeolojik özellikleri, sıyırma metodu, mevcut yatırım miktarı ve ulaş1labilir teknoloji gibi farklı parametrelerin bir arada düşünülmesini gerektiren karmaşık ve zaman alıcı bir işlemdir.

$\mathrm{Bu}$ çalışmada, seçim işleminin etkinliğini ve hızını arttırmak amacıyla, konvansiyonel seçim yöntemleri irdelenmiş ve Draglayout isimli bilgisayar destekli seçim programı geliştirilmiştir. Geliştirilen yazılım, maksimum asılı yük ve gereken erişim faktörüne dayanarak mevcut yer kazarlar arasından amaçlanan kazıyı gerçekleştirebilecek en uygun makinaları önermektedir.

Seçim prosedürü başlıca dört aşamadan oluşmaktadır. Bunlar:

i. Operasyon parametrelerinin başlangıç tahminlerinin yapılması (çekme kepçe kullanabilirliği ve kullanımı, yıllık kazı süresi, bir döngü süresi, yıllık üretim, geri kazanma),

ii. İlk maden tasarım geometrisini tanımlaması, 
iii. Kullanılabilir çekme kepçeli yerkazar geometrisi ve maden tasarımı ilişkilerinin belirlenmesi,

iv. Yukarıdaki adımları gözden geçirilip, en uygun çekme kepçeli yerkazarların seçilerek önerilmesi.

Geliştirilen Draglayout yazılımı, çekme kepçe seçmek için kolay ve kullanışlı bir araçtır. Draglayout maden mühendislerine ve karar vericilere en uygun ve hedeflenen kazıyı gerçekleştirecek çekme kepçeli yerkazarı seçmeleri konusunda etkin ve kolay bir araç sağlamaktadır.

Anahtar sözcükler: açık ocak, çekme kepçe, seçim, basit kazı yöntemi. 
To My Niece Deniz Dinç 


\section{ACKNOWLEDGMENTS}

I would like to thank my sister and my mother for their continuous support and faith in me.

I wish to express my appreciations to my supervisor Assoc. Prof. Dr. Nuray DEMİRL for her assistance and continuous help throughout making of this thesis.

I also express my gratitude to my thesis Examining Committee members Prof. Dr. Celal KARPUZ, Prof. Dr. Bahtiyar ÜNVER, Assoc. Prof. Dr. Hasan Aydın BİLGIN and Assoc. Prof. Dr. Mehmet Ali HINDISTAN for their interest and time spent.

also would like to thank:

My METU professors from Mining Engineering department for their knowledge given to me.

My friends Yashar Abbas, Ismayil Heyderli, Valeh Muzaffer, Elnara Ghurbanova, Ensar Ilhan, Nijat Mutallibov for their interesting ideas that put me on the right track throughout making of this thesis. 


\section{TABLE OF CONTENTS}

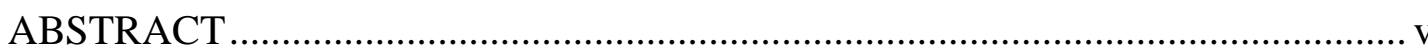

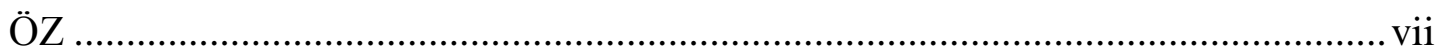

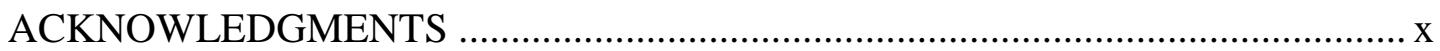

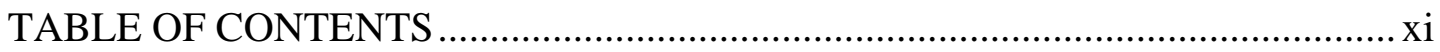

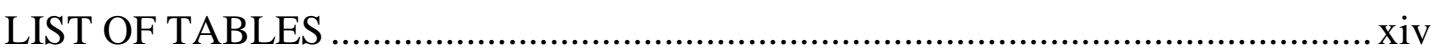

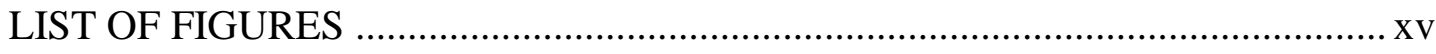

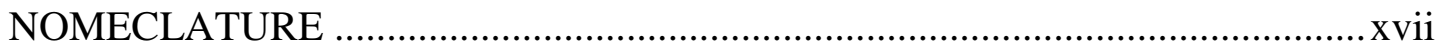

\section{CHAPTERS}

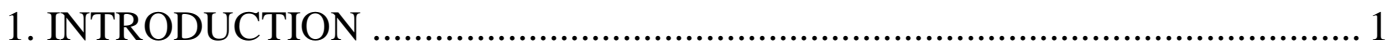

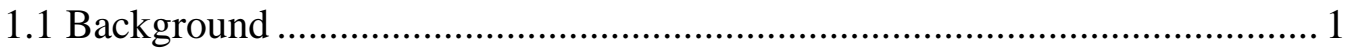

1.2 Statement of the Problem .......................................................................... 2

1.3 Objective and Scope of the Thesis ........................................................... 2

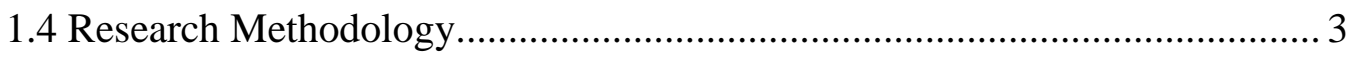

1.5 Significant Industrial and Theoretical Contributions of the Study ............... 4

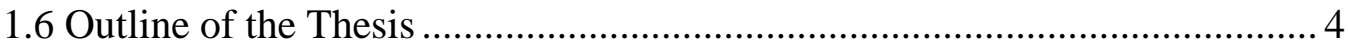

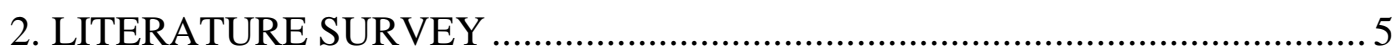

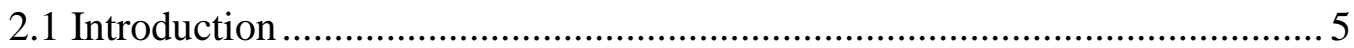

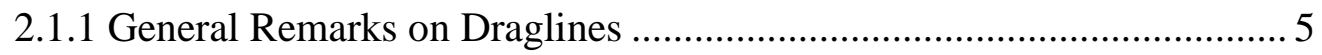

2.1.2 Dragline Applications and Advantages............................................... 6

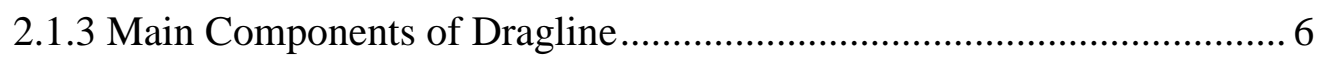

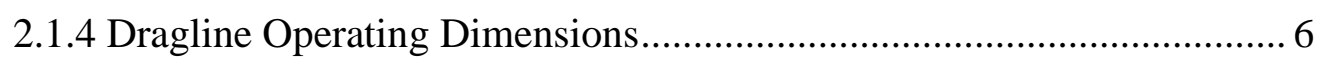

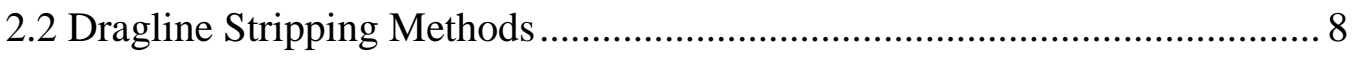

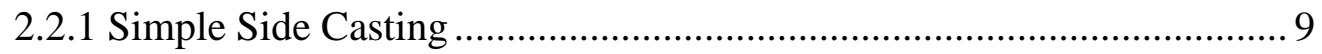


2.2.2 Advance Benching ............................................................................ 11

2.2.3 Standard Extended Bench with an Advance Bench ............................... 12

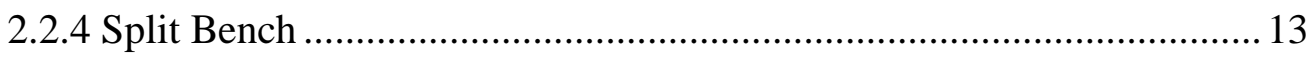

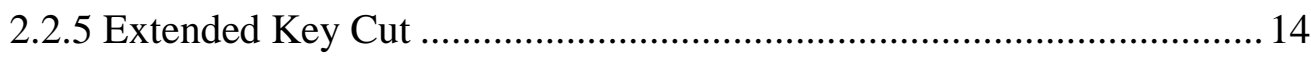

2.3 Blasting in Dragline Operations ................................................................... 14

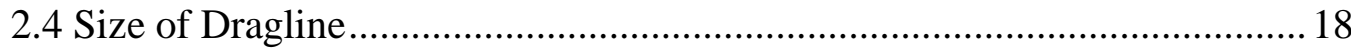

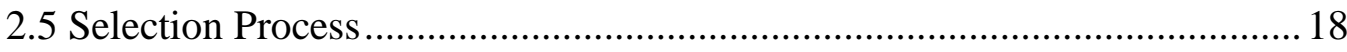

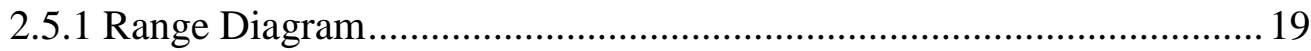

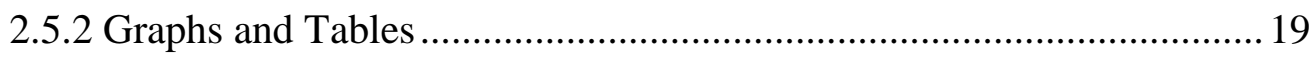

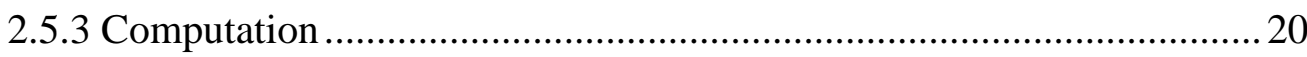

2.6 Previous Researches on Dragline Selection ................................................. 20

3. DEVELOPMENT OF A DRAGLINE SELECTION PROGRAM .....................23

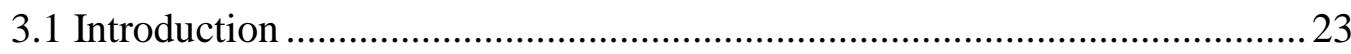

3.2 Flow of Selection Process …………………………………………….... 23

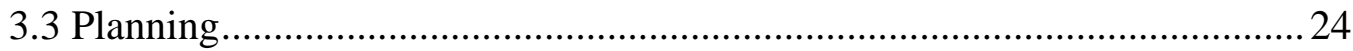

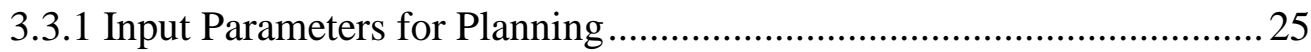

3.3.2 Production Estimations and Operation Parameters ................................. 27

3.4 Mine Layout Design and Geometry ......................................................... 28

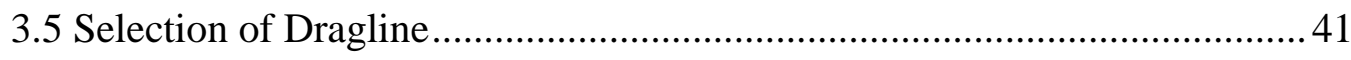

3.5.1 Selection Chart ................................................................................... 41

3.5.2 Developed Draglayout Software Selection .......................................... 42

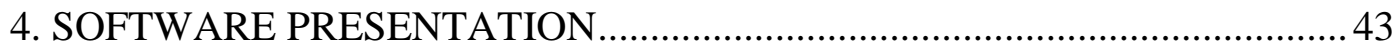

4.1 Installing and Running the program........................................................... 43

4.2 Creating a New Project ……………………………………………….... 43

4.3 Opening Existing Project ......................................................................... 45

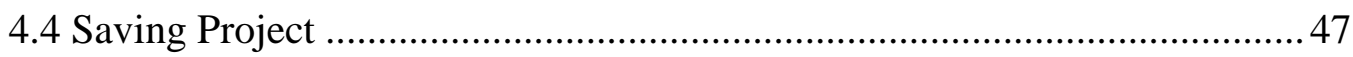

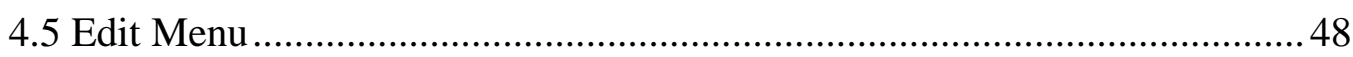

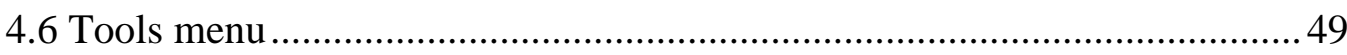

4.6.1 Tools: Add and Remove Models.......................................................... 51

4.6.2 Tools: Selection Criteria.................................................................... 51 


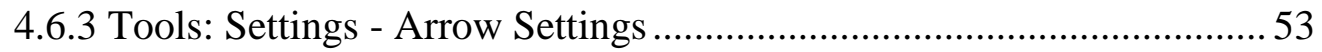

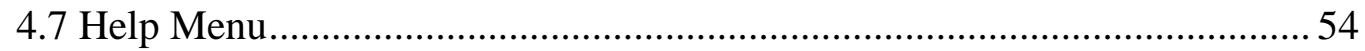

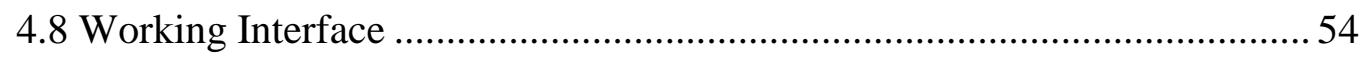

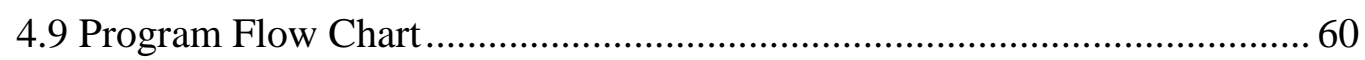

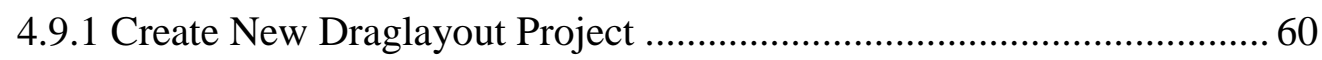

4.9.2 Load Existing Draglayout Projects ...................................................... 60

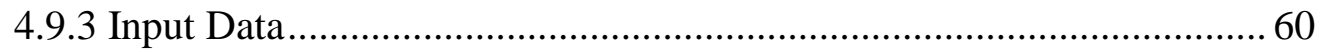

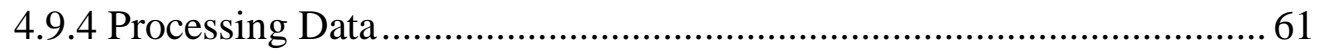

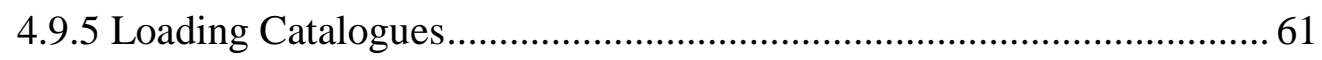

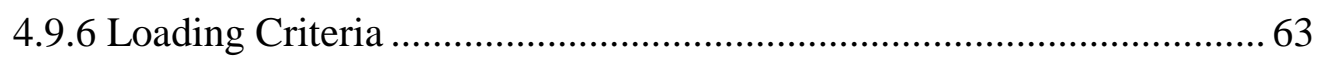

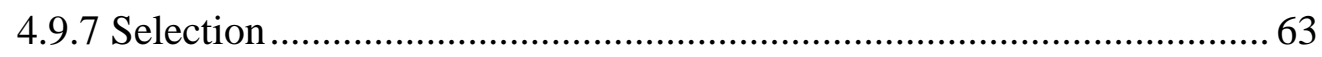

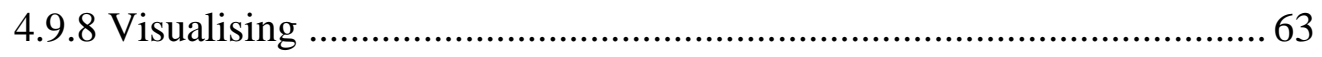

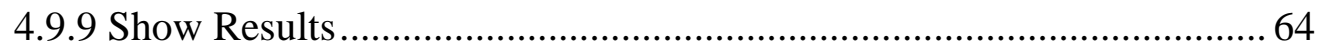

4.10 Validation of the Developed Software ….................................................... 64

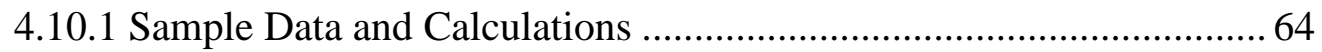

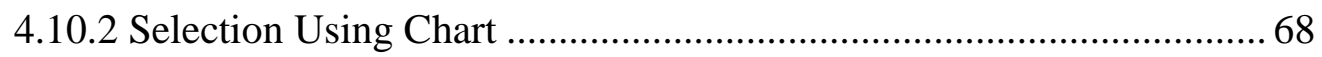

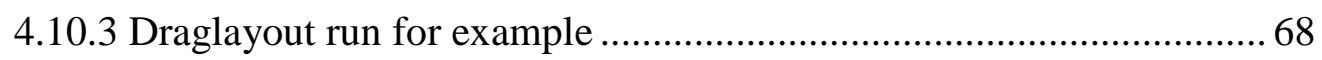

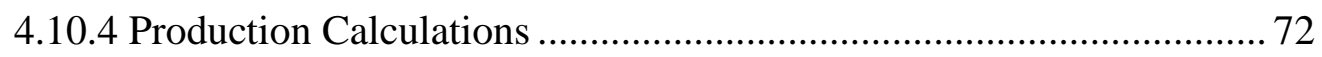

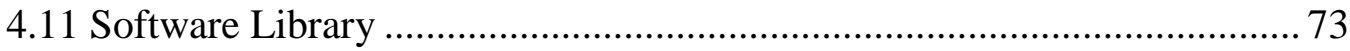

5. CONCLUSIONS AND RECOMMENDATIONS ......................................... 77

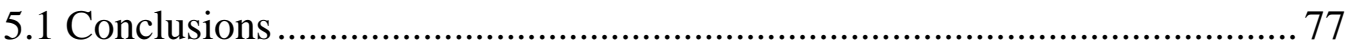

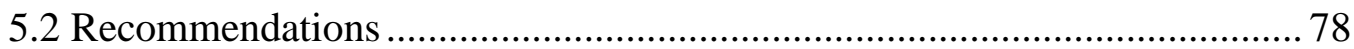

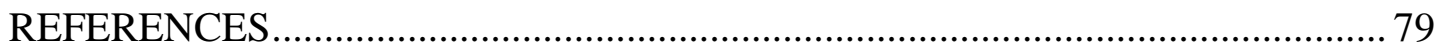




\section{LIST OF TABLES}

\section{TABLES}

Table 1. Relation between overburden conditions, swell factor and bucket fill

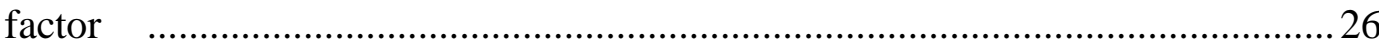

Table 2. Theoretical cycle time according to dragline operation swing angles and

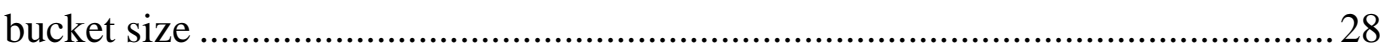

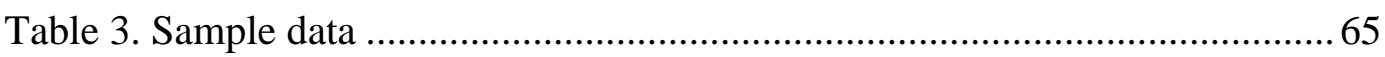

Table 4. Dragline standard machine selection table ........................................... 73 


\section{LIST OF FIGURES}

\section{FIGURES}

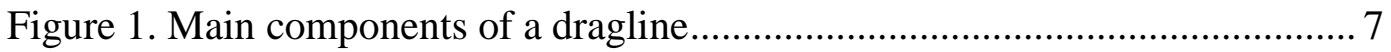

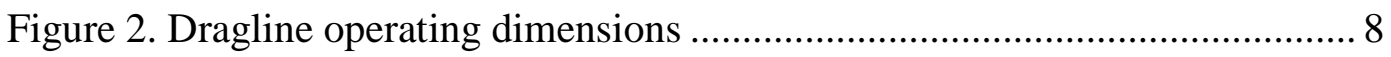

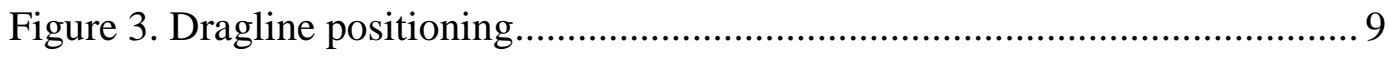

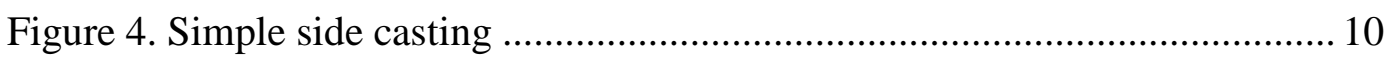

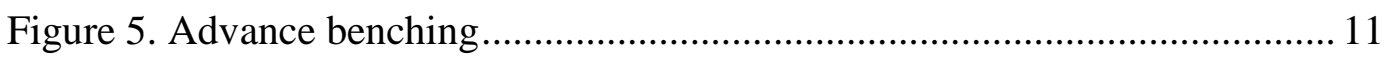

Figure 6. Extended bench ............................................................................. 13

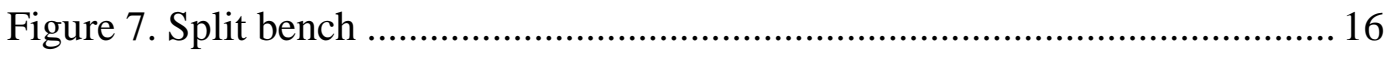

Figure 8. Extended key cut method ...................................................................... 17

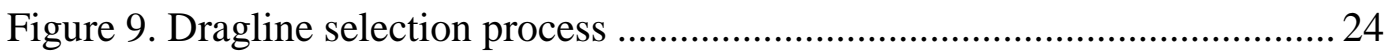

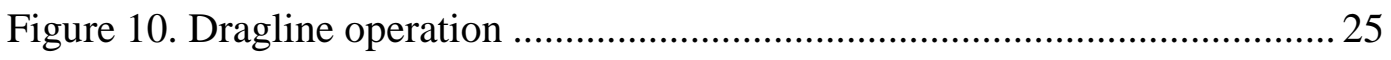

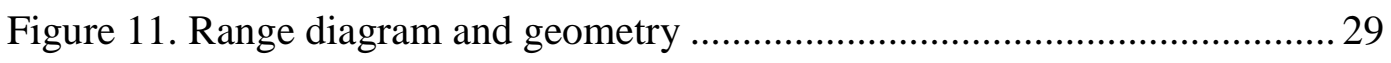

Figure 12. Volume of spoil pile for a unit thickness (VAs) and volume of

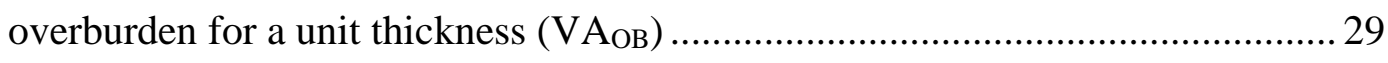

Figure 13. Spoil pile height and stacking height parameters .............................. 32

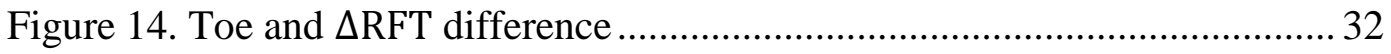

Figure 15. Reach Factor and operation radius ................................................. 34

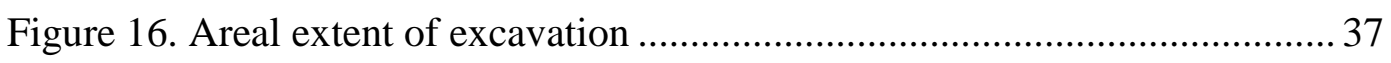

Figure 17. Dragline standard selection chart .................................................. 41

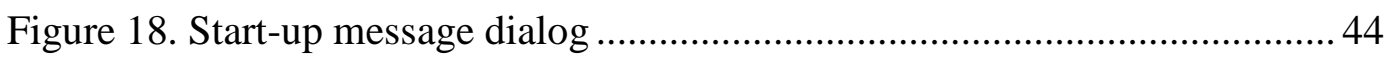

Figure 19. Creating new project dialog .............................................................. 46

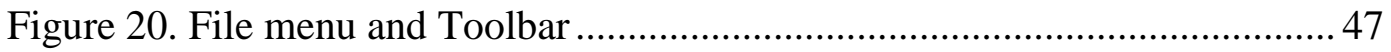

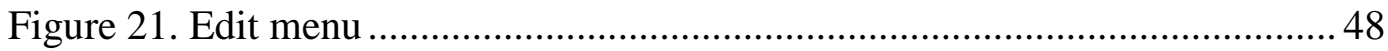

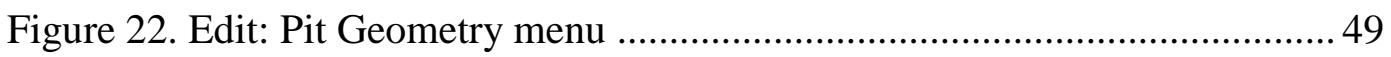

Figure 23. Edit: Material Characteristics menu................................................... 50

Figure 24. Edit: Operation Parameters dialog ................................................. 50

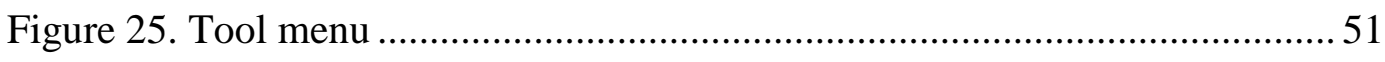




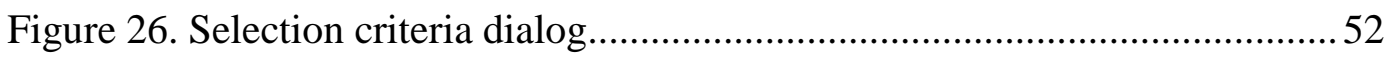

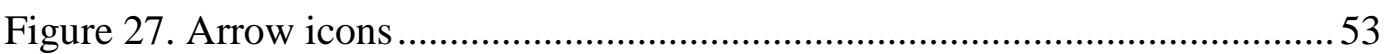

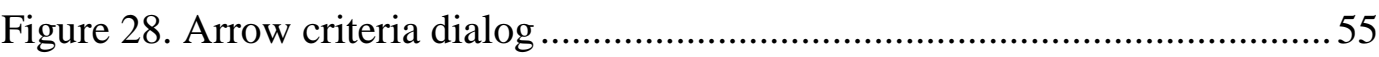

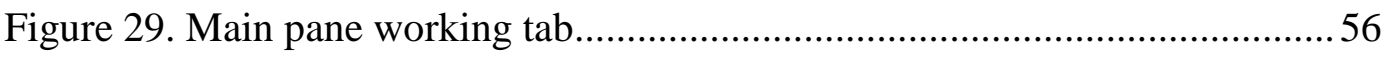

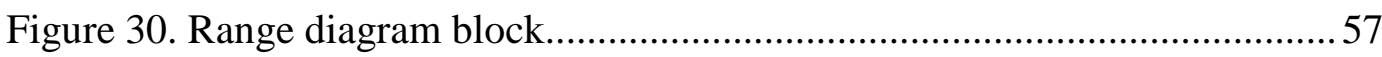

Figure 31. Working tab a) Parameters block, b) Output block..............................58

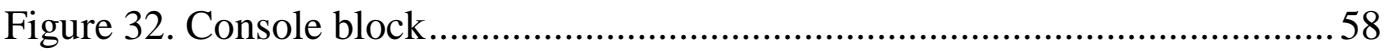

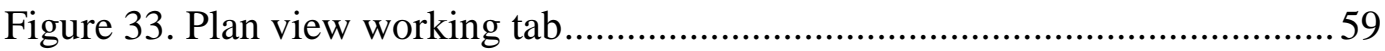

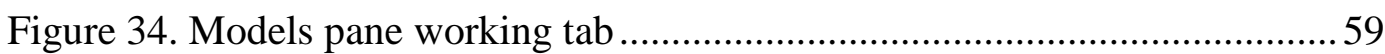

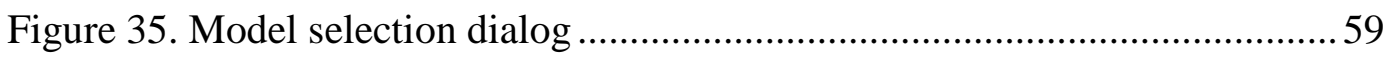

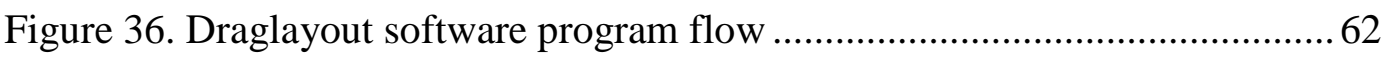

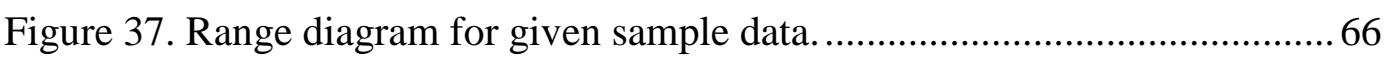

Figure 38. Selecting an appropriate model by their parameters from chart .......... 69

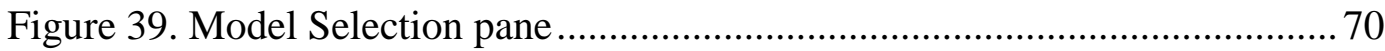

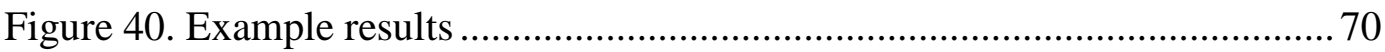

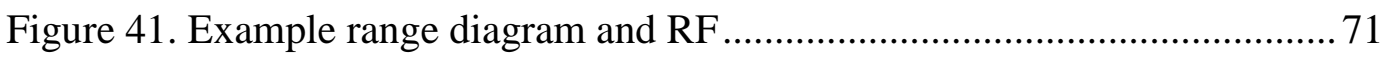

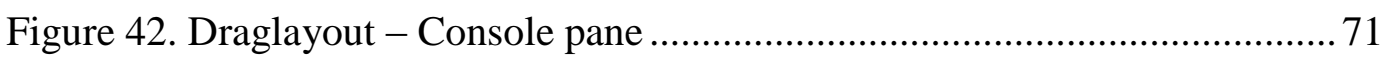

Figure 43. Draglayout output screen after changes on toe applied and related

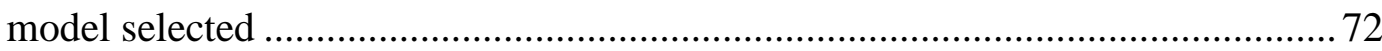




\section{NOMECLATURE}

$\boldsymbol{\theta}:$ Spoil pile angle

$\boldsymbol{\beta}$ : Pit slope angle

$\gamma_{B}$ : The specific unit weight of empty bucket respect to its capacity

$\gamma_{L}$ : Lose weight of overburden rock material

$\boldsymbol{A}$ : Dragline availability

BA: Boom angle

$\boldsymbol{B C}:$ Required bucket capacity

$\boldsymbol{B C}_{\boldsymbol{M}}$ : Bucket capacity of model

$\boldsymbol{B F}$ : Bucket fill factor

BH: Boom foot height

BP: Boom point height

CH: Clearance height

CR: Clearance radius

CT: One cycle time of dragline in seconds

D: Overburden thickness.

$\boldsymbol{d}_{\boldsymbol{C}}:$ Coal density

$\boldsymbol{d}_{\boldsymbol{O} \boldsymbol{B}}$ : Overburden density

DC: Dumping clearance

DD: Digging depth

DH: Dumping height

FR: Boom foot radius

JRE: Java Runtime Environment

$\boldsymbol{H}$ : Height of spoil pile

$\boldsymbol{h}_{\text {Toe }}$ : Toe height in meters

$\boldsymbol{L}$ : Length of cut

MA: Areal extend of excavation 
MSL: Maximum suspended load

$\boldsymbol{M S \boldsymbol { L } _ { \boldsymbol { M } }}$ : Maximum allowable load of model

$\boldsymbol{O}$ : Dragline operating time

$\boldsymbol{O}_{L}:$ Coal lost

$\boldsymbol{O}_{U}:$ Coal uncovered

$\boldsymbol{O} \boldsymbol{B}_{\boldsymbol{M} \boldsymbol{t}}$ : Estimated total overburden material which will be excavated with this model

$\boldsymbol{O B}_{T}$ : Total overburden removed per year

$\boldsymbol{O D}$ : Overburden material density

$\boldsymbol{O P}$ : Total operation time of dragline

$O R$ : Operating radius

OR: Operating radius

$P$ : Required coal production

$\boldsymbol{P}_{\boldsymbol{M}}$ : Production offered by model

PD: Dragline positioning

PS: Point sheave pitch diameter

R: Coal recovery

$\boldsymbol{R D}$ : Coal density

$\boldsymbol{R F}:$ Total reach factor required

$\Delta \boldsymbol{R F}_{T}:$ Difference in reach factor applying toe will cause

$\boldsymbol{R} \boldsymbol{F}_{T}$ : Total reach factor required using toeing

$\boldsymbol{R} \boldsymbol{F}_{\mathbf{1}}:$ Reach distance required to reach spoiling area

$\boldsymbol{R} \boldsymbol{F}_{2}$ : Reach distance along the spoil pile to the dumping point

$\boldsymbol{S F}:$ Swell factor of broken overburden material

SH: Stacking height

T: Seam thickness

TD: Tub diameter - The diameter of dragline tub leg on surface.

$\boldsymbol{T o e}_{\%}$ : Toe value referred as a percentage of seam thickness

$\boldsymbol{U}$ : Dragline utilization

$\boldsymbol{V} \boldsymbol{A}_{\boldsymbol{O}}$ : In-Situ volume of overburden cut for a unit thickness.

$V A_{s}:$ Volume of spoil pile for unit thickness 
$\boldsymbol{V}_{\boldsymbol{O B}}$ : Volume of overburden.

$W$ : Pit width.

$\boldsymbol{W}_{\boldsymbol{D}}$ : Dead weight of bucket

$\boldsymbol{W}_{S}$ : Bucket empty unit weight

$\boldsymbol{W}_{\boldsymbol{L}}$ : Pay load of bucket

$\boldsymbol{w}_{1}, \boldsymbol{w}_{2}$ : are the specific weight minimum and maximum ranges 



\section{CHAPTER 1}

\section{INTRODUCTION}

\subsection{Background}

Removal of overburden in open cast coal mines to uncover coal seams is widely done by draglines. Draglines are highly advantageous over shovel truck system because of high productivity and low costs of process in open cast mines. They can handle overburden excavation, haulage and dumping operations with single equipment which results in increase in mining productivity and decrease in mining costs. Although operating cost is low, the initial investment of dragline is high and dragline equipment selection has to be done very carefully since, there is no chance to change it.

Optimum dragline selection is closely related to stripping method to be applied. There are several factors that have to be considered such as, the deposit burial conditions, mine production rate, cast blasting results, stripping operation method, and parameters that may comprehensively influence the optimal selection of technical specifications of the dragline. The same model of dragline can be employed in various stripping methods. The best performance can be achieved only when it is employed in a specific stripping method that best characterizes the conditions of mine site and fits ability of selected dragline equipment. It means that the capacity and the productivity of a dragline should be compatible with the geometry of the cut and hence the production and overburden stripping requirements. The selected dragline should meet the geometrical constrains of stripping method which will be applied and also should be capable of removing required volume of overburden in a given period of time. 


\subsection{Statement of the Problem}

Draglines have large usage in recent years and are one of the most capital intensive machines in mining industry. There are few well-known companies that manufacture draglines with different specifications and parameters. Since, it is the most expensive unit for a mining project, the selection of this equipment is one of the most important tasks on equipment selection and it should be made with utmost care. The way of selecting dragline requires consideration of geological properties of deposit, mining method to be applied, and the availability of resources and aspects of available technology offered on market. On selecting appropriate dragline equipment, all these factors have to be taken in to account.

There are several steps and processes to calculate and consider these factors that are related to selection of this equipment. However, a tool or a model, which is specifically utilized for dragline selection, is not currently available. Therefore, selections are done based on some of predefined parameters and market catalogues. This process may cause human error and may yield wrong selection of equipment.

Wrong selection of dragline equipment may cause low production and delays on aimed task, which means loss of money and time. In conventional selection methods using range diagrams and manual computations, dragline model, which is compatible to required stripping, is selected based on predefined design of the cut and required overburden stripping. In order to check the compatibility of others models associated with their productivities, the same drawings and computations should be repeated. This is time-consuming and error-prone process. However, using computerized tools gives an ability to see compatibility of other models and make this selection process quickly.

\subsection{Objective and Scope of the Thesis}

The main objective of this thesis is to develop a dragline selection and productivity prediction program by varying mine layout and dragline parameters to minimize human error affecting the selection procedure. The elements of this objective are (i) conducting a comprehensive literature survey about conventional 
methods; (ii) reviewing and evaluating the dragline selection process with modern approach, (iii) develop a model to minimize human error in calculations and selection, and (iv) validate the developed program with a manual selection procedure.

The study is expected to contribute to mining industry by providing a more flexible, user-friendly, and robust model for dragline selection. The scope of this study covers draglines therefore; the program cannot be used for selection of any other mining equipment.

\subsection{Research Methodology}

In this research, several methods and equations from recent literature used to calculate required bucket capacity and dragline operating dimensions for an optimum dragline equipment to be selected. General concentration decided to be based on simple side casting stripping method because of its simplicity and flexibility.

The main stages of methodology are as follows:

i. Considering "Maximum suspended load" calculations based on required bucket capacity to reach expected production amount.

ii. Developing a computer program, which makes calculations and shows the list of dragline models with required parameters from the catalogues.

iii. Developing a new formula for calculating new approximate production amount based on selected dragline equipment's maximum suspended load.

iv. Developed new software also must calculate and draw the range diagram to see the whole picture better and let preview for acceptable changes on mine layout design.

v. Discussion on finding best dragline equipment and mine layout design pair to reach best production rates. 


\subsection{Significant Industrial and Theoretical Contributions of the Study}

This research brings a new automated tool for dragline equipment selection. Computerized systems are more accurate and fast which results in time saving. The research also introduces an insight into equipment selection and mine design.

With developing modern technologies and increasing market, it is sometimes impossible to follow abilities of new technologies and tools. It is always important to involve researchers to make more studies in developing modern tools in mining industry.

\subsection{Outline of the Thesis}

First chapter of the thesis contains the problem statement and explains the objective, the scope of the thesis, and research methodology. Also, gives some information about the expected contributions of the study. The second chapter, literature survey, contains a background section, summarizes some important knowledge about surface mining, dragline methods and applications, types of dragline equipment and dragline operating dimensions which is crucial in understanding this study. Also conventional selection methods are summarized. At the last section of this chapter, some previous studies related to computerized selection of dragline equipment have been discussed. The third chapter describes all steps of study as, initial planning and mine design, input and output parameters and their calculations, walking dragline selection and interpretation of selection process. The forth chapter presents the software which contains a manual guide for using the developed computerized dragline software (Draglayout). All menus and options provided by the graphical interface of Draglayout are described step by step in separate sections. It also contains step by step guide for installing and loading the software. At the end of the fourth chapter, an example problem illustrates the application and the output results which have been verified by the conventional methods. The last chapter contains the conclusions drawn from the study and some recommendations for future improvements. 


\section{CHAPTER 2}

\section{LITERATURE SURVEY}

\subsection{Introduction}

Open cast mining method which is commonly known as stripping method is a method where the overburden cover is stripped aside a short distance or in to a previous cut with small portions. This process is repeated after the uncovered coal is removed and the overburden from next portion of cut is collected into the previous empty cut. In open cast mining one dragline unit frequently performs both the digging and the transporting functions.

\subsubsection{General Remarks on Draglines}

Draglines are large excavators, used to strip overburden material and sometimes to dump onto spoil banks near the pits from which it excavated. Figure 1 presents a schematic diagram of a typical dragline. The use of large walking draglines for stripping overburden rocks in large open cast coalmines is growing steadily in many countries.

The main application of walking draglines exist in opencast coal projects where the volume of overburden to be handled is many times greater than the volume of mineral to be excavated. For instance, one-meter coal seam may have thirty-meter thick cover of overburden, which may still be an economic proposition to be mined by draglines (Rai, 2004). 


\subsubsection{Dragline Applications and Advantages}

- Draglines are designed to excavate below the level of the machine.

- Generally, they do not have to go in to a pit/hole to excavate it, but operates adjacent to the pit while excavate material from the pit by casting its bucket.

- In addition, ability to excavate from outside the pit is a big advantage, when earth is removed from ditch, canal, or pit containing water.

- It is possible to use a dragline with a long boom if the material excavated can be deposited near the pit to eliminate the need for hauling units, which is reducing the cost of material handling in enormous manner.

\subsubsection{Main Components of Dragline}

Draglines are largest excavators and usually build at the place. Some of the components of a dragline can be modified or replaced according to task requirements. The simple walking dragline consists of 15 main components as shown in Figure 1.

\subsubsection{Dragline Operating Dimensions}

Operating dimensions of dragline are visualized in Figure 2. All terminology and symbols described below are referred to Figure 2 and Figure 3 as well.

- Clearance radius (CR): Clearance radius is the minimum distance from dragline positioning centre which have to be free for safe dragline rotation.

- Boom foot radius (FR): Radius of boom foot.

- Clearance height $(\mathbf{C H})$ : The clearance height for dragline swing or rotation.

- Dumping clearance (DC): The distance between highest position of dragline bucket and boom point end.

- Dumping height (DH): The dumping height from highest position of dragline bucket and dragline operating surface level. 


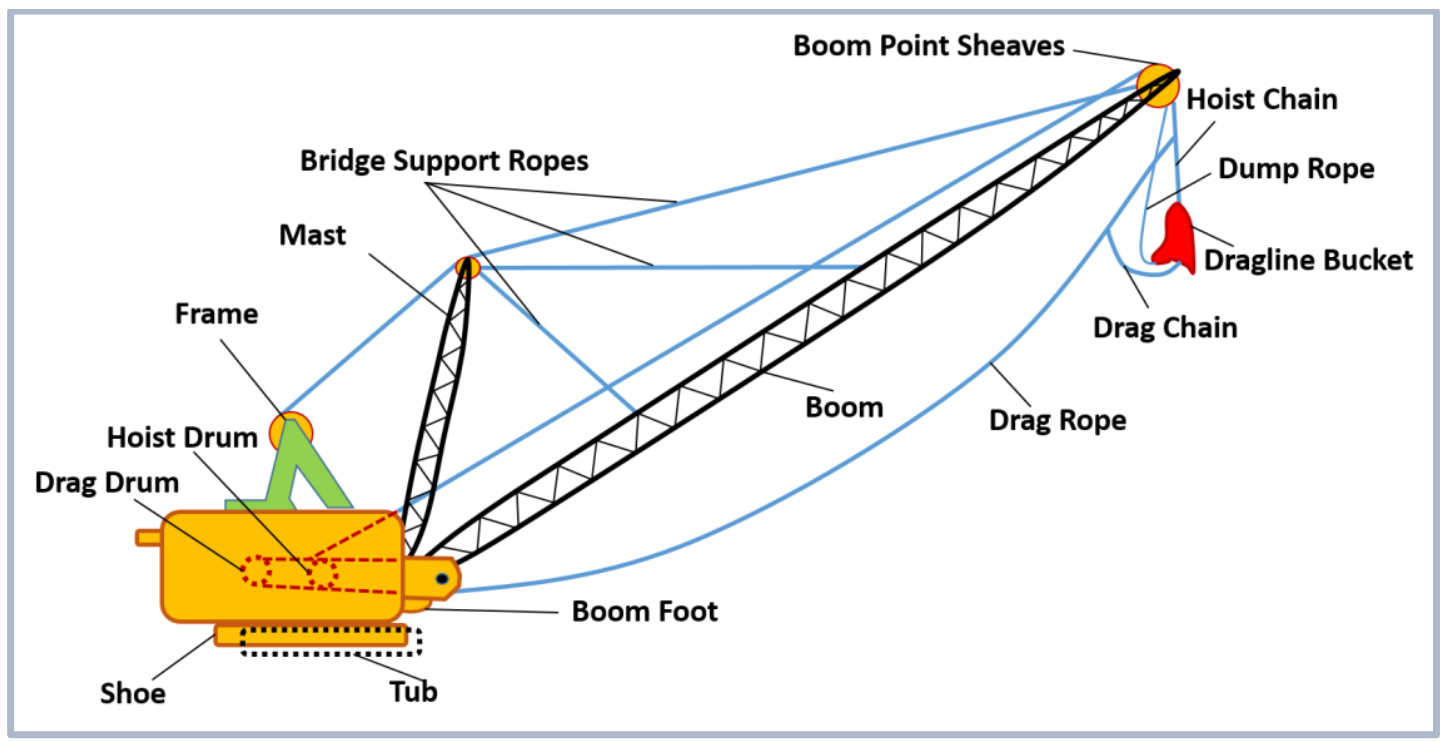

Figure 1. Main components of a dragline (modified from Karpuz and Demirel, 2016)

- Boom point height (BP): The height from boom point end to dragline operating surface level.

- Digging depth (DD): The digging depth of cut.

- Point sheave pitch diameter (PS): Diameter of a pulley block carrying the main rope of dragline bucket

- Tub diameter (TD): The diameter of dragline tub leg on surface.

- Boom angle (BA): Maximum angle of boom from horizontal.

- Boom foot height (BH): Height of boom foot from dragline operating surface.

- Dragline positioning (PD): Dragline positioning is the distance from dragline tub centre point to the end of operating bench. It is usually $75 \%$ of dragline tub diameter (Figure 3.).

- Operating radius (OR): Operating radius is the maximum operating or distance of swinging from the positioning point that dragline available reach in both dragging and spoiling operations (Figure 3.).

- Reach factor (RF): The reach factor of dragline is maximum distance from bench end that equipment can reach (Figure 3.). 


\subsection{Dragline Stripping Methods}

The main usage of a dragline in open cast stripping mining is to remove overburden material in order to uncover the underlying coal/ore. Considering the geological conditions and the size of this monsters different methods and combinations can be applied to complete stripping of a block of material by dragline.

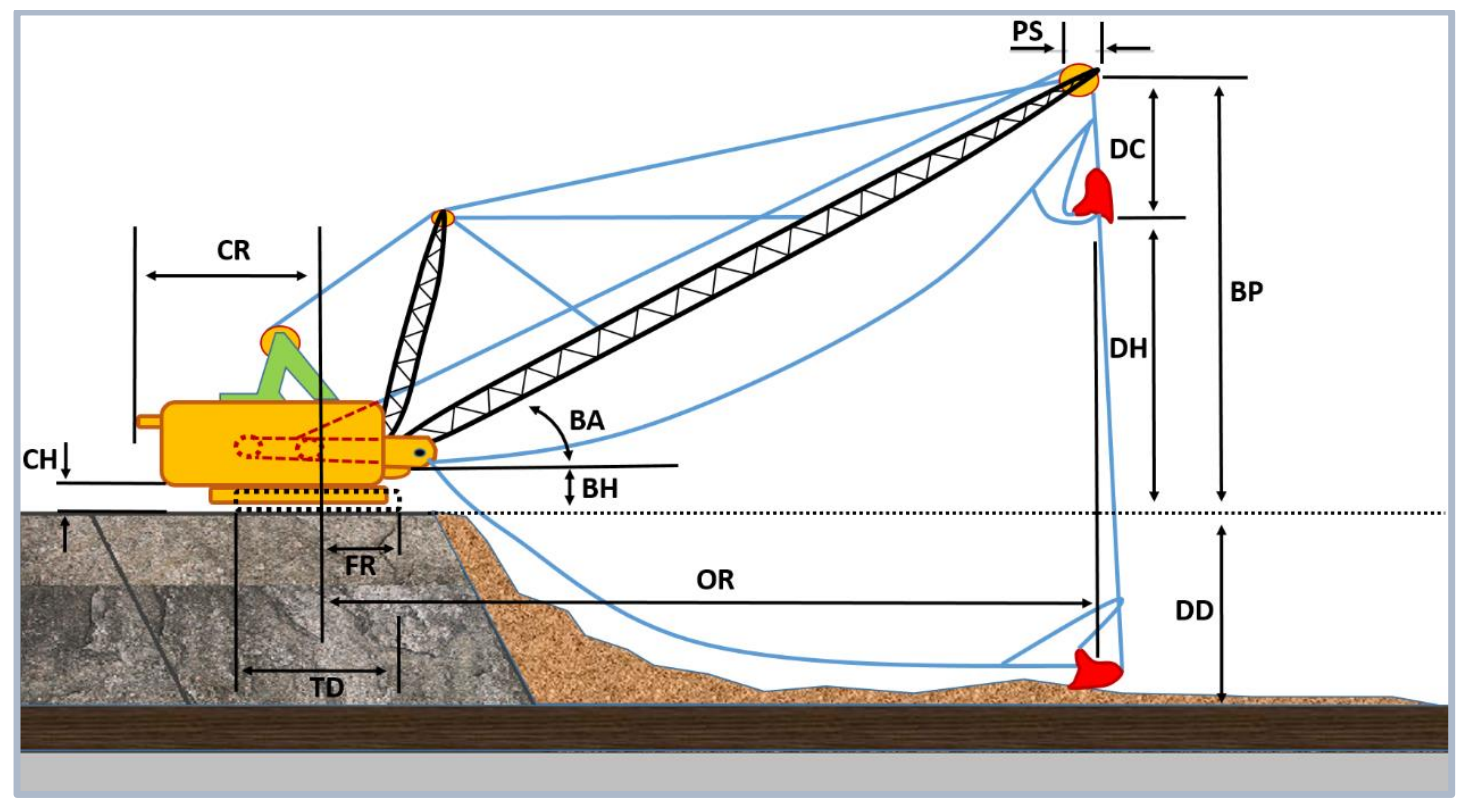

Figure 2. Dragline operating dimensions (modified from Bucyrus-Erie Company Handbook, 2001)

Main geological conditions, which affect the method selection, are:

- Depth of ore or the height of the overburden which must be removed

- Nature of overburden material

- Highwall angle and stability

- Spoil pile angle and stability

- The dragline dimensions (If dragline in hand will be used) 


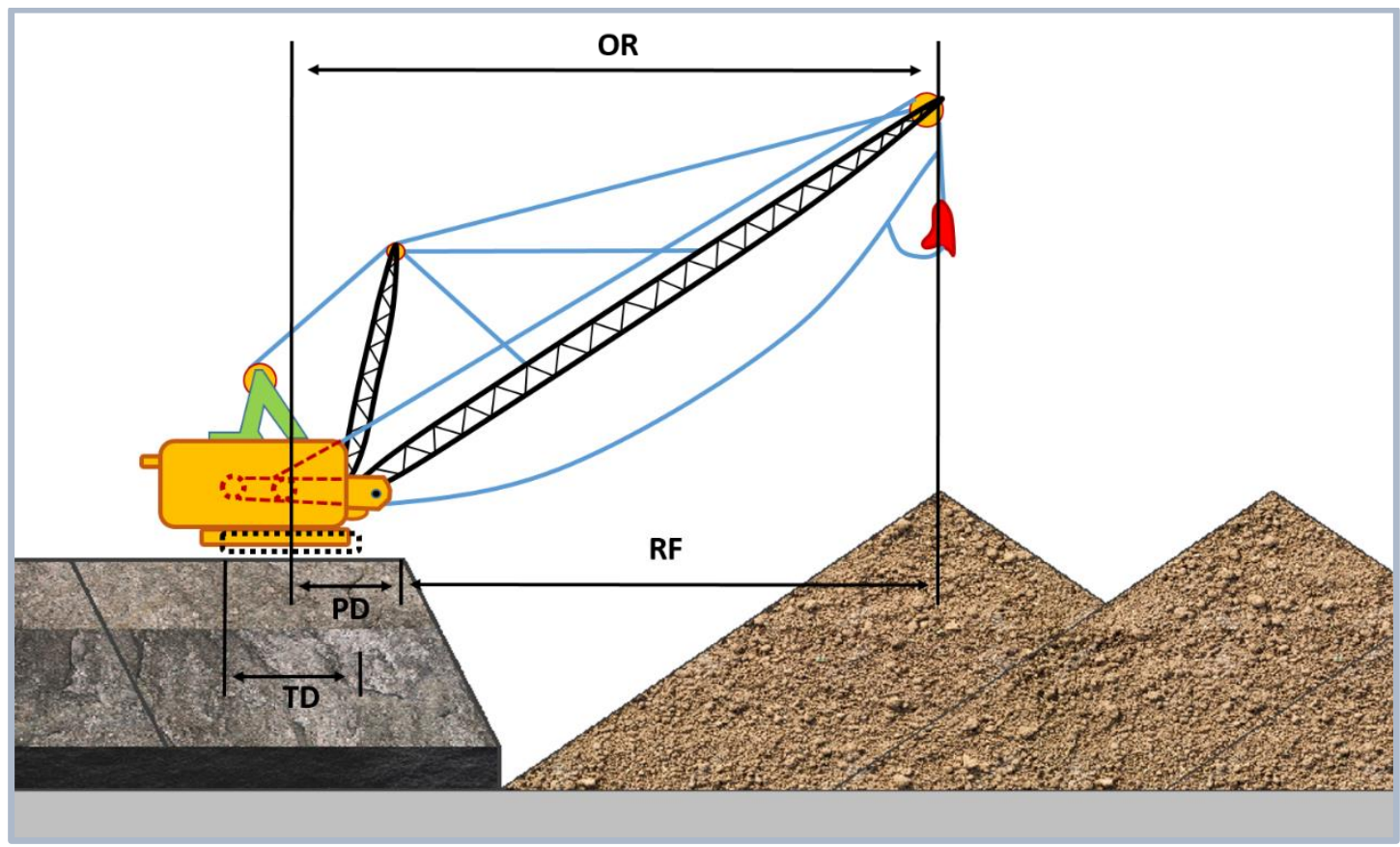

Figure 3. Dragline positioning: OR-Operating radius, RF-Reach factor, Ppositioning, D-Tub diameter (modified from Bucyrus-Erie Company Handbook, 2001)

There are more than twenty traditional dragline stripping methods worldwide. The main common digging methods currently used are:

1. Simple side casting

2. Advance benching

3. Standard extended bench with an advance bench

4. Split bench

5. Extended key cut

\subsubsection{Simple Side Casting}

The basic method for single seam operations with shallow depths is simple side casting method. No rehandle is involved, except some rehandling around coal access ramps. The main process of the method is the dragline placed on the main 
pass level surface and digging the surface of ore/coal and dropping the removed overburden in to a pile at one side (Figure 4).

Advantages of this method are

- Simple system and simple site geometry

- The swing angles of dragline are minimum

- No rehandle needed if the digging depth is greater than the overburden depth

The main disadvantage of this method is, capacity is limited and controlled by dragline geometry. For a medium size dragline with a $90 \mathrm{~m}$ operating radius, simple side casting is only possible in shallow depths less than $30 \mathrm{~m}$ (Mirabediny, 1998).

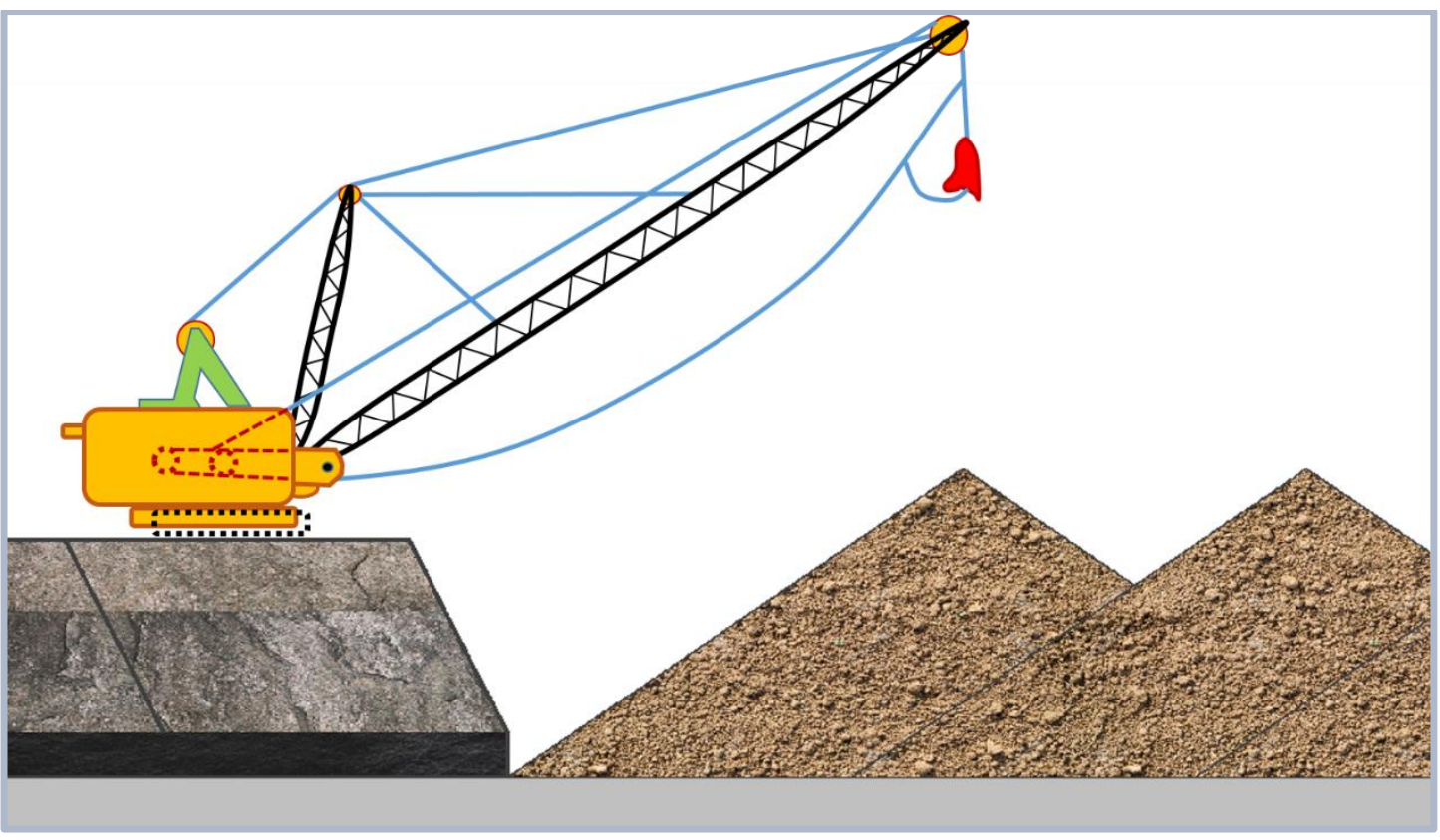

Figure 4. Simple side casting (modified from Bucyrus-Erie Company Handbook, 2001) 


\subsubsection{Advance Benching}

With an increasing overburden depth, often the simple side casting method can be modified to an advance bench method to avoid rehandling. Advance bench method is used when the dragline working bench level is lower than the real surface level. In such situation, the dragline must work in an overhand chop mode of operation. The swing angles are greater during removing advance bench (130 to 180 degrees), and this cause of increasing cycle time and reducing the productivity. Often there is a maximum 15-20 m limitation for the advance bench height that can dragline handle. The main process of the method is cutting the bench in one pit in advance of the working pit (Figure 5).

This method is very useful in soft surface conditions by permitting the machine to seek a firmer working level. Because of the disadvantages of chop operations, as the overburden depth increases, many strip mines prefer to use following digging methods such as extended bench method and split bench method.

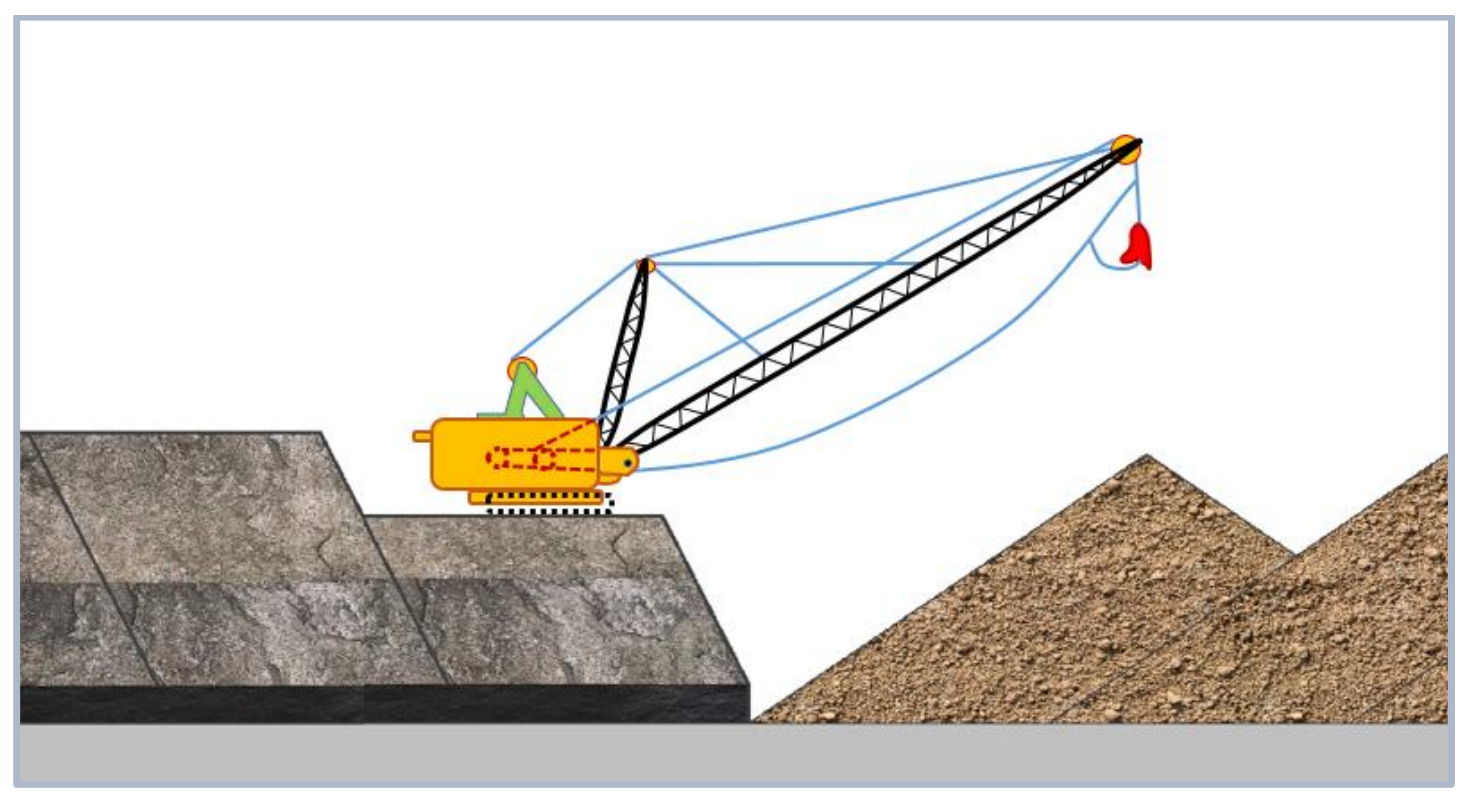

Figure 5. Advance benching (modified from Bucyrus-Erie Company Handbook, 2001) 


\subsubsection{Standard Extended Bench with an Advance Bench}

Sometimes, with an increasing depth of overburden and for wide pit width conditions, it is getting difficult to spoil all material without rehandling a high percentage of the material moved by the simple side casting method. In such situations, reach factor capability of the dragline have to be increased. This can be achieved by positioning the dragline closer to the spoil pile to provide enough spoil room so that all the overburden can be dumped in to the previous pit. To increase the capabilities of dragline, usually extended bench/bridge is used. Built the bridge allows dragline equipment to position toward the spoil pile and this provides the dragline to reach the required spoil peak. This method is called as standard extended bench method (Figure 6).

The material used on building extended bridge is provided from key cut and advance bench if there is. However, used material is rehandling material and must be excavated later to clear the coal edge of next block. The critical factors that affect the amount of rehandle are the dragline spoiling capabilities, material swell factor, highwall angle and spoil angle. 


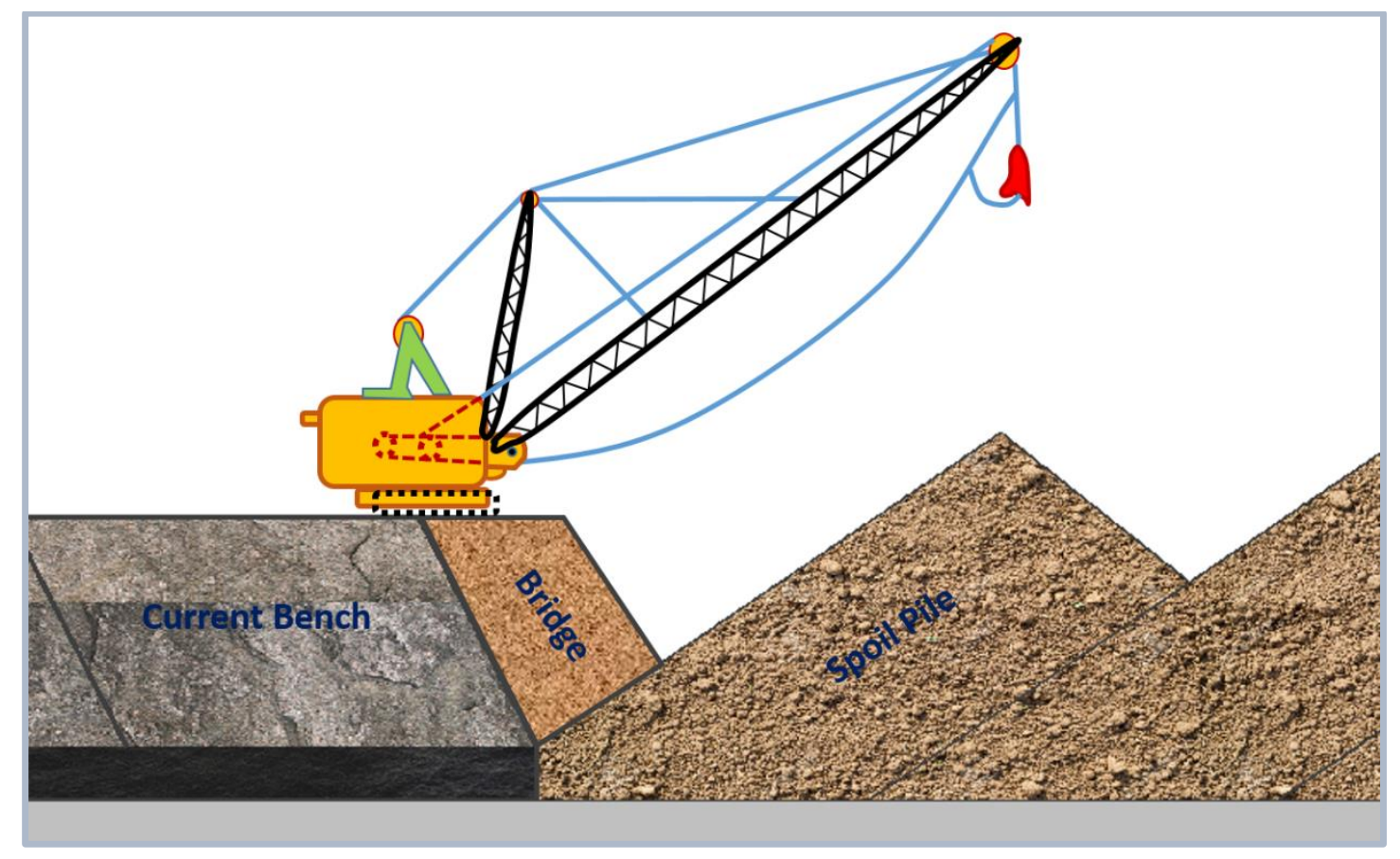

Figure 6. Extended bench (modified from Bucyrus-Erie Company Handbook, 2001)

\subsubsection{Split Bench}

In very deep overburden situations, when the dragline working level is limited by the maximum overburden depth that the dragline can dig. The rehandle material percentage is increasing significantly with increasing overburden depth. To reduce rehandle quantity an advance bench ahead of dragline main pass is one of the best solutions. This method is called split bench method and is often used in thick overburden conditions. To avoid chop down operations and also to increase the advance bench depth, two dragline passes are used in each strip.

In this method two highwall passes are using. First pass is the upper layer of the overburden and removing with the simple side casting method (Figure 7/a). Second pass is the main pass where a conventional extended bench method is applying (Figure $7 \mathrm{~b}$ ). The depth of the passes are controlled by the digging abilities of the dragline/draglines and the spoil balance. By using this method, the overburden depth that can be removed with a medium sized dragline can be increased in enormous manner. 


\subsubsection{Extended Key Cut}

Another useful two-pass operation method is extended key cut method which employing a highwall extended cut in first cut and lowwall pullback operation in the second pass. The main process of method is as follows:

First, the throw blasting method is applied. Throw blasting method is described in blasting operations of this section. The overburden throw blasting must be held in such a way to achieve a maximum blasted material dropped into the old pit to produce a new highwall for the dragline. After the new highwall leveled by dozers, the dragline is positioning on the new highwall. Then the dragline extends a key cut along the strip and forms an in-pit bench on the lowwall side on blasted material (Figure 8/a). The first pass does not uncover coal and therefore the method requires shorter cuts than the extended bench and lowwall in-pit bench digging methods (Hill, 1989).

After completing the first pass, the dragline positioning on the new in-pit bench by a ramp constructed. Afterwards, the dragline chops the highwall and removing the remaining material in a pullback mode and fill behind to form a stable working in-pit bench in lowwall side (Figure 8/b). At the last stage chopping and dumping operation continues for final spoiling (Figure 8/c). Sufficient wide return road must be left to allow the dragline way back after stripping over. The swing angles are very high in this digging method, especially in wide strip cases.

\subsection{Blasting in Dragline Operations}

The blasting operations do not differ from conventional open cut blasting operations. However, unlike shovel a dragline excavates by dragging its bucket over the fragmented overburden material bank instead of pushing it into fragmented material bank. Therefore, more care must be taken in dragline blasting operations, because in poor fragmented material case, the dragline productivity will drop rapidly than that of shovels working in similar material (Morey, 1990). Consequently, blasting operations is more critical for a dragline operation than for shovel operations. 
There are two kind of common blasting methods often used for dragline stripping as Standard blasting method (often called stand up blasting method) and throw blasting method

The standard blasting method is used to loosen bank materials rather than the highwall. This provides a stable seat and safer working area on the highwall for dragline. The advantage of standard blasting is relatively lower cost of drilling and blasting as well.

The throw blasting method is to push the overburden in to the spoil area as much as possible. This reduces the overburden material which must be removed by dragline thereby increases the dragline productivity. In thick overburden case, this method provides a lower working level for a dragline, which reduces dragline rehandle. Nevertheless, unlike standard blasting method the drilling and blasting costs and some extend of the dragline pad preparation costs are much higher in throw blasting method (Morey, 1990).

In most dragline stripping operations, which uses cast-blasting technique, because of unstable working conditions after a heavy blasting, the dragline must work from the spoil pile. Which, increases the swing angle and bucket filling time, thereby the dragline productivity decreases (Mirabediny, 1998). 


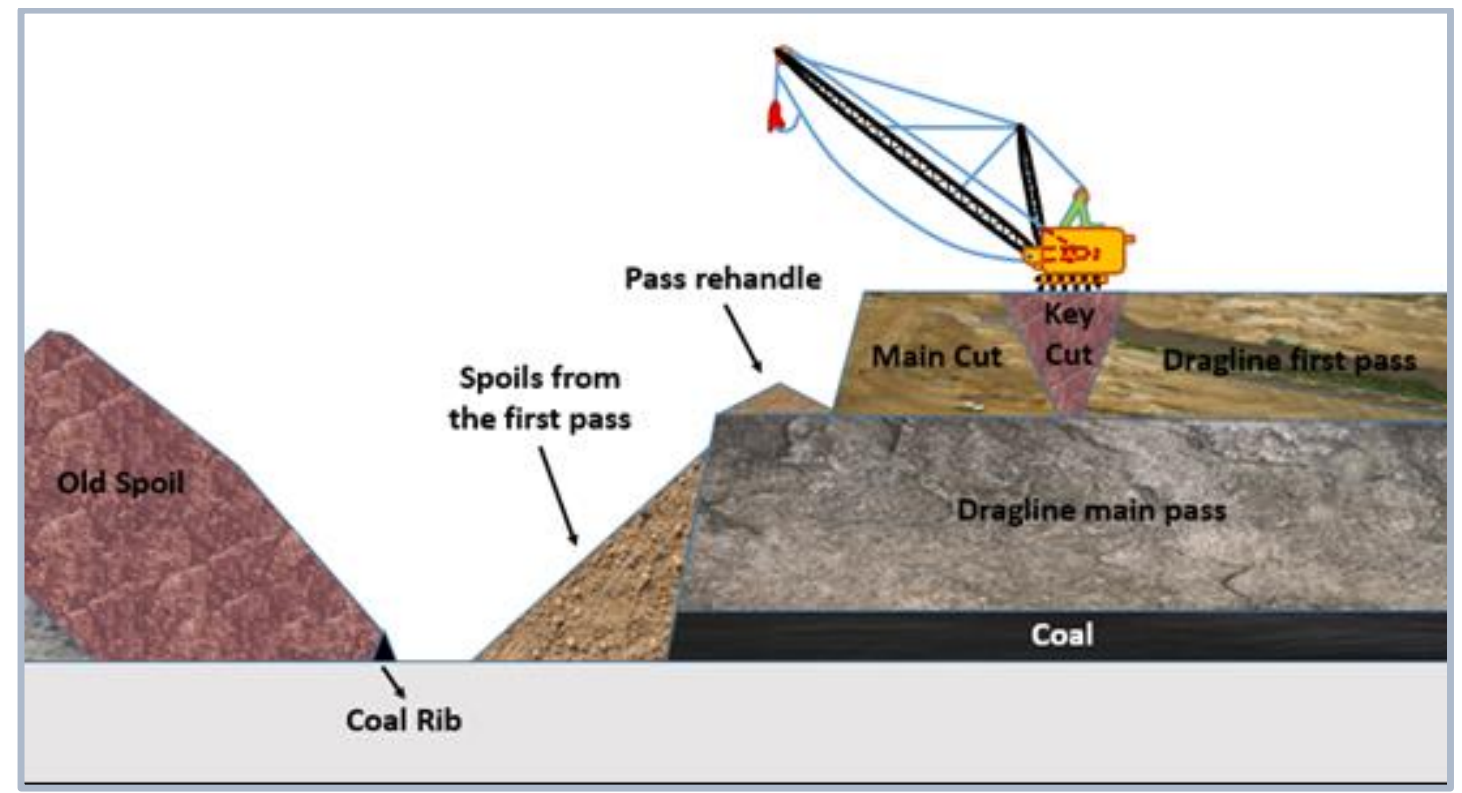

a)

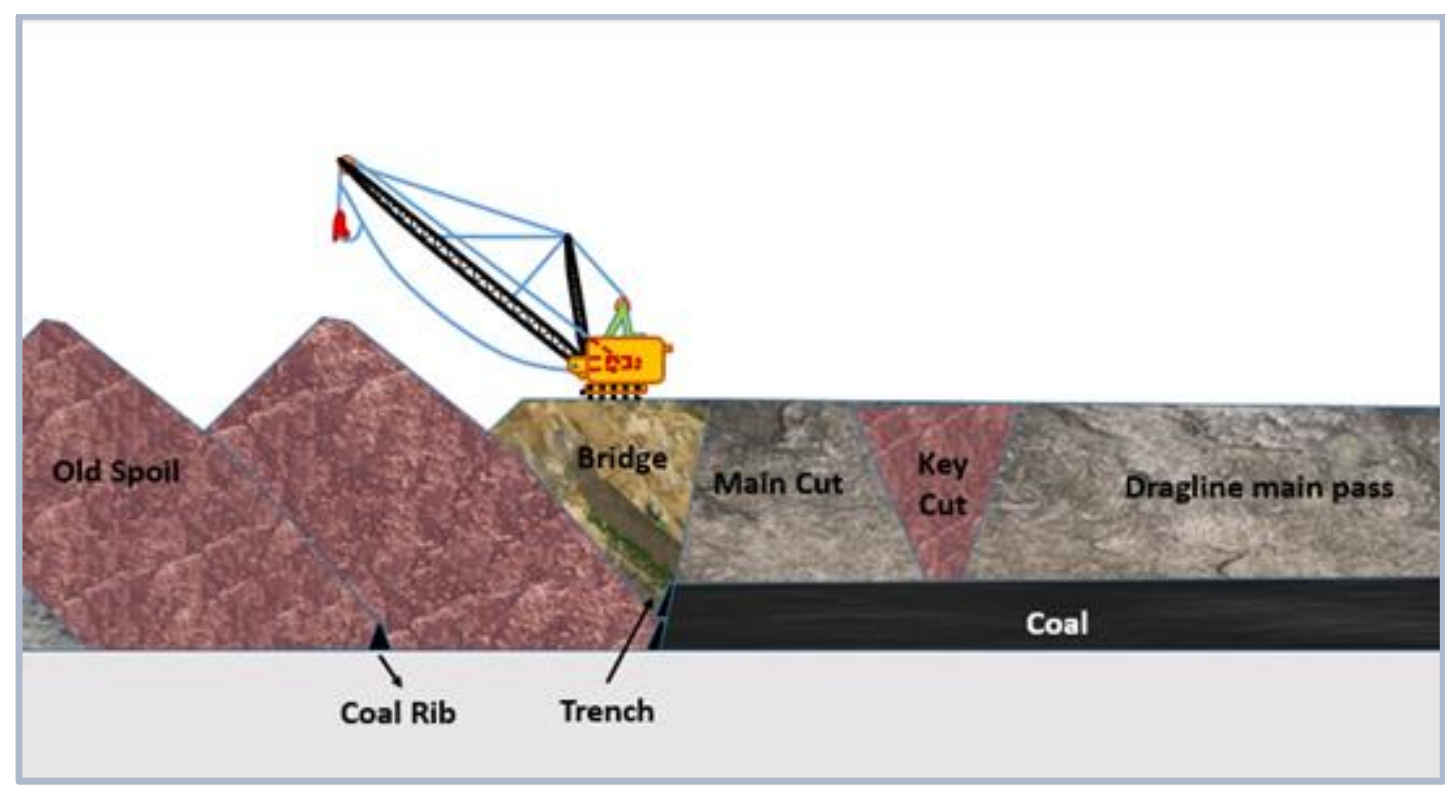

b)

Figure 7. Split bench $\boldsymbol{a}$ ) extending a key cut along the strip and building an in-pit bench on the lowwall side on blasted material, b) chopping the highwall and removing the remaining material in a pullback mode and building a stable working in-pit bench in lowwall side (modified from Mirabedniy, 1998) 


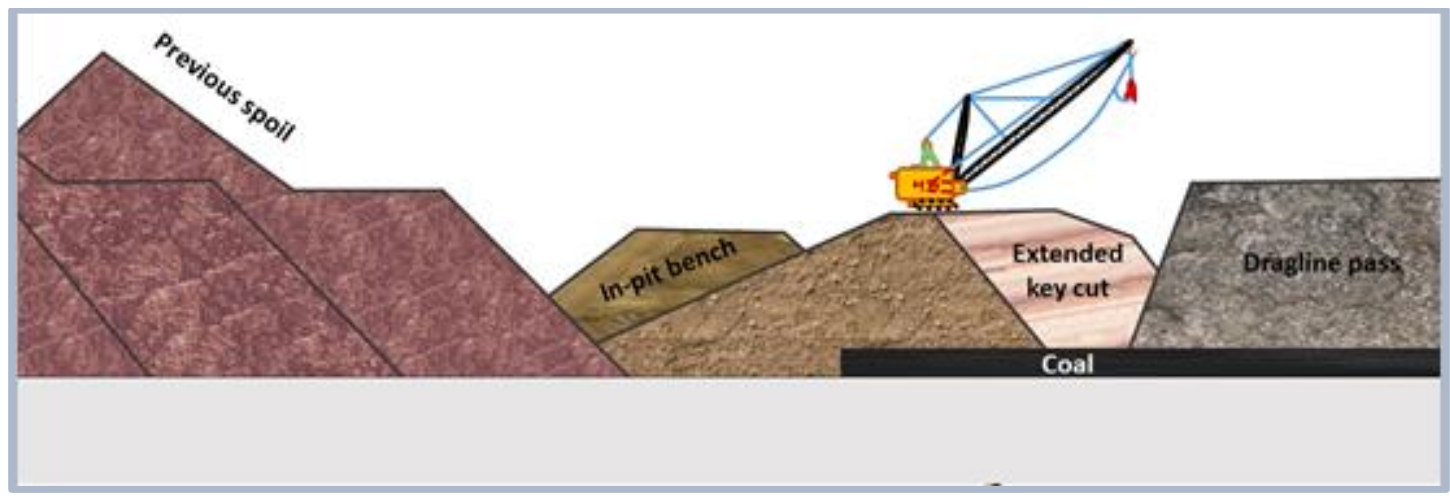

a)

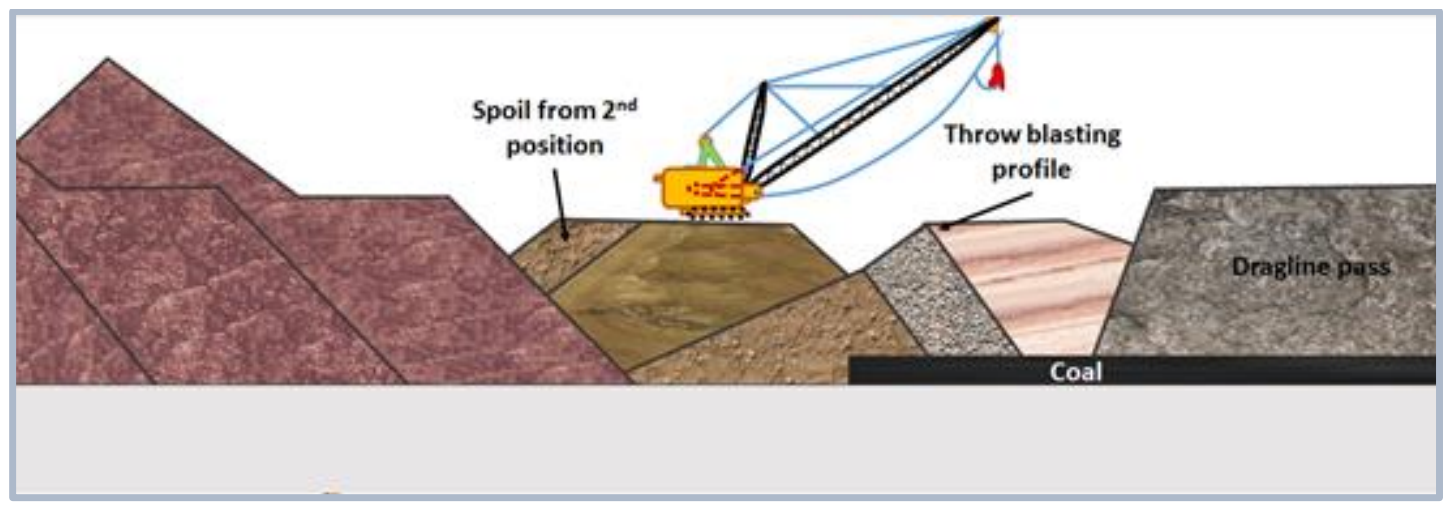

b)

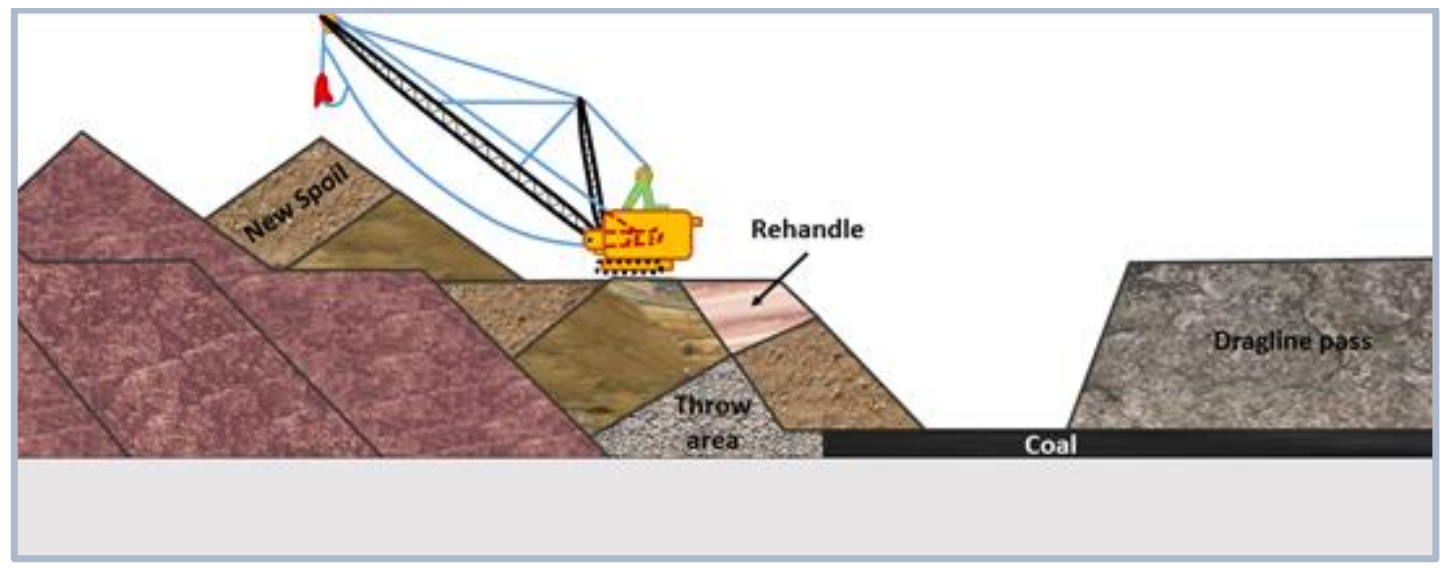

c)

Figure 8. Extended key cut method, a) extending a key cut along the strip and building an in-pit bench on the lowwall side on blasted material, $\boldsymbol{b}$ ) chopping the highwall and removing the remaining material in a pullback mode and building a stable working in-pit bench in lowwall side, $c$ ) wide return road must be left to allow the dragline way back after stripping over (modified from Mirabedniy, 1998) 


\subsection{Size of Dragline}

The size of the dragline is often expressed with bucket capacity of dragline. To calculate the required bucket capacity of a dragline the annual coal production requirements and coal uncovering rate have to be considered first.

One method for determining bucket capacity is a mathematical approach, which uses the standard excavator sizing equation with an adjustment for rehandle (Hrebar and Dağdelen, 1979).

\subsection{Selection Process}

Key parameters affecting mine design can be categorized into three following groups:

- Geological parameters: Overburden and interburden depth, thickness of coal seams and partings, swell factor of material, bench and spoil repose angles.

- Equipment specifications: Mechanical parameters of an equipment being used.

- Operational Parameters:

The geological parameters cannot be controlled and mine design must be made to meet these constrains. Whereas, the mechanical parameters of an equipment being used, can be controlled and selected according to these limits to meet these geological constraints (Morey, 1990).

In open cut stripping mine design using dragline as the major overburden removal unit, the production target has to be met first and then it will be possible to select a dragline which meets predefined production requirements. However, there is a situation such as companies have got an existing dragline equipment and want to use it. In such cases, the stripping/digging methods and stripping geometry will be dependent on this available dragline (Hrebar, 1990). Some of specifications of these machines can be varied within specific limits. Moreover, it can be modified to meet the geological constraints of the mine. However, the maximum suspended load of the dragline will be varied by changing the boom length and the boom angle of the dragline. 
There are four important parameters to be determined first as given below (Sweigard, 1992):

- Reach factor (RF) or the dragline reach:

- To what depth must it dig: Maximum dig depth capability that, the dragline must have.

- How high must it stack: Maximum dump height that, the dragline must reach.

- Required capacity of dragline bucket:

In addition to these parameters, the speed specifications of an equipment: such as swing speed, hoist and payload speed also can be added to these main criteria. When these parameters are determined, sufficient dragline models, which met these criteria, can be chosen. When there are several dragline options, there are many other factors that can affect selection. In determining these factors, range diagrams, graphs and tables, and computations can be utilized.

\subsubsection{Range Diagram}

Range diagram method is mandatory method often used in complex applications. This method is a graphic method with an accurate scaled drawings and determined solutions made by actual measurements. The method is very slow, but provides a basic explanation in the graphic results.

\subsubsection{Graphs and Tables}

It is the best suited method for obtaining average conditions and provides solutions for simple situations with average conditions. This method is an approach in which mathematical solutions are expressed in graphic and tabular form. The method is very fast but answers are limited with graphs units' accuracy. 


\subsubsection{Computation}

This method is a fully mathematical method. This method is fast and also provides more accurate answers calculated by given data. However, it is not useful for solution of complex situations. Complex cases must be discussed and analyzed.

\subsection{Previous Researches on Dragline Selection}

Walking draglines are very expensive equipment and due to its dimensions, in case of wrong selection, it would be almost impossible to change it. Where influencing operation parameters must be fully understood to pay the return of investment with improving the dragline performance. It can be done with optimizing working process and ranges. Where lots of scenarios and configuration variations have to be compared to each other which is time-consuming process due to the large number of parameters involved. Moreover, this optimizing process requires a repetitive arithmetic and analytic solutions, which can be error prone. This can be countered with computer applications or simulation methods. During the last forty years, various software packages and computer-aided simulators have been developed for simulating different working processes with dragline equipment. Most of these computer models use mathematical, graphical, and analytical techniques in solving two joint problems, such as planning and design of dragline operations (Mirabediny, 1998).

These software packages and computer-aided simulators can be a guide for choosing best stripping method and suitable dragline parameters for selecting the equipment. Where should be noticed that, it is proper to select dragline equipment for the stripping design rather than design for dragline equipment.

Some of useful researches and computer aided simulators are as follows:

The very first remarkable research on best suitable dragline equipment selection was held by Rumfelt (1961). The author has developed a computer program, which helps to analyse the relationship between some important factors named as Maximum Usefulness Factors (MUF) and the pit geometry. The author used MUF in collaboration with pit geometry to select the parameters of suitable 
dragline equipment. The MUF was defined according to required bucket capacity and required reach of an equipment for stripping.

Another research on simulating a dragline operation was reported in 1966 by Nikiforuk and Zoerb (1966). The authors have attempted to develop an analogue computer simulation model for investigation of performance of different movements of the dragline and its bucket. The research expected to simulate basic movements of the dragline such as swinging, hoisting and dumping, dragging etc. to show full picture of process both graphically and analytically.

During 1970s, the US Federal Government financed simulation models researches and computer programs in pit optimization and equipment selection. Many researchers and companies are involved in the program such as Stefanko et al. (1973), Ford, Bacon and Davis Inc. (1975), McDonnell Douglas Co. (1978); Sadri and Lee (1982). Developed computer programs were all based on single seam operations and software's could be run only on mainframe computers as expressed in Hamilton (1990). Because of their hardware restrictions and poor graphical interfaces, these programs were not widely used (Hamilton, 1990).

Later in 1979, Hrebar and Dagdelen (1979) reported a computer simulation method. They have modified conventional methods for reach and bucket capacity determination to a 3D approach to calculate optimum required dragline parameters. Hrebar and Dagdelen (1979) has claimed that, the reach factor requirements for a dragline operation was underestimated with using a conventional 2D approaches.

During 1980s, many researchers worked on developing dragline operation and computer aided dragline operation simulations. Gibson and Mooney (1982) reported a research on selecting a suitable size of the dragline. The authors used nonlinear analytical approach techniques to minimize the cycle time for overburden stripping and cost per ton of removed coal.

In 1990, Sharma and Singh reported working on developing a new computer program that was calculating reach and bucket capacity considering factors such as the blasting effects on the swell factor and response angles (Sharma et al., 1990).

In 1996, Erdem and Çelebi worked on developing computer aided expert simulation system for dragline and method selection in surface coal mines. In this research author also worked on several problems that can occur in dragline selection. 
Research uses seven main surface stripping methods for modelling and simulating dragline selection and stripping process. Moreover, during research Erdem developed several algorithms on modelling and simulating production both single and tandem dragline systems. The dragline selection strategy of developed expert system based on forward changing algorithm.

One of the recent researches on computer-simulated selection model of the walking dragline equipment for open cast stripping mine is held in 2003 by Zhang et al. They have developed a computer simulation model for simulating dragline stripping operation for the purpose of selecting the optimum dragline equipment, according to working face parameters results obtained again by the same simulation. Simulation process iterates till the convenient results are obtained (Zhang et al., 2003).

Having reviewed previous researches on dragline selection, it is perceived that most of researches are concentrated on selecting best dragline parameters for stripping. However, it may be not available to reach dragline equipment with the same parameters on market.

Most of the developed computer programs on machine selection are not interacted with market and most of the developed simulators are simulating the process only for dragline with chosen parameters. The simulators need an enormous input data to be entered by user as an input data. Other reported studies and their developed simulation models are not computerized and not available like computer application or software. 


\section{CHAPTER 3}

\section{DEVELOPMENT OF A DRAGLINE SELECTION PROGRAM}

\subsection{Introduction}

In this thesis, the author is concentrated on selecting a new dragline from the market catalogues. To select an optimum dragline, firstly, planned mine layout, spoiling and excavation operations, target production requirements have to be decided and tasks for selecting equipment needs be to defined. In the selection process, the objective is to find the most appropriate model for the required overburden stripping. In this thesis, simple cast stripping method was used for the selection because it is one of the most widely utilized dragline stripping methods. Furthermore, this method can easily be converted to other stripping methods such as advanced benching, extended bench in increasing overburden depth situations.

\subsection{Flow of Selection Process}

After the stripping method is chosen, dragline selection process can be preceded. In this process, there are several steps to be followed and these steps interact with each other. Steps that will be followed as a selection process are as follows (Figure 9):

- Initial estimations and calculations of such parameters as: dragline availability, dragline utilization, dragline operating hours, average duration of single cycle time, estimated ore production and recovery are taking. According to these parameters maximum suspended load is calculating. 
- In this step initial mine design geometry parameters are defining. And according to them reach factor is calculating.

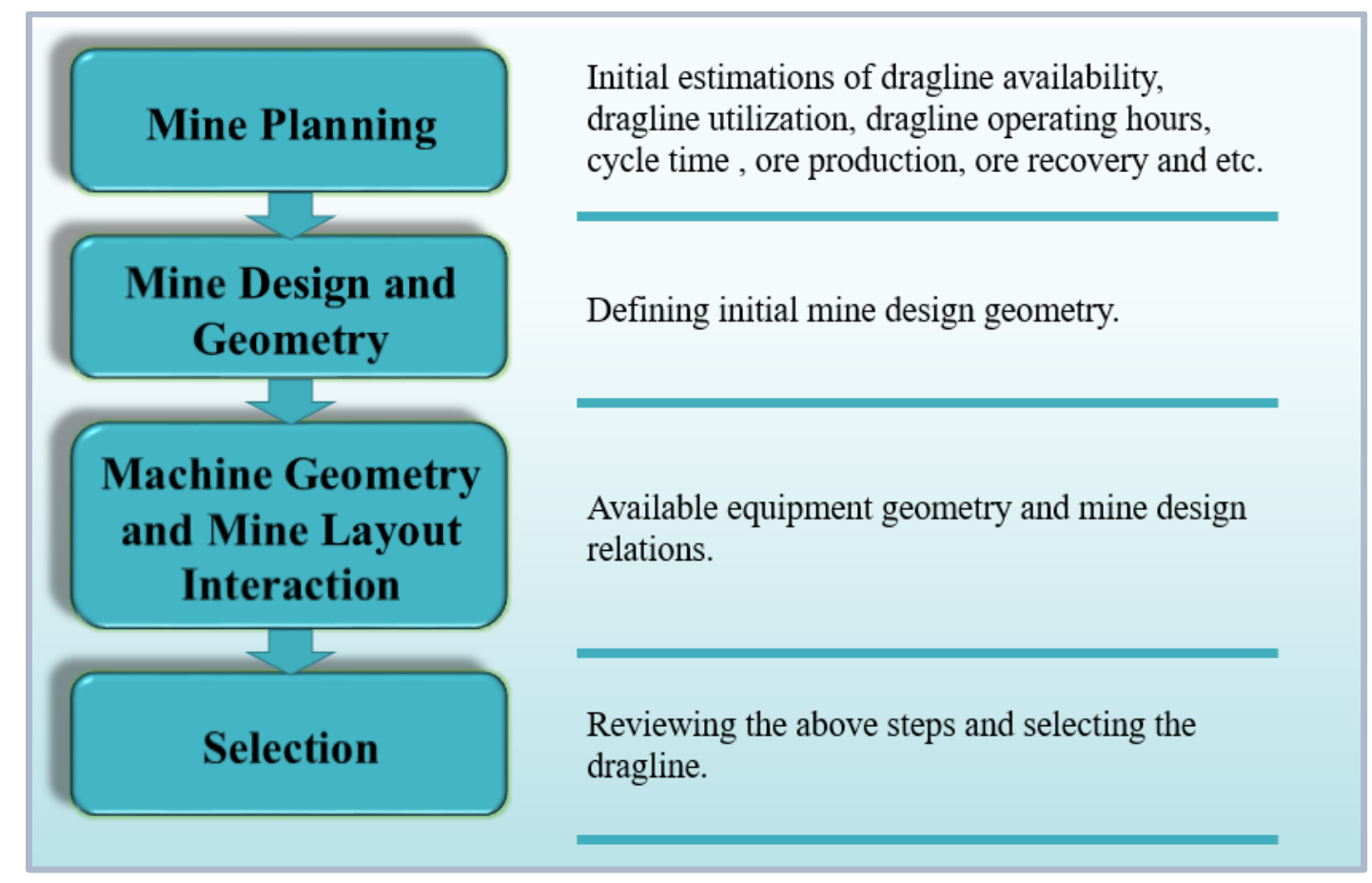

Figure 9. Dragline selection process

- In the third step according to previously calculated maximum suspended load and reach factor requirement available draglines from catalogues are choosing and last decisions on the mine geometry is holding.

- For the final step, best dragline is selecting from catalogues.

\subsection{Planning}

In stripping method, series of parallel and narrow cuts are made in the ground surface for extracting bedded deposits such as coal. It means, to reach coal, it is necessary to excavate large quantities of waste overburden material. For extracting this waste material usually, dragline, shovel and truck operations are used. Dragline 
stripping methods are much preferable in large mine fields because of its higher productivity, simplicity, and lower costs.

"The operating costs are less with the dragline while a lower initial investment is required for a shovel and truck systems" (Learmont, 1983).

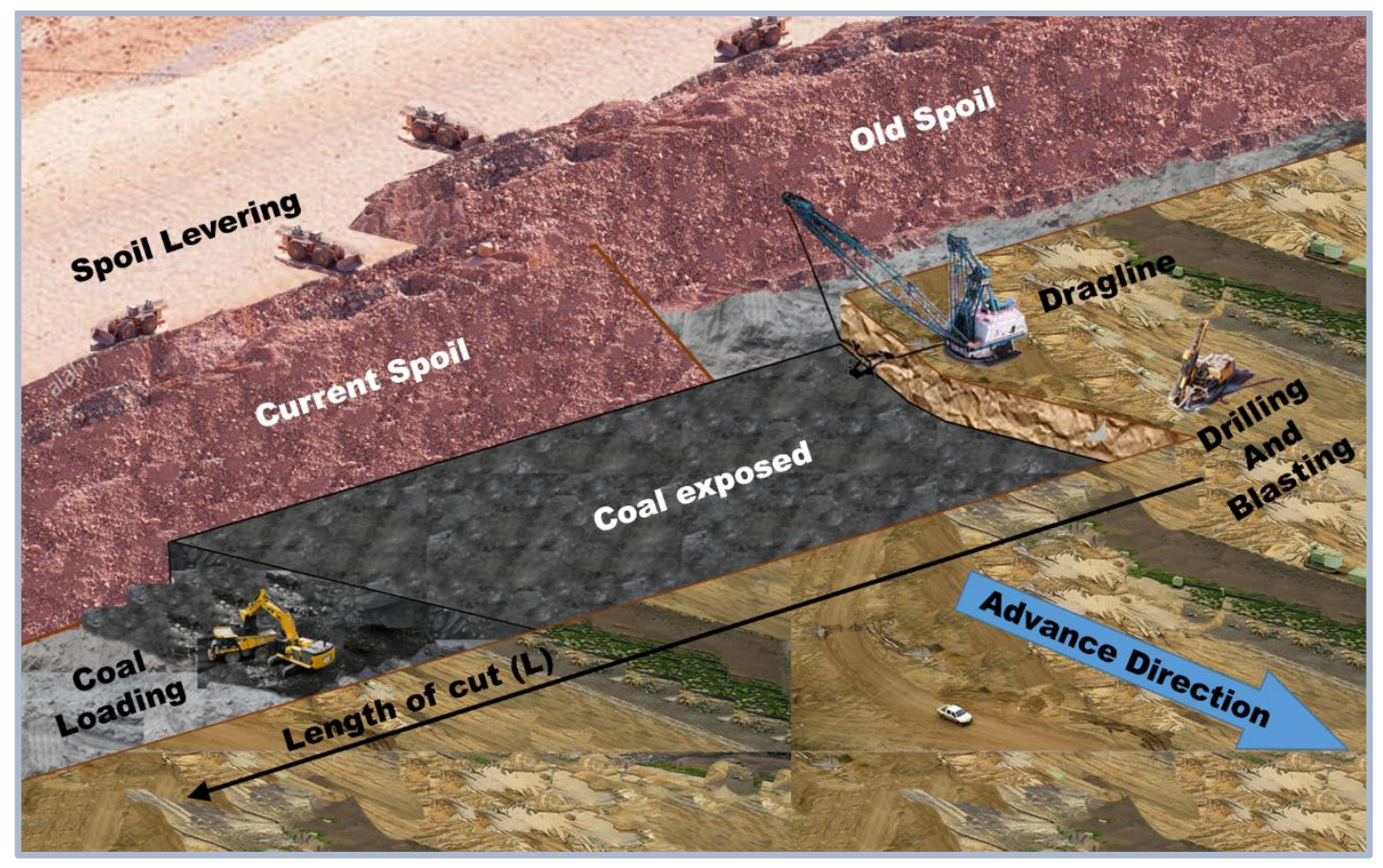

Figure 10. Dragline operation

\subsubsection{Input Parameters for Planning}

For project planning stage several parameters for next calculations have to be decided and collected. These parameters are as follows:

Material characteristics: These parameters express in-situ material characteristics of overburden strata, mineral or coal characteristics and broken overburden material condition as:

- Overburden density: The average density of overburden material overlaid on the mineral. 
- Coal density: The average density of the mineral should be determined. This thesis research is concentrated on horizontally bedded coal mineral and for the reason the mineral is expressed as a coal seam.

- Swell factor: The ratio of the weight or volume of loose excavation material to the weight or volume of the same material in place (Table 1).

Table 1. Relation between overburden conditions, swell factor and bucket fill factor (Karpuz and Hindistan (2005) in Eskikaya vd. (2005)).

\begin{tabular}{lcc}
\hline \multicolumn{1}{c}{ Overburden Conditions } & Swell Factor & Bucket Fill Factor \\
\hline Light Blasting & 1.23 & $0.85-0.90$ \\
Medium Blasting & 1.33 & $0.80-0.90$ \\
Heavy Blasting & 1.40 & $0.75-0.85$ \\
Bad Fragmentation & 1.45 & $0.70-0.75$ \\
\hline
\end{tabular}

- Bucket fill factor: Fill factor is another parameter resulting on overburden conditions. It is the fillability of broken rock in to the dragline bucket and it also related to the overburden conditions (Table 1).

- Bucket empty weight: Another important parameter is the unit weight of the dragline empty bucket that will be used in bucket dead weight $\left(\mathrm{W}_{\mathrm{D}}\right)$ calculations later.

Geometric characteristics: Geometric input parameters are the planned geometric parameters of the mine design as follows and the symbols are referred to the Figure 11:

- Overburden thickness (D): The depth of overburden strata which must be excavated.

- Coal thickness (T): The mineral seam thickness will be exposed.

- Pit width (W): The planned width of one cut. 


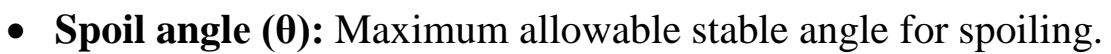

- Pit angle (ß): Maximum allowable stable angle for bench.

- Toe: This parameter is referred in the percentage of seam thickness as it can be increased with increasing seam thickness. Explained later in calculations about toe section.

\subsubsection{Production Estimations and Operation Parameters}

In this section all input operation parameters and production estimation for an operation period time (usually 1 year) have to be estimated. These parameters are as follows:

- Scheduled operation time: The full scheduled working time of dragline equipment.

- Dragline availability: The percentage of time which dragline is available to be operated. Can be referred as dragline operating time divided by net available operation time.

- Dragline utilization: The percentage of time which dragline is utilized. Can be referred as the planned operating time divided by net operation time of mine.

- Dragline operating hours: This parameter is the result of previous 3 parameters.

- Cycle time: The time spent for single cycle of dragline digging and spoiling operation. This parameter depends on operation swing angles and bucket size (Table 2).

- Required ore production: Estimated coal production in a period (year in this thesis).

- Ore recovery: Estimated coal recovery percentage. The proportion of the ore that is extracted after accounting for mining losses. The mining recovery can vary widely both within a single mine and from property to property due to a range of factors including deposit geometry and mining method. 


\subsection{Mine Layout Design and Geometry}

The main mine layout geometry is described on range diagram as seen in Figure 11 . The geometry parameters and calculations for mine layout design for simple casting method are as follows:

Table 2. Theoretical cycle time according to dragline operation swing angles and bucket size (Karpuz and Hindistan (2005) in Eskikaya vd. (2005)).

\begin{tabular}{ccccc}
\hline $\begin{array}{c}\text { Bucket size } \\
\left(\mathbf{m}^{\mathbf{3}}\right)\end{array}$ & \multicolumn{4}{c}{$\begin{array}{c}\text { Theoretical cycle time according to } \\
\text { swing angles (sec) }\end{array}$} \\
\hline up to 15 & 55 & 62 & 69 & 77 \\
$16-26$ & 56 & 63 & 70 & 78 \\
$27-44$ & 57 & 64 & 71 & 79 \\
$45-57$ & 59 & 65 & 72 & 80 \\
$58-92$ & 60 & 66 & 73 & 81 \\
$93-150$ & 62 & 69 & 76 & 84 \\
\hline
\end{tabular}

Volume of Overburden: In-Situ volume of overburden cut for a unit thickness is equal to the areal extent of parallelogram formed by cut face (Figure 12). Can be calculated as follows (Karpuz and Demirel, 2016):

$$
\begin{gathered}
V_{O B}=W \times D \times L \\
V A_{O B}=W \times D \times 1
\end{gathered}
$$

Where:

$V_{\boldsymbol{O}}:$ Volume of overburden $\left(\mathrm{m}^{3}\right)$

$\boldsymbol{V} \boldsymbol{A}_{\boldsymbol{O}}$ : In-Situ volume of overburden cut for a unit thickness $\left(\mathrm{m}^{3}\right)$

$\boldsymbol{W}:$ Pit width (m) 
D: Overburden thickness (m)

L: Length of cut (m)

Volume of Spoil Pile: The volume of a pile of excavated overburden material is greater than in-situ volume of overburden material, because of a swell factor of broken rock.

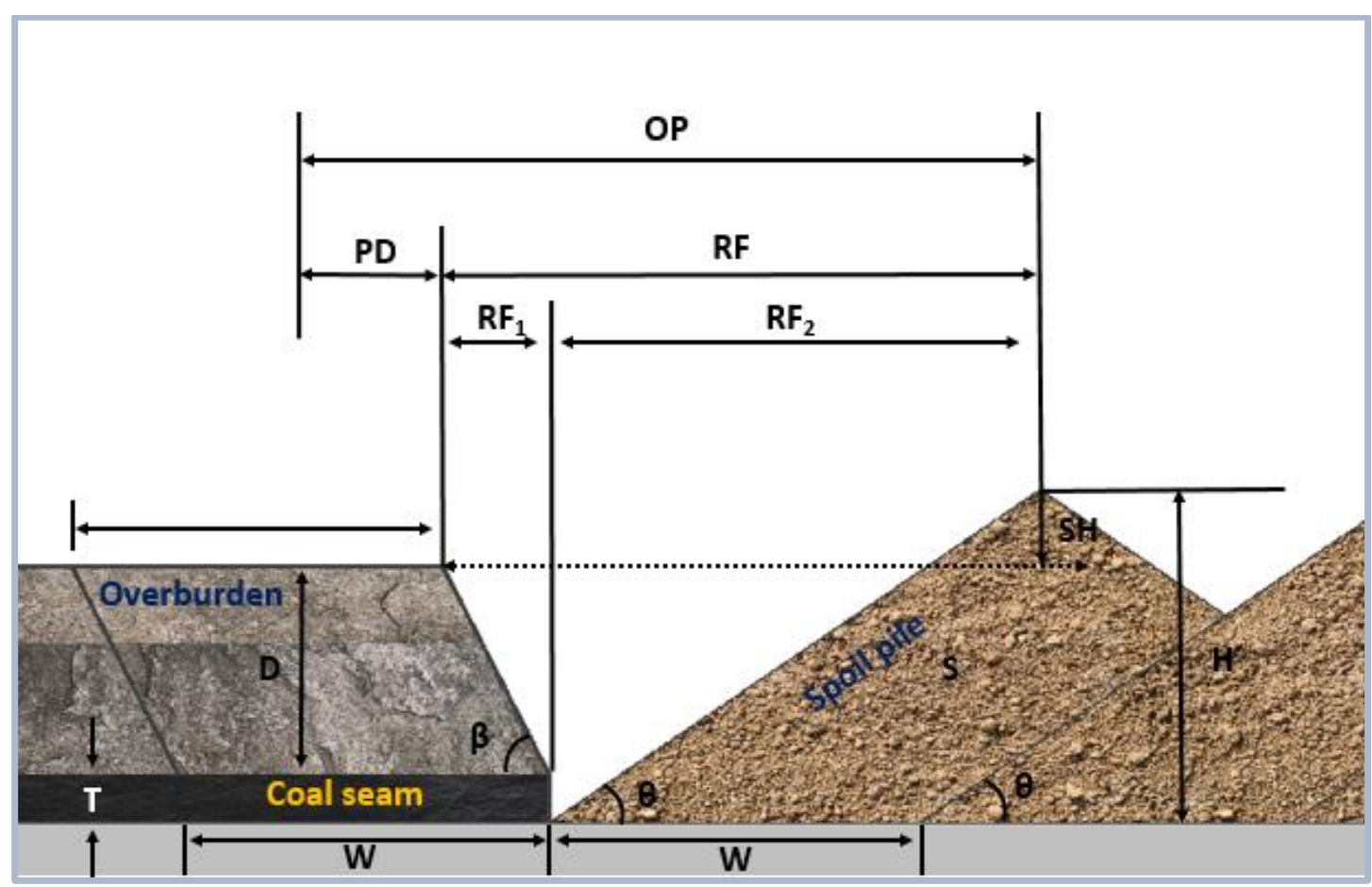

Figure 11. Range diagram and geometry (modified from Karpuz and Demirel, 2016)

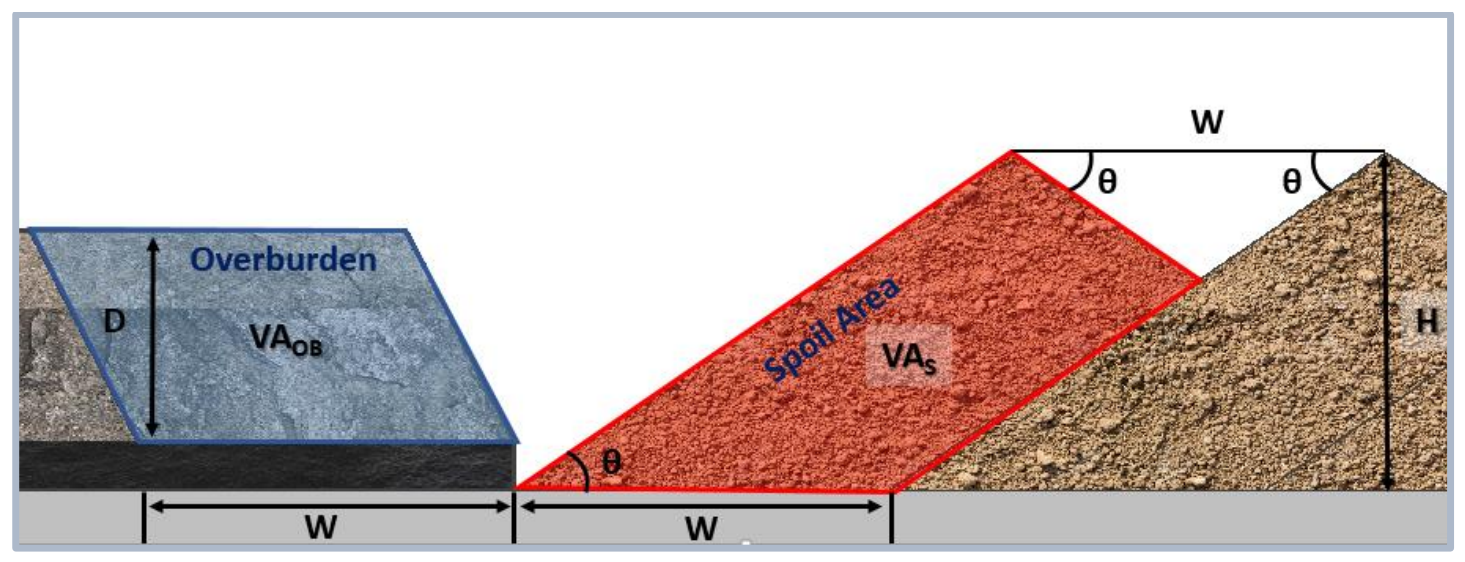

Figure 12. Volume of spoil pile for a unit thickness (VAs) and volume of overburden for a unit thickness (VA) (modified from Karpuz and Demirel, 2016) 
The volume of excavated rock for a unit length of stripping cut, can be calculated as (Karpuz and Demirel, 2016):

$$
\begin{gathered}
V A_{s}=V A_{O B} \times S F \\
V A_{s}=W \times H-\left(\frac{W}{2}\right)^{2} \times \tan \theta \times 1 \\
V A_{O B} * S F=W \times H-\left(\frac{W}{2}\right)^{2} \times \tan \theta \times 1
\end{gathered}
$$

Where:

$\boldsymbol{V} \boldsymbol{A}_{\boldsymbol{s}}$ : Volume of spoil pile for unit thickness $\left(\mathrm{m}^{3}\right)$

$\boldsymbol{V} \boldsymbol{A}_{\boldsymbol{O}} \boldsymbol{B}$ : In-Situ volume of overburden cut for a unit thickness $\left(\mathrm{m}^{3}\right)$

$\boldsymbol{S F}$ : Swell factor of broken overburden material according to blasting conditions

$\boldsymbol{W}$ : Pit width (m)

$\boldsymbol{H}$ : Height of spoil pile (m)

$\boldsymbol{\theta}$ : Spoil pile angle (degree)

Spoil Pile Height: The spoil pile height (H) (Figure 13) can be calculated as the height of parallelogram overlapped on to other spoil pile and also combining equation 2 and 5, equation 6 is formed (Equation 6) (Karpuz and Demirel, 2016):

$$
H=D \times S F+\frac{W}{4} \times \tan \theta
$$

Where:

$\boldsymbol{S F}$ : Swell factor of broken overburden material according to blasting conditions

D: Overburden thickness (m)

$W$ : Pit width (m)

$\boldsymbol{H}$ : Height of spoil pile (m)

$\boldsymbol{\theta}$ : Spoil pile angle (degree) 
Stacking Height: Stacking height is the difference of bench height and spoil pile (Figure 13). Bench height is the sum of overburden height (Overburden depth (D)) and the seam thickness (T) (Equation 7) (Karpuz and Demirel, 2016).

$$
S H=H-(D+T)
$$

Where:

SH: Stacking height (m)

$\boldsymbol{T}$ : Seam thickness (m)

D: Overburden thickness (m)

$\boldsymbol{H}$ : Height of spoil pile (m)

Toe value: In this thesis toe referred as the percentage of seam thickness (Equation 8.). Applying toe will reduce reach factor by $\Delta \boldsymbol{R} \boldsymbol{F}_{\boldsymbol{T}}$ difference and it can be calculated with trigonometric function as in the Figure 14 (Equation 9) (Karpuz and Demirel, 2016).

$$
\begin{gathered}
\boldsymbol{h}_{t}=\frac{\boldsymbol{T} \times \boldsymbol{T o e}_{\%}}{100} \\
\Delta R F_{T}=\frac{\boldsymbol{h}_{\text {Toe }}}{\tan \theta}
\end{gathered}
$$

Where:

$\boldsymbol{T o e}_{\%}:$ Toe value referred as a percentage of seam thickness (\%)

$\boldsymbol{h}_{\text {Toe }}$ : Toe height (m)

$\Delta \boldsymbol{R}_{\boldsymbol{T}}$ : Difference in reach factor applying toe will cause (m)

$\boldsymbol{\theta}$ : Spoil pile angle (degree)

$\boldsymbol{T}:$ Seam thickness (m) 


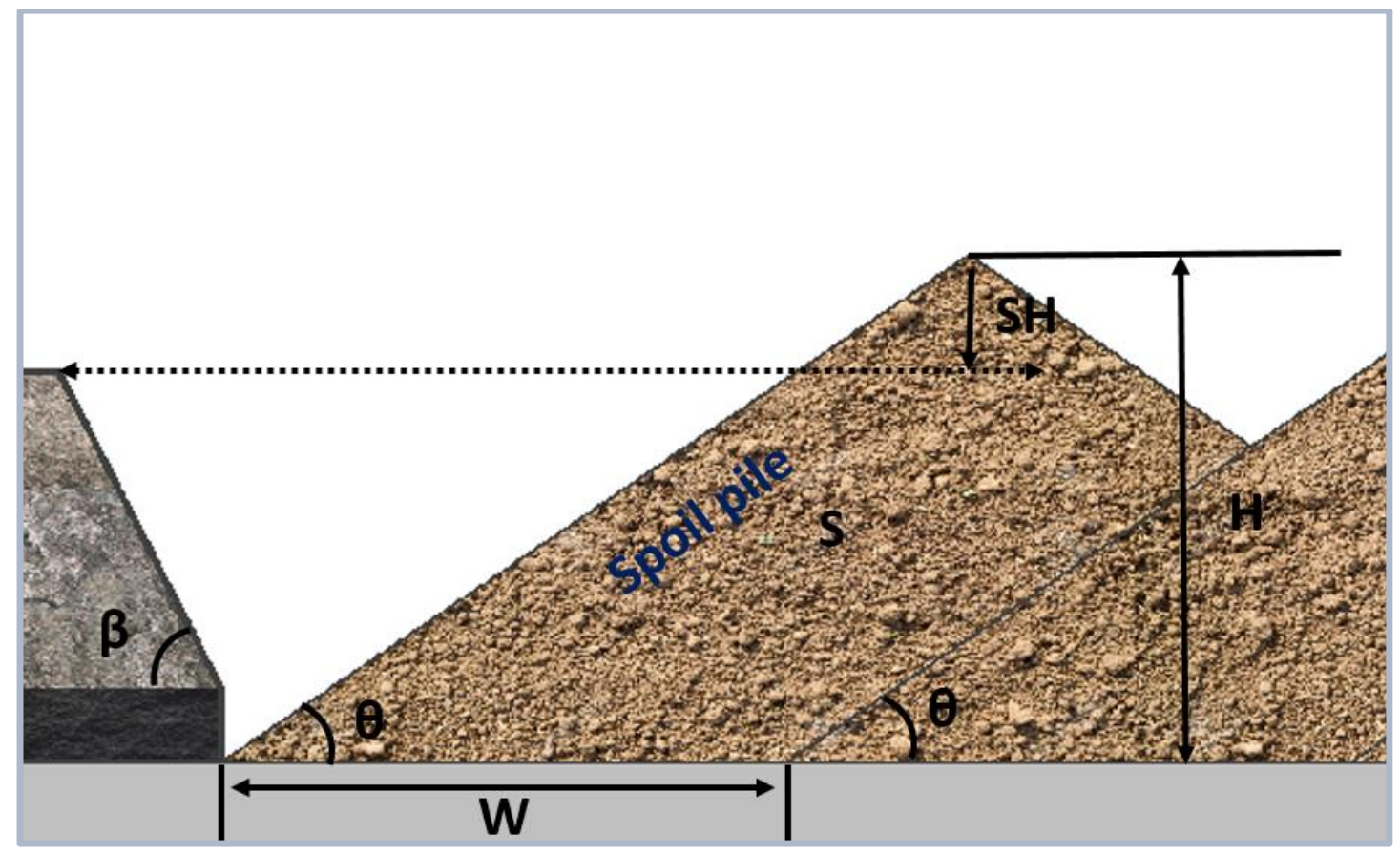

Figure 13. Spoil pile height and stacking height parameters

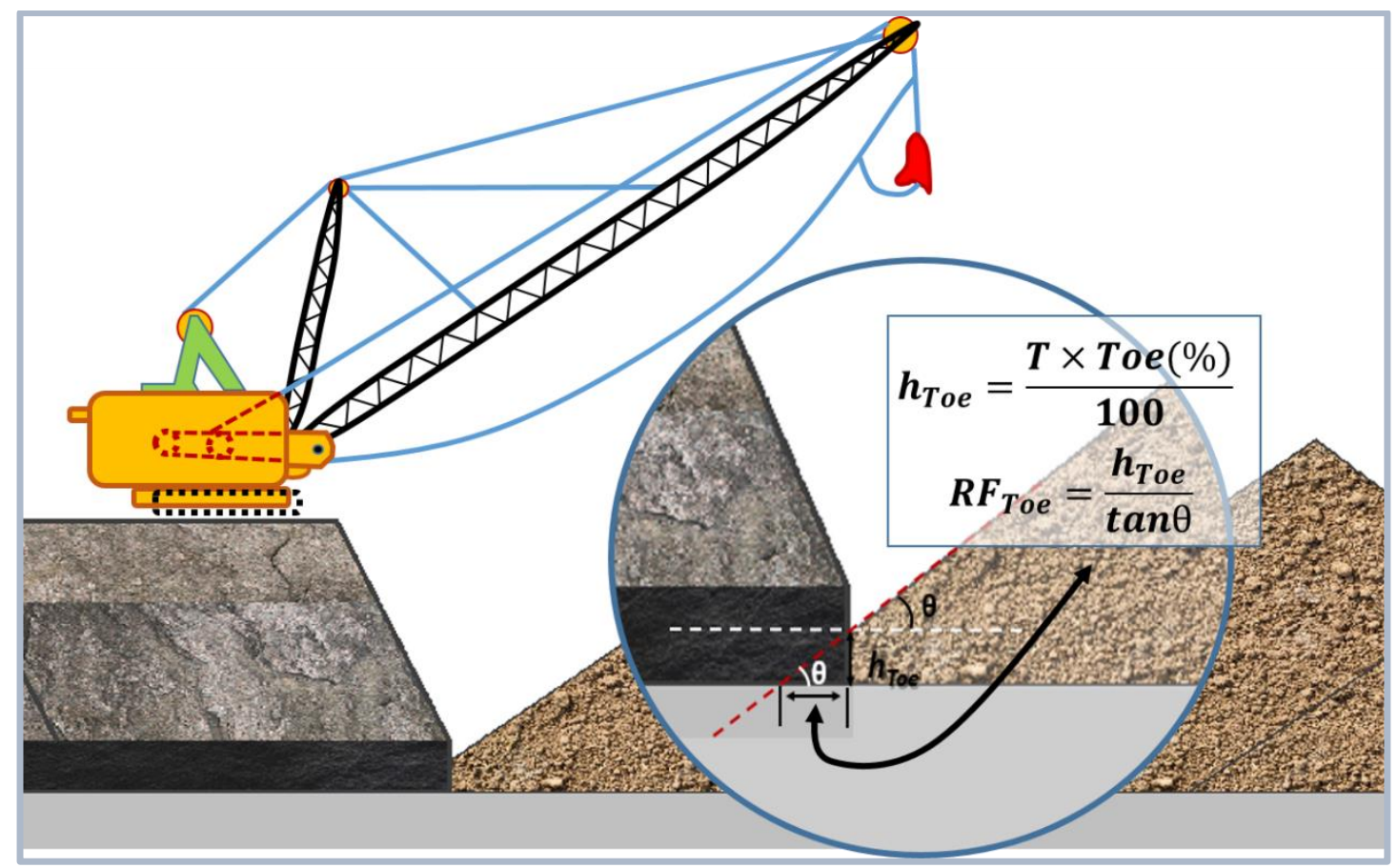

Figure 14. Toe and $\Delta R F_{T}$ difference 
Reach Factor: is one of the important parameters in selecting the dragline equipment. Reach factor is total of the distance that dragline machine have to reach on both dragging and dumping operations (Figure 15)

$$
\begin{gathered}
R F=R F_{1}+R F_{2}=\frac{D}{\tan \beta}+\frac{H}{\tan \theta} \\
R F=\frac{D}{\tan \beta}+\frac{D \times S F}{\tan \theta}+\frac{W}{4}
\end{gathered}
$$

Where:

$\boldsymbol{R F}_{\mathbf{1}}$ : Reach distance required to reach spoiling area (m)

$\boldsymbol{R F}_{2}:$ Reach distance along the spoil pile to the dumping point (m)

$\boldsymbol{\theta}:$ Spoil pile angle (degree)

$\boldsymbol{\beta}$ : Pit slope angle (degree)

$\boldsymbol{S F}$ : Swell factor of broken overburden material according to blasting conditions

D: Overburden thickness (m)

$\boldsymbol{W}$ : Pit width (m)

Reach Factor with Toe: Using toe will decrease the reach factor required for a $\Delta \boldsymbol{R F}_{\boldsymbol{T}}$ distance as described in before. Whereas, the total reach factor with toe use will be as follows (Karpuz and Demirel, 2016):

$$
R F_{T}=\frac{D}{\tan \beta}+\frac{D \times S F}{\tan \theta}+\frac{W}{4}-\frac{h_{T o e}}{\tan \theta}
$$

Where:

$\boldsymbol{R F}_{T}$ : Total reach factor required using toeing $(\mathrm{m})$

$\boldsymbol{\theta}:$ Spoil pile angle (degree)

$\boldsymbol{\beta}$ : Pit slope angle (degree) 
$\boldsymbol{S F}$ : Swell factor of broken overburden material according to blasting conditions

D: Overburden thickness (m)

$W:$ Pit width (m)

$\boldsymbol{h}_{\text {Toe }}$ : Toe height in meters (m)

Operation Radius: is the total distance from the edge of the dragline positioning point to maximum reach point (Figure 15) (Karpuz and Demirel, 2016):

$$
O R=R F+P D
$$

Where:

$\boldsymbol{O R}$ : Operating radius $(\mathrm{m})$

$\boldsymbol{R F}:$ Total reach factor required $(\mathrm{m})$

PD: Positioning of dragline (m)

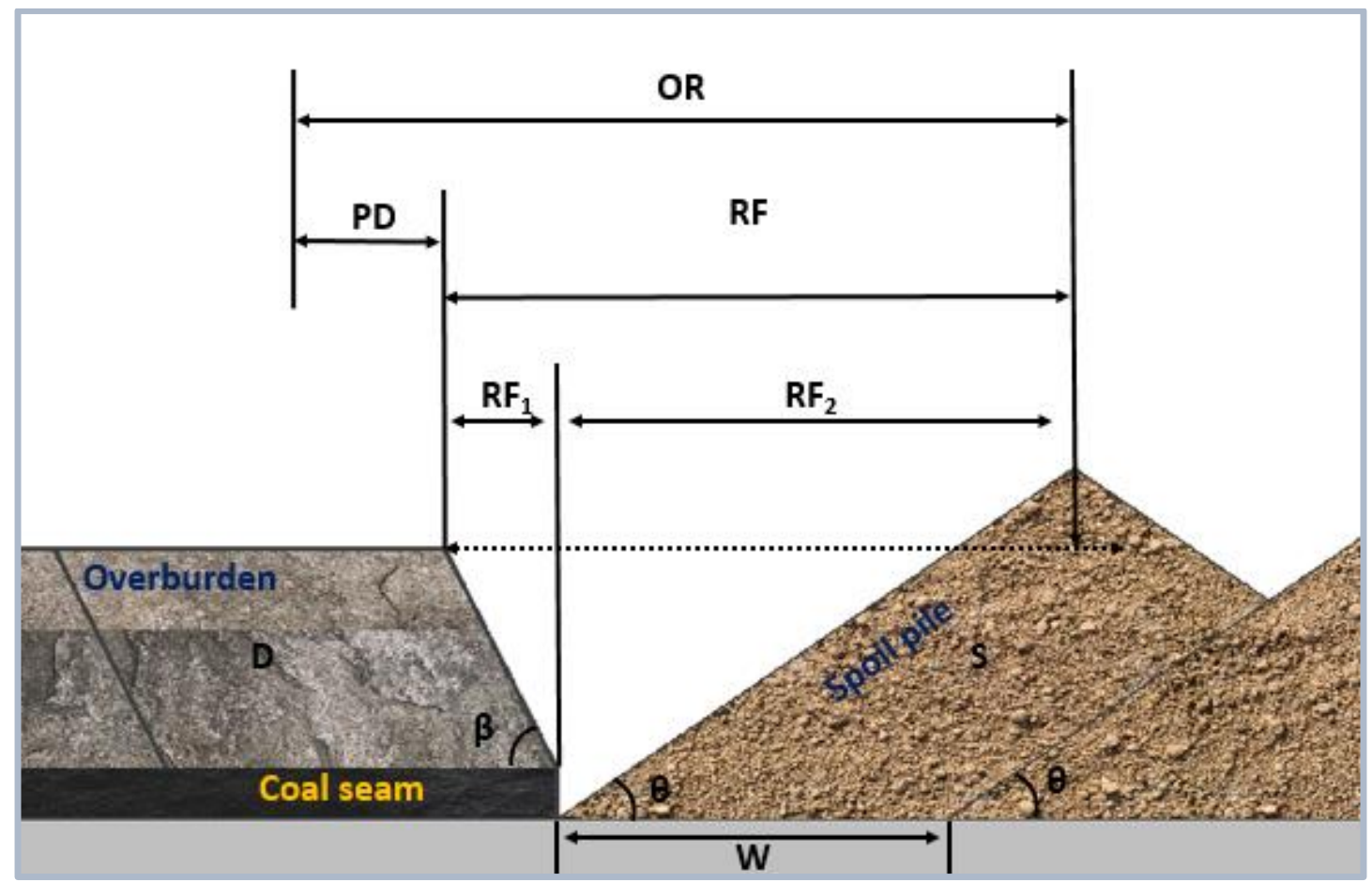

Figure 15. Reach Factor and operation radius 
Coal Uncovered: Amount of coal which must be exposed in year (Karpuz and Demirel, 2016).

$$
\boldsymbol{O}_{U}=\frac{P}{R}
$$

Where:

$\boldsymbol{O}_{\boldsymbol{U}}:$ Coal uncovered $(\mathrm{t} / \mathrm{yr})$

P: Required coal production $(\mathrm{t} / \mathrm{yr})$

$\boldsymbol{R}:$ Coal recovery factor

Coal Lost: Amount of coal lost is as follows (Karpuz and Demirel, 2016):

$$
\boldsymbol{O}_{L}=\boldsymbol{O}_{U}-\boldsymbol{P}
$$

Where:

$P$ : Required coal production $(\mathrm{t} / \mathrm{yr})$

$\boldsymbol{O}_{U}:$ Coal uncovered (t/yr)

$\boldsymbol{O}_{L}:$ Coal lost (t/yr)

The Areal Extent of Excavation: is in-situ areal extent of overburden excavated or coal surface exposed in period of time. The areal extent of excavation can be calculated as the area of rectangle formed by excavation (Equation 16) or as the instance of production rate of excavation in period of time (Equation 17) with the formulas as follows (Figure 16) (Karpuz and Demirel, 2016):

$$
\begin{gathered}
M A=W \times L \\
M A=\frac{P}{R \times R D \times T}
\end{gathered}
$$


Where:

MA: Areal extend of excavation $\left(\mathrm{m}^{2} / \mathrm{yr}\right)$

$\boldsymbol{R D}$ : Coal density (bank) $\left(\mathrm{t} / \mathrm{m}^{3}\right)$

P: Required coal production $(\mathrm{t} / \mathrm{yr})$

$\boldsymbol{R}$ : Coal recovery factor

L: Length of cut (m/yr) (Figure 16)

$\boldsymbol{W}$ : Width of cut (m)

Overburden Removed Per Year: With the same logic total volume of overburden excavated in period of time can be calculated by multiplying areal extent of excavation $(\boldsymbol{M A})$ by its thickness (D) (Equation 18). If substitute the equation 18 with equation 16 the equation 19 will be formed (Karpuz and Demirel, 2016).

$$
\begin{gathered}
O B_{T}=M A \times D \\
O B_{T}=W \times L \times D
\end{gathered}
$$

Where:

MA: Areal extend of excavation per year $\left(\mathrm{m}^{2} / \mathrm{yr}\right)$

D: Overburden depth (m)

$\boldsymbol{O B}_{T}$ : Total overburden removed per year $\left(\mathrm{m}^{3} / \mathrm{yr}\right)$

L: Length of cut (m/yr) (Figure 16)

$W$ : Width of single cut (m)

Operating Hours: is operation time of dragline usually referred by hours per year. Total operation time effected by parameters such as availability and utilization of dragline as it shown in formula (Equation 20) (Karpuz and Demirel, 2016):

$$
O P=O \times A \times U
$$


Where:

OP: Total operation time of dragline $(\mathrm{hr} / \mathrm{yr})$

$\boldsymbol{U}$ : Dragline utilization factor

$\boldsymbol{A}$ : Dragline availability factor

$\boldsymbol{O}$ : Dragline operating time $(\mathrm{hr} / \mathrm{yr})$

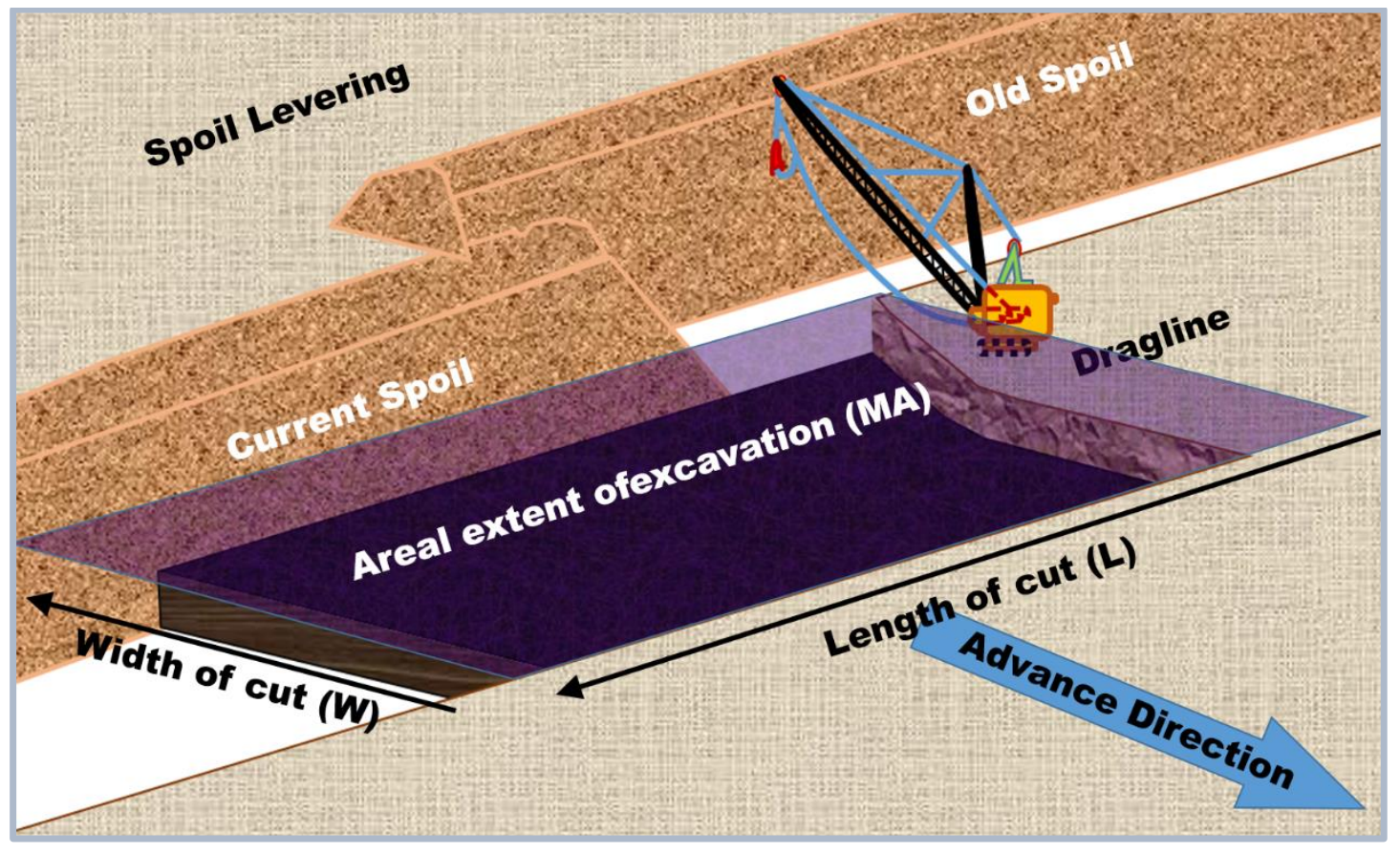

Figure 16. Areal extent of excavation

Bucket Capacity: is the bucket capacity required to handle the task. The bucket capacity requirement increases by increasing swell factor condition and decreases with the high operating time, dragline availability and dragline utilization and the operation cycle time. Also higher the fill ability of bucket lower the bucket capacity required (Karpuz and Demirel, 2016).

$$
\begin{array}{r}
B C=\frac{O B_{T} \times S F \times C T}{O \times A \times U \times B F} \\
o r \\
B C=\frac{O B_{T} \times S F \times C T}{O P \times B F}
\end{array}
$$


Where:

$\boldsymbol{B C}$ : Required bucket capacity $\left(\mathrm{m}^{3}\right)$

CT: One cycle time of dragline (hr)

$\boldsymbol{B F}$ : Bucket fill factor

$\boldsymbol{O P}$ : Total operation time of dragline $(\mathrm{hr} / \mathrm{yr})$

$\boldsymbol{U}$ : Dragline utilization factor

$A$ : Dragline availability factor

O: Dragline operating time (hr/yr)

SF: Swell factor of broken overburden material according to blasting conditions

Maximum Suspended Load (MSL): is the most important parameter in selecting optimum dragline for the project. This parameter will be related with allowable (maximum) suspended load parameters of equipment's from chart or catalogues. MSL is the total of dead weight $\boldsymbol{W}_{\boldsymbol{D}}$ and pay load $\boldsymbol{W}_{\boldsymbol{L}}$ of loaded bucket that can dragline lift (Karpuz and Demirel, 2016).

$$
M S L=W_{D}+W_{L}
$$

Where:

MSL: Maximum suspended load (kg)

$\boldsymbol{W}_{\boldsymbol{D}}$ : Dead weight of bucket $(\mathrm{kg})$

$\boldsymbol{W}_{\boldsymbol{L}}$ : Pay load of bucket $(\mathrm{kg})$

Dead Weight: can be referred as the empty bucket weight (Karpuz and Demirel, 2016).

$$
\begin{gathered}
W_{D}=B C \times \gamma_{B} \\
\left\{\begin{array}{c}
W_{D}=B C \times \gamma_{B} \\
\gamma_{B}=\left\{w_{1} \sim w_{2}\left[\frac{k g}{m^{3}}\right]\right\}
\end{array}\right.
\end{gathered}
$$


Where:

$\boldsymbol{B C}$ : Required bucket capacity $\left(\mathrm{m}^{3}\right)$

$\gamma_{\boldsymbol{B}}$ : The unit weight of empty bucket respect to its capacity $\left(\mathrm{kg} / \mathrm{m}^{3}\right)$

$\boldsymbol{w}_{1}, \boldsymbol{w}_{2}$ : Minimum and maximum unit weight ranges for empty bucket $\left(\mathrm{kg} / \mathrm{m}^{3}\right)$

$\boldsymbol{W}_{\boldsymbol{D}}$ : Dead weight of bucket $(\mathrm{kg})$

$\boldsymbol{W}_{\boldsymbol{L}}$ : Pay load of bucket $(\mathrm{kg})$

Pay Load: is the weight of maximum content of broken rock filled in full dragline bucket. Weight of broken rock decreases with the increasing swell factor or bad fragmentation and increases with the higher bucket fill ability (modified from Karpuz and Demirel, 2016).

$$
\begin{gathered}
W_{L}=B C \times B F_{B} \times \gamma_{L} \\
\gamma_{L}=\frac{O D}{S F}
\end{gathered}
$$

Where:

$\boldsymbol{\gamma}_{\boldsymbol{L}}$ : Weight of broken (loose) overburden rock material filled in to the dragline bucket $\left(\mathrm{kg} / \mathrm{m}^{3}\right)$

$\boldsymbol{O D}$ : In-Situ overburden material density $(\mathrm{kg} / \mathrm{m} 3)$

$\boldsymbol{W}_{\boldsymbol{L}}$ : Pay load of bucket $(\mathrm{kg})$

$\boldsymbol{B C}$ : Required bucket capacity $\left(\mathrm{m}^{3}\right)$

$\boldsymbol{B F}_{\boldsymbol{B}}$ : Bucket fill factor

$\boldsymbol{S F}$ : Swell factor of broken overburden material according to blasting conditions

Production: After selecting dragline model it's possible to calculate production potential of selected dragline model according to its maximum allowable load (MAL or MSL) parameter and applied mine design parameters. For calculating model production ability in this thesis following formulas are evaluated.

Equation 28 is derived according to Equation 23. 


$$
B C_{M}=\frac{M S L_{M}}{W_{S}+B F \times\left(\frac{d_{O B}}{S F}\right)}
$$

Equation 29 is derived from Equation 22.

$$
O B_{M t}=\frac{B C_{M} \times O P \times B F}{S F \times C T}
$$

Equation 30 is derived according to Equations 14,15,17,18.

$$
P_{M}=\frac{O B_{M t}}{\frac{D}{d_{C} \times R \times T}+\frac{1-R}{d_{C} \times R}}
$$

Where:

$\boldsymbol{M S} \boldsymbol{L}_{\boldsymbol{M}}$ : Maximum allowable load of model $(\mathrm{kg})$

$W_{S}$ : Unit weight of empty bucket material $\left(\mathrm{kg} / \mathrm{m}^{3}\right)$

$\boldsymbol{B C}_{\boldsymbol{M}}$ : Bucket capacity of model $\left(\mathrm{m}^{3}\right)$

$\boldsymbol{O} \boldsymbol{B}_{\boldsymbol{M} \boldsymbol{t}}$ : Estimated total overburden which will be excavated (bank) $\left(\mathrm{m}^{3} / \mathrm{yr}\right)$

$\boldsymbol{P}_{\boldsymbol{M}}$ : Production offered by model (t/yr)

$\boldsymbol{R}$ : Coal recovery factor

$\boldsymbol{B} \boldsymbol{F}$ : Bucket fill factor

CT: Operation cycle time in seconds $(\mathrm{hr} / \mathrm{yr})$

T: Seam thickness (m)

$\boldsymbol{O P}$ : Total operation time of dragline $(\mathrm{hr} / \mathrm{yr})$

$\boldsymbol{d}_{\boldsymbol{C}}:$ Coal density (bank) $\left(\mathrm{t} / \mathrm{m}^{3}\right)$

$\boldsymbol{d}_{\boldsymbol{O B}}$ : Overburden density (bank) $\left(\mathrm{kg} / \mathrm{m}^{3}\right)$ 


\subsection{Selection of Dragline}

Selection of a dragline depends on several dragline equipment parameters, but it begins with relating most important parameters such as, reach factor and maximum suspended load with the same parameters of models existing on market.

The selection process can be held either by conventional chart method or by the software, named as Draglayout, developed in this thesis.

\subsubsection{Selection Chart}

Selecting dragline equipment using chart is easy and fast. However, this selection may not be accurate and also it is very hard to add new models in to the chart. Selection chart is a two dimensional graph with maximum allowable load and reach factor parameters of models (Figure 17). To select an optimum model after calculating these parameters the nearest models to the crossing point of MSL and RF have to be discussed for selection.

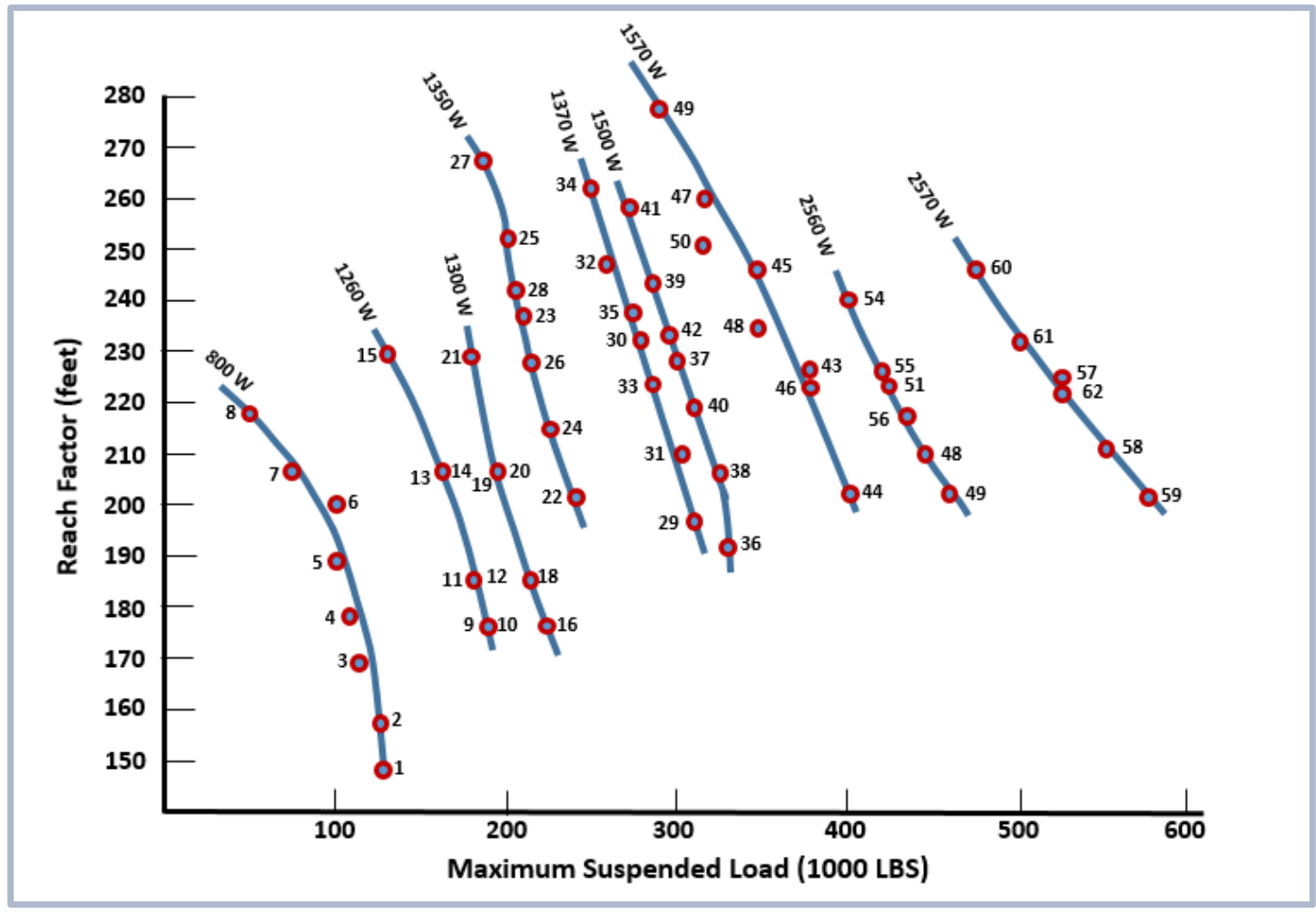

Figure 17. Dragline standard selection chart (Bucyrus Erie Company, 1977) 


\subsubsection{Developed Draglayout Software Selection}

Running Draglayout begins with creating new project. With the sufficient input dialogs all estimated and existing mine design data can be entered. After all input parameters entered, create button creates the new project and simultaneously calculates all described calculations and display results. Draglayout also draws range diagram and choose several applicable models from catalogues for display. This selection goes according to the selection criteria described comprehensively in Chapter 4 Section (Software Presentation) of this thesis. Draglayout guides to make changes and make best selection. On selection action all production rates for different models are calculated and represented as a result. 


\section{CHAPTER 4}

\section{SOFTWARE PRESENTATION}

\subsection{Installing and Running the program}

The default installation procedure creates a desktop icon of Draglayout. Also adding the copy of software manual (Manual.pdf) to the program directory. To load Draglayout, simply click the appropriate icon in the Draglayout located folder or on desktop. The graphic interface loading may take several seconds to initialize while the Java Runtime Environment (JRE) is being loaded. The initialization time can be affected by other programs running in the background. If you notice a significant delay in the initialization of the graphics mode, it may be necessary to close other Windows applications.

The first time you load Draglayout it is asked whether create a new project or open an existing one (Figure 18). This message dialog will appear on start-up every time you load the software. If the user does not want to see this message dialog on Start-up uncheck the checkbox "Show me this on start-up". It is possible to change this later from the tools menu $\rightarrow$ settings section.

\subsection{Creating a New Project}

The Create New Project option will lead user to the data input dialogs in 3 steps (Figure 19: $a, b, c$ ). This steps are as follows:

1. Pit Geometry Input Dialog: Where user expected to enter mine design geometry measures and criteria as thickness of the coal and the 
overburden material, considered width of the cut, pit angle and spoil angle (Figure 19a). Also presented checkbox and input area for toe value if used.

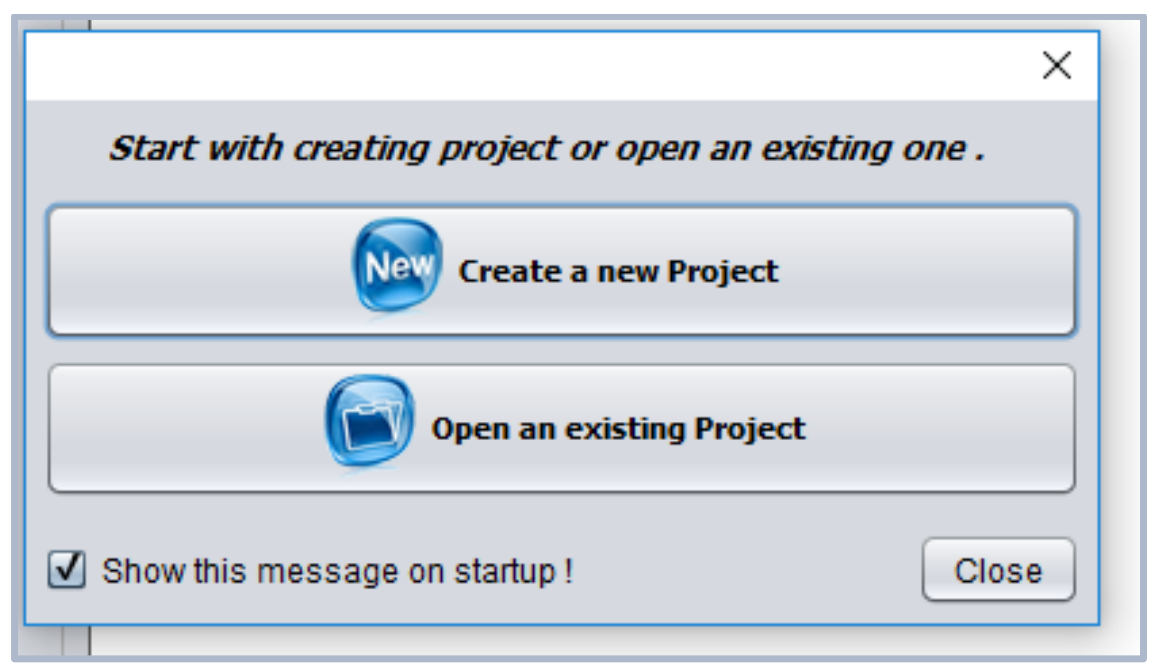

Figure 18. Start-up message dialog

2. Material Characteristics Input Dialog: Where user expected to enter all existed materials characteristics of mine. Such as: Coal and overburden bank densities, swell and fill factors and the empty bucket unit weight parameter for the estimated bucket calculations (Figure 19b). A radio button option presented for empty bucket unit weight area for selecting whether two ranges for calculating bucket empty weight or direct input.

3. Production Dialog: Final step will be the required or predicted production and operating parameters data input dialog (Figure 19c). In this dialog two radio buttons are presented whether input scheduled operating hours in a year and dragline availability and utilization data or direct dragline operation hours value. 
Create New Project function can also be reached from the following options:

- Start-up dialog (Figure 18)

- $\quad$ File $\rightarrow$ New menu (Figure 20a)

- By pressing “Ctrl+N" hotkey

- By single click to new icon from toolbar (Figure 20b)

Create New Project option allows switching back to previous dialog but do not allow leave empty fields. The warning message appears in empty fields' case.

\subsection{Opening Existing Project}

Open Project option refers to standard Open dialog with Draglayout (*.dlp) files filter. In first load of software Draglayout creates "Draglayout\Projects〉" folder in default user root. Then refers Open dialog to the same folder. Later it can be changed default folder from Tools $\rightarrow$ Settings menu.

Open Project function can also be reached from the following options:

- Start-up dialog (Figure 18)

- File $\rightarrow$ Open Project menu (Figure 20a)

- By pressing “ $\mathrm{Ctrl}+\mathrm{O}$ ” hotkey

- By single click to open icon from toolbar(Figure 20b) 


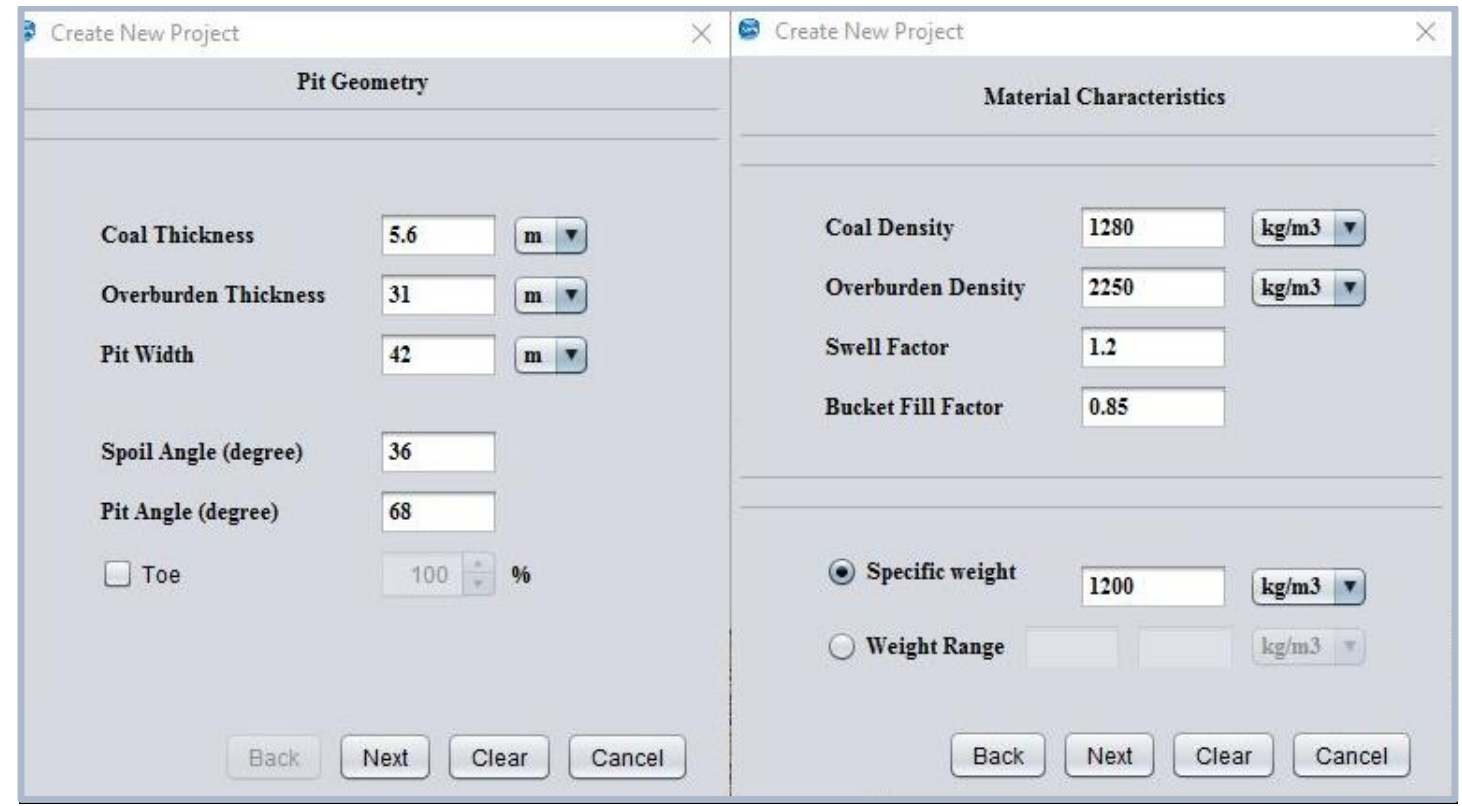

a)

b)

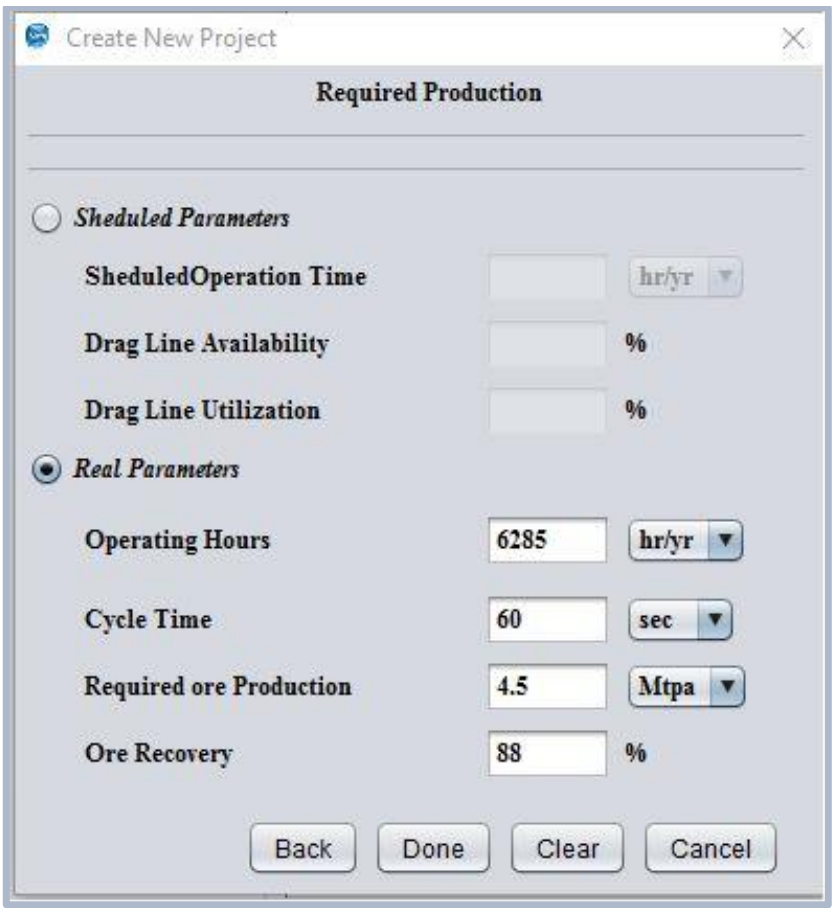

c)

Figure 19. Creating new project $\operatorname{dialog} \boldsymbol{a})$ Pit Geometry input dialog, $\boldsymbol{b}$ ) Material Characteristics input dialog, $c$ ) Required production input dialog

Also it is possible to open a ".dlp" file direct by standard open with function of Windows and by dragging over the software icon. 


\subsection{Saving Project}

There are several ways to save project. In case if the project is not saved, while closing question message dialog appears if you want to save the project or changes. While saving process if the project file does not exist standard Save As dialog appears.

Both Save and Save As functions can also be reached from the following options:

- $\quad$ File $\rightarrow$ Open Project menu (Figure 20a)

- By pressing " $\mathrm{Ctrl}+\mathrm{S}$ " and " $\mathrm{Ctrl}+\mathrm{Shift}+\mathrm{S}$ " hotkeys

- By single click to Save icon from toolbar(Figure 20b)

Note: Save icon and save menu items are disabled while status of the project is "saved".

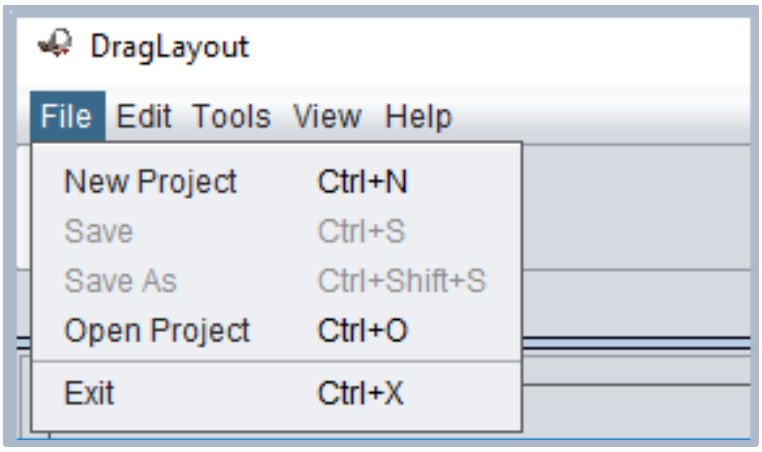

a)

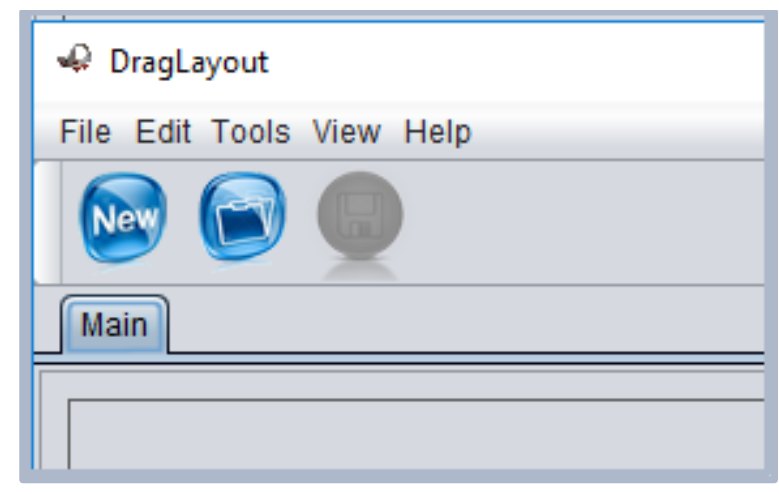

b)

Figure 20. File menu and Toolbar $\boldsymbol{a}$ ) File menu, $\boldsymbol{b}$ ) Toolbar 47 


\subsection{Edit Menu}

With Edit menu Draglayout offer three additional options where entered data can be changed (Figure 21).

Note: If project is not created or any existing project file is not loaded this options are not enabled.

\subsubsection{Edit: Pit Geometry}

With this option changes on previously entered mine design geometry input parameters such as thickness of the coal and the overburden material, considered width of the cut, pit angle and spoil angle (Figure 22) are available. Also presented checkbox and input area for toe value if used.

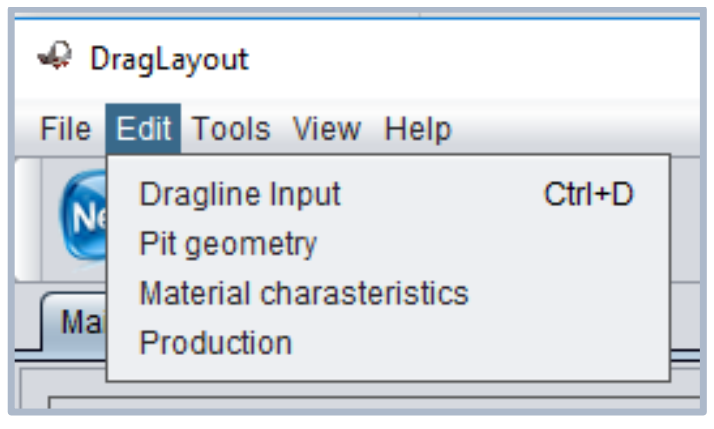

Figure 21. Edit menu

\subsubsection{Edit: Material Characteristics}

With this option changes on previously entered material characteristics input parameters such as: Coal and overburden bank densities, swell factor, fill factor and the empty bucket unit weight (Figure 23) are available. A radio button option presented for unit weight of empty bucket have 2 area for selecting whether 2 ranges for calculating empty bucket unit weight or direct input. 


\subsubsection{Edit: Production}

With this option changes on previously entered required or predicted production and operating parameters input data (Figure 24) are available. In this dialog two radio buttons are presented for scheduled operating hours in a year and dragline availability and utilization data or direct dragline operation hours value.

\subsection{Tools menu}

This menu include three usable options (Figure 25)

- Add and remove models

- Selection criteria (Figure 26)

- Settings

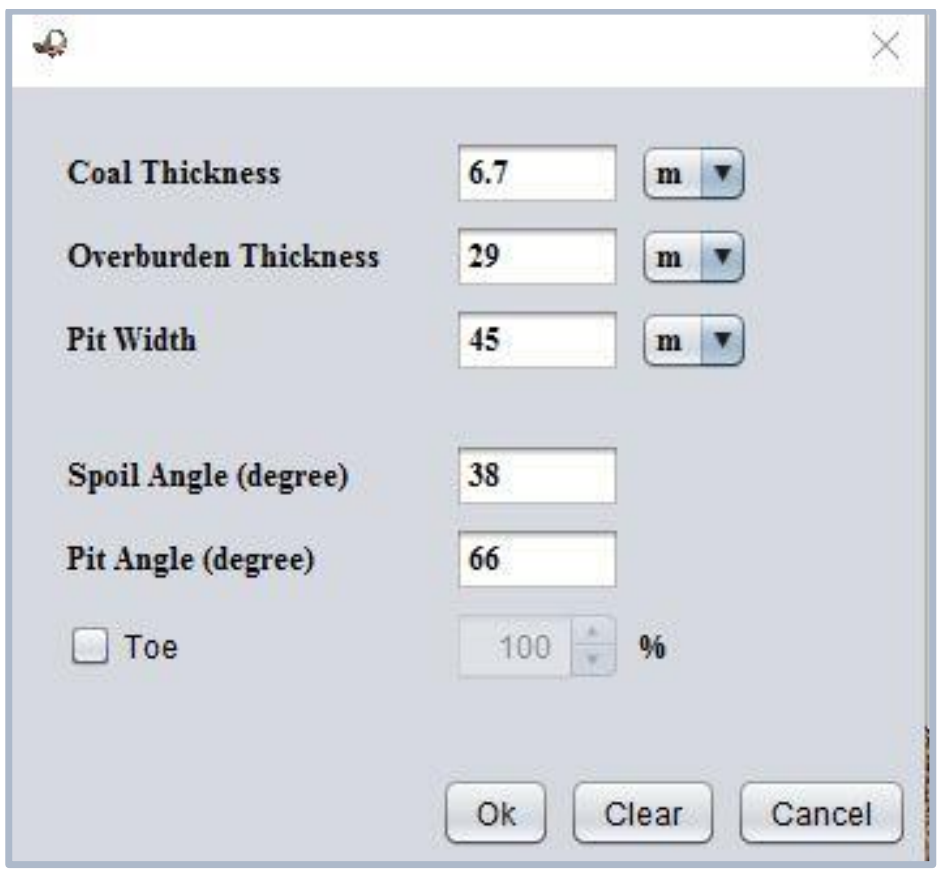

Figure 22. Edit: Pit Geometry menu 


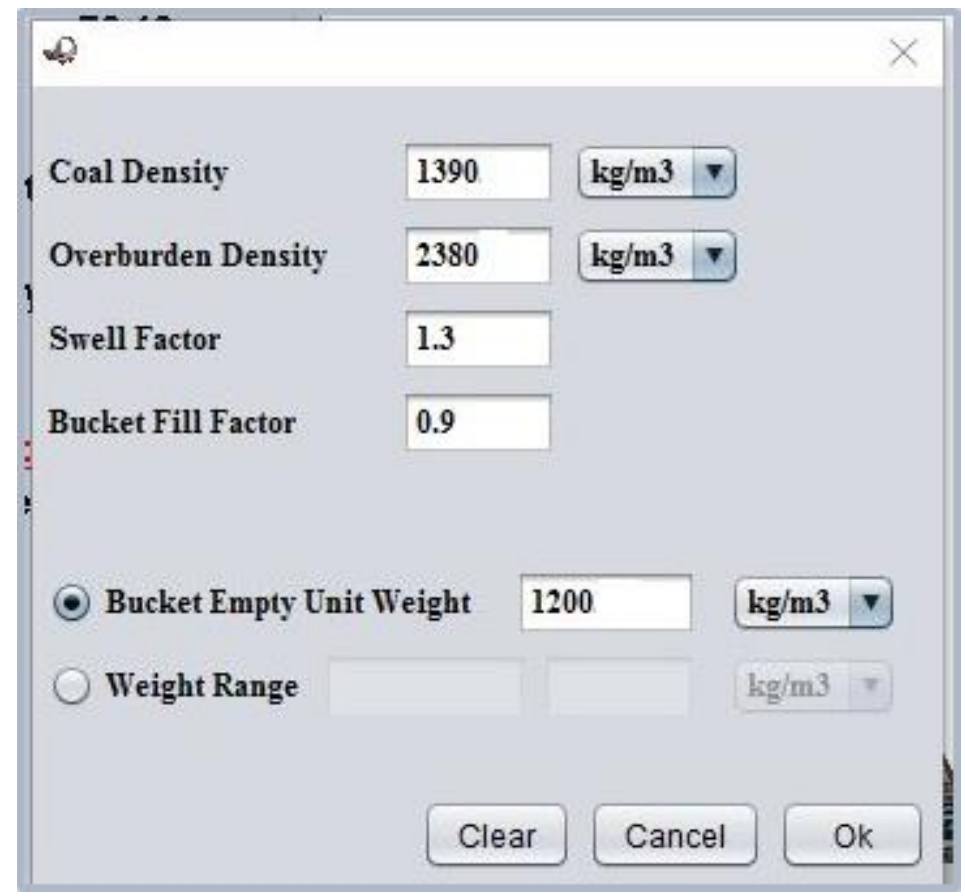

Figure 23. Edit: Material Characteristics menu

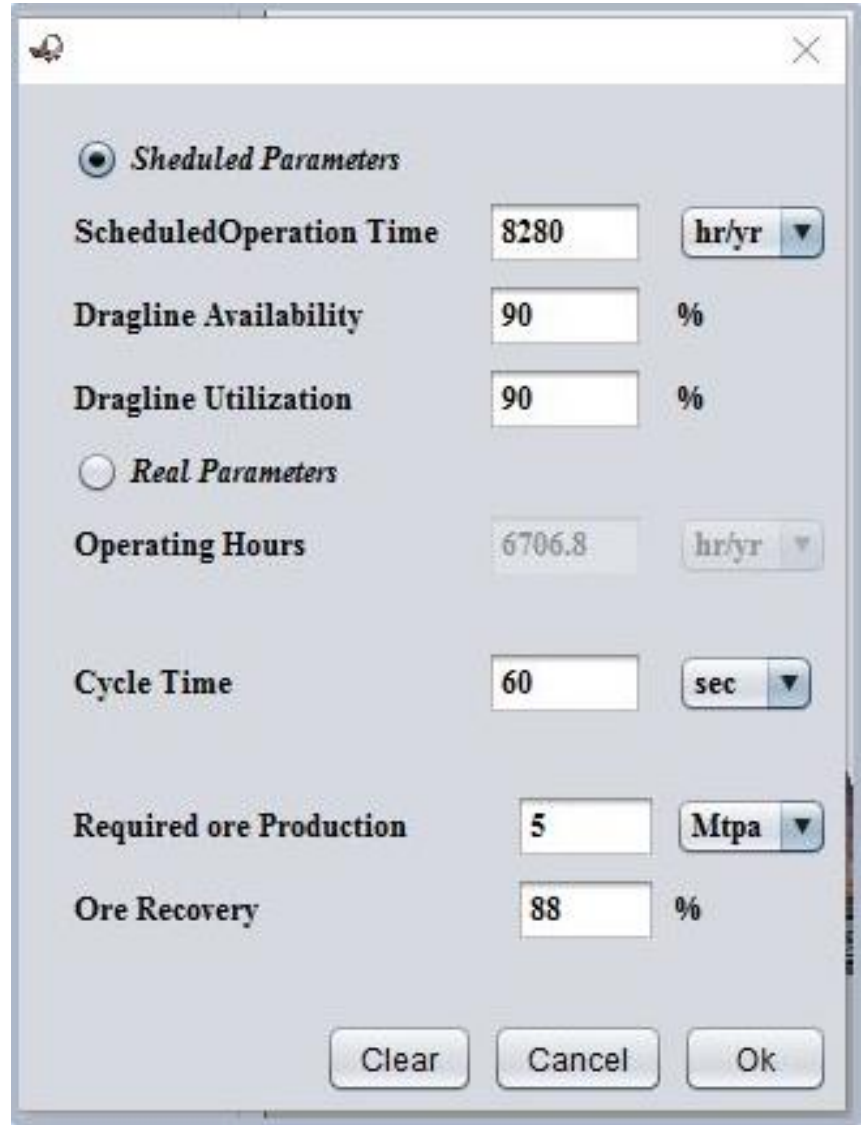

Figure 24. Edit: Operation Parameters dialog 


\subsubsection{Tools: Add and Remove Models}

This option is available only for advanced users. With this option all model parameters can be changed and new models can be added or removed. Also all installed dragline models catalogue is available.

\subsubsection{Tools: Selection Criteria}

Another option for advanced users only, which allows to change the selection criteria of software. The selection criteria is criteria to decide which models will pass to the compatible models list for selecting. The Selection Criteria dialog will appear where will be available four spinner models for four related selection criteria (Figure 26). These criteria are:

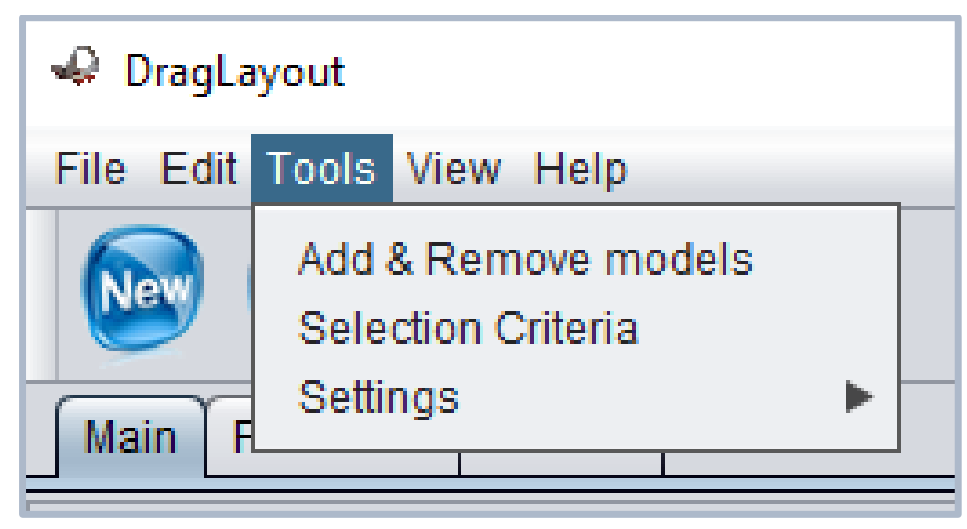

Figure 25. Tool menu

- Under Reach Factor: allows the models with reach ability less than project reach factor output amount.

- Above Reach Factor: allows the models with reach ability more than project reach factor output amount.

- Under Maximum Suspended Load: allows the models with maximum allowable load ability less than project output. 
- Above Maximum Suspended Load: allows the models with maximum allowable load ability more than project output.

Also available three related buttons as:

- Set Criteria button: applying changes.

- Cancel button: cancelling changes to current ones.

- Default button: change the criteria to default allowable.

Note: Selection criteria is stored in project file "*.dlp" and it's available to store different criteria for different projects. When selection criteria are not default Draglayout will warn from console panel (see working interface: Console pane section).

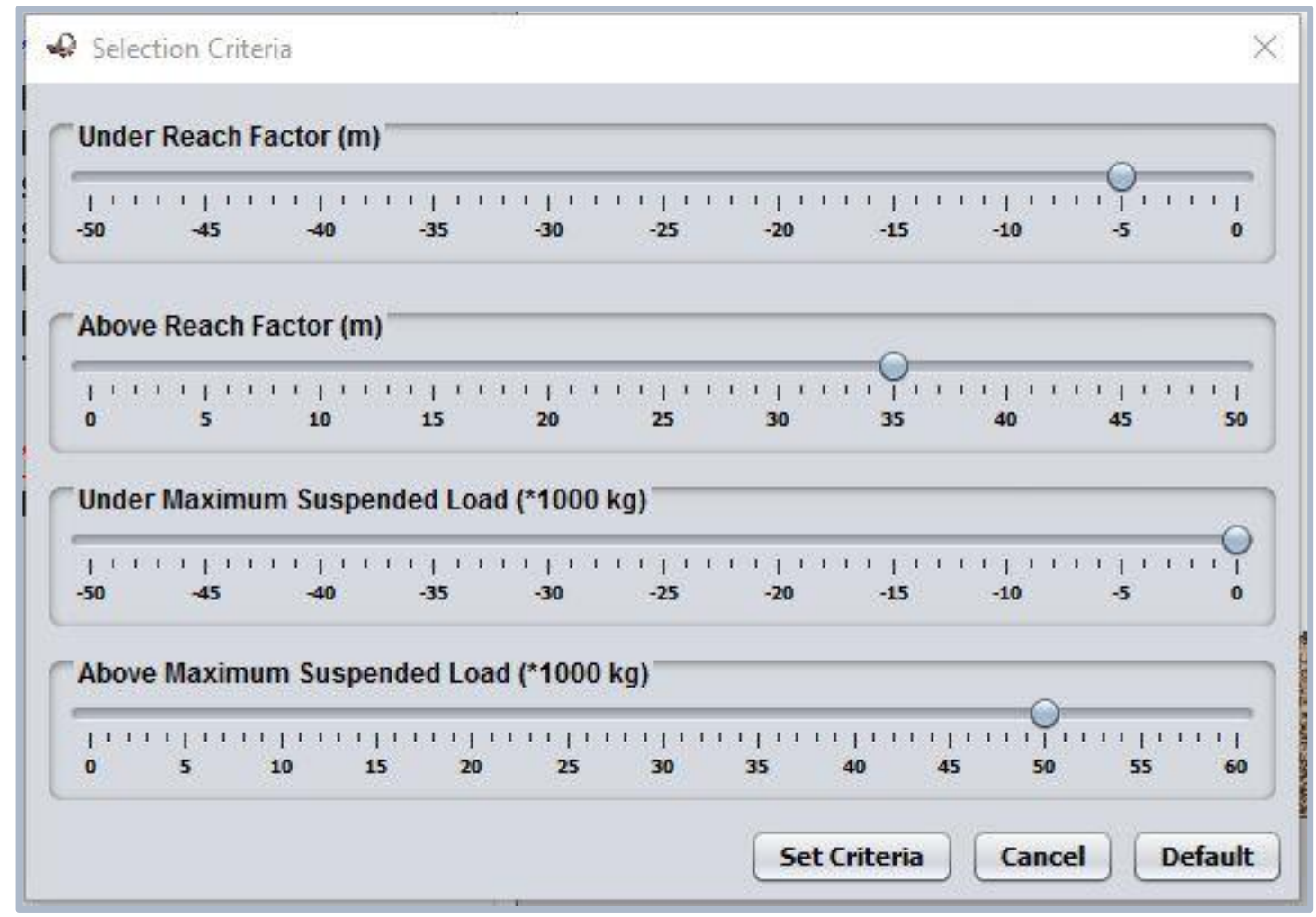

Figure 26. Selection criteria dialog 


\subsubsection{Tools: Settings - Arrow Settings}

Another option for advanced users only, which allows to change the selection criteria of arrows. The arrows are displayable icons in front of the parameters of compatible dragline models (Figure 27). The Arrow Criteria dialog will appear where will be available four spinner models for four related selection criteria (Figure 28). These criteria are:

- Under Reach Factor: allows the models with reach ability less than project reach factor output amount.

- Above Reach Factor: allows the models with reach ability more than project reach factor output amount.

- Under Maximum Suspended Load: allows the models with maximum allowable load ability less than project output.

- Above Maximum Suspended Load: allows the models with maximum allowable load ability more than project output.

\begin{tabular}{|c|c|c|c|c|}
\hline Main & Plan View & Models & & \\
\hline \multicolumn{2}{|c|}{ Name } & & MSL & Reach Factor $\mathbf{B c}$ \\
\hline \multicolumn{3}{|c|}{ Model 51} & 192,777 & $\Rightarrow 68.7$ \\
\hline \multicolumn{3}{|c|}{ Model 52} & 201,849 & 64.7 \\
\hline \multicolumn{3}{|c|}{ Model 53} & 208,652 & 62.3 \\
\hline \multicolumn{3}{|c|}{ Model 55} & 190,509 & $\Rightarrow 69.6$ \\
\hline \multicolumn{3}{|c|}{ Model 56} & 197,313 & $\sqrt{66.8}$ \\
\hline \multicolumn{3}{|c|}{ Model 60} & 215,456 & $\Rightarrow 75.7$ \\
\hline \multicolumn{3}{|c|}{ Model 61} & 226,796 & $\Rightarrow 71.5$ \\
\hline
\end{tabular}

Figure 27. Arrow icons

Also available three related buttons as:

- Set criteria button: applying changes

- Cancel button: cancelling changes to current ones 
- Default button: change the criteria to default allowable

Also one checkbox field "Show arrows on models" for switching arrow mode (Figure 27).

This feature is disabled by default. It's available to enable this feature from Arrow Settings menu or using View $\rightarrow$ Arrows On. Also "Ctrl+A" hotkey is available. Arrow settings are stored in system settings data and it is not related to the projects. Once arrow settings are changed they will be stored in Draglayout settings and will affect at the next load of Draglayout. Changing arrow settings back to default must be held manually from this section.

\subsection{Help Menu}

With this menu can be reachable some "About" information dialog, which displays the version and some other usable information about Draglayout software. Also with help menu this current "Draglayout Manual" can be reached. To display the manual any "PDF" file reader should be installed on your device.

\subsection{Working Interface}

Draglayout software offers "Multi Tabbed Pane" interface in three working tab panes, which allows to concentrate on problem. These panes are:

- Main Pane: This working tab pane is available on start. After project created or loaded all usable information about the project is reachable from related sections (Figure 29). This screen tab is informational tab and include only information, no changes on project can be done with this working tab pane.

Range Diagram Block: At the east side of pane "Mine range diagram" is visualized (Figure 30). The textures of materials can be changed from View: Textures section. Any changes on display characteristics such as 


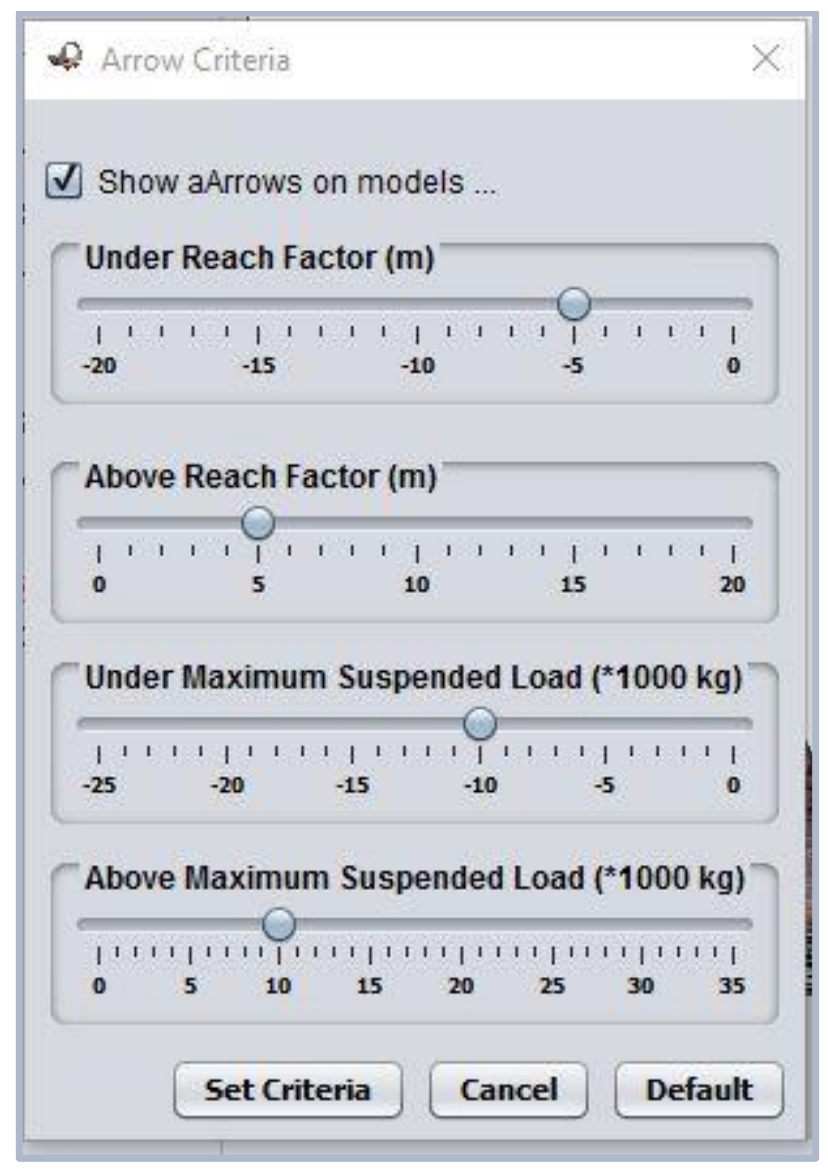

Figure 28. Arrow criteria dialog

> “display ruler" "display RF" checkbox from Plan View Pane (next described) will affect to this visualisation.

$>$ Parameters block: At the left section all input data is available for display (Figure 31a).

Output block: The middle section displays output results and selected model parameters (if any model selected) (Figure 31b).

Console block: Console block contains small text display. This feature is very useful for alerts. From this colourful text display Draglayout displays some important warnings (Figure 32). 


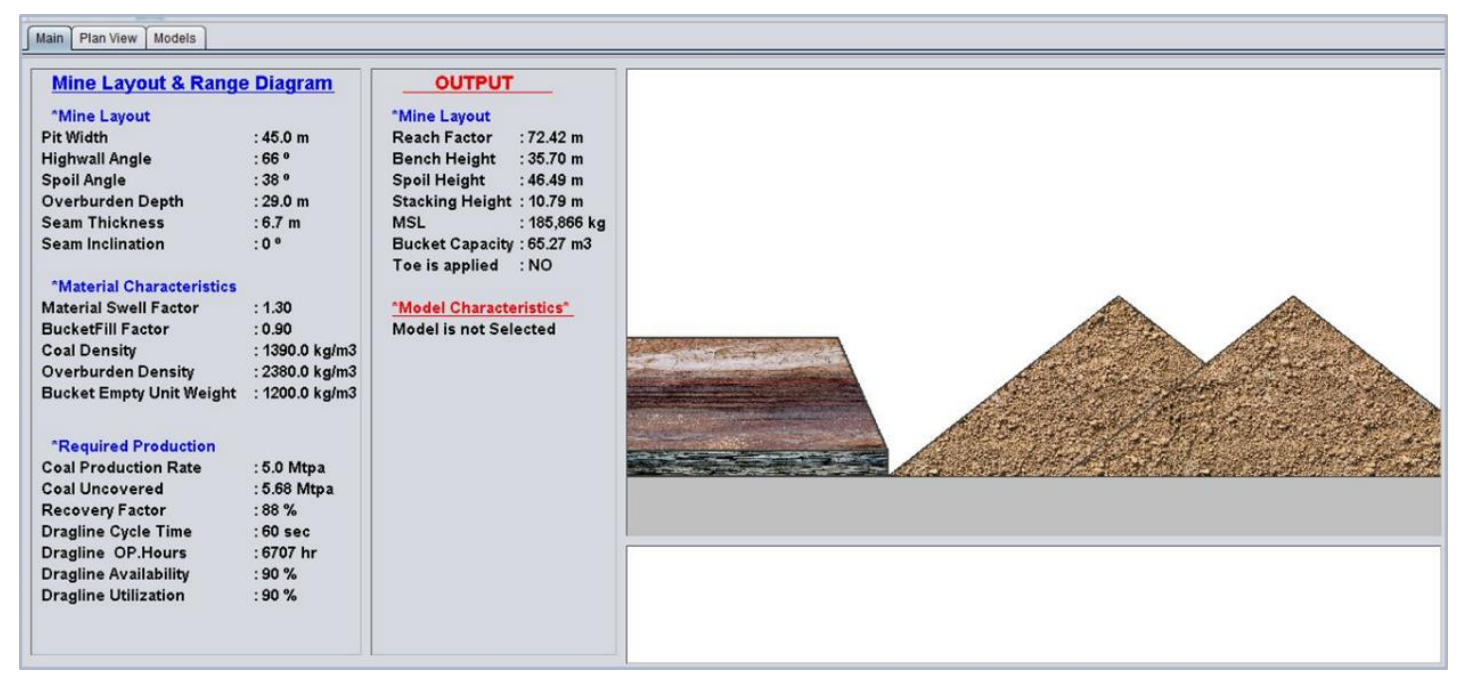

Figure 29. Main pane working tab

- Plan View Pane: This tab is not available on start. Only after project created or loaded will be available (Figure 33). From this tab pane all geometrical parameters are available spinners and input areas are represented to enter a new data or change the previous entered data. Refresh button refers to affect and fix the new entered data to project. This button also works for reloading all working tab panes with one click. In case of changing input data previous selected model removes itself.

- Models Pane: This working tab pane is not available on start. Only after project created or loaded will be available (Figure 34). After running the project all suitable dragline models from catalogue will be displayed (see Selection criteria option). 


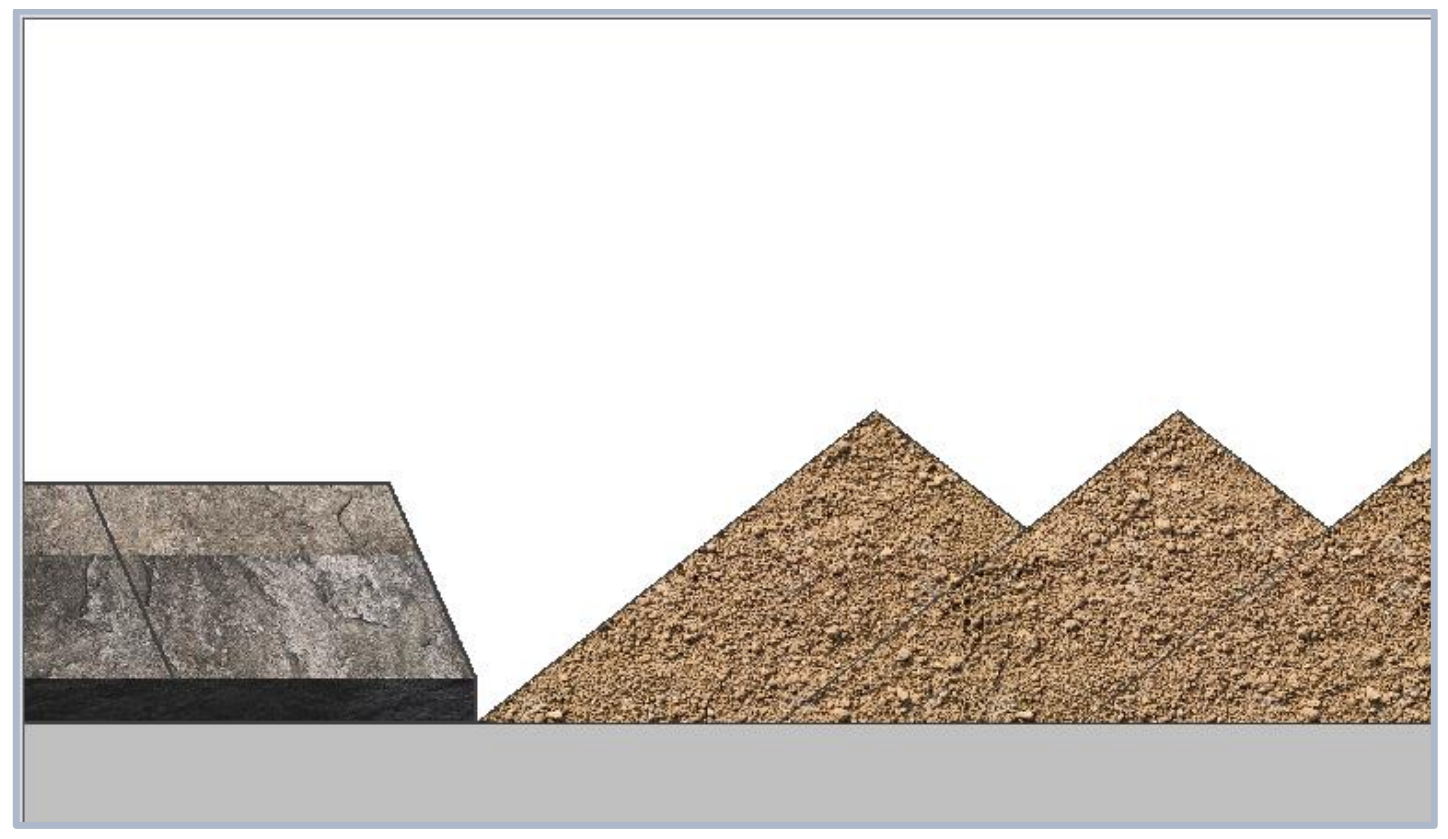

Figure 30. Range diagram block

Also some output results information is available at the right section of pane. It's available to select dragline model from list of suitable models shown.

By clicking on the name of model from list the Model Selection dialog will appear (Figure 35). This dialog displays some important parameters of selected dragline model and also shows results of production value which will prepare this model according to project details. Any changes on project will remove the selected model from project. 


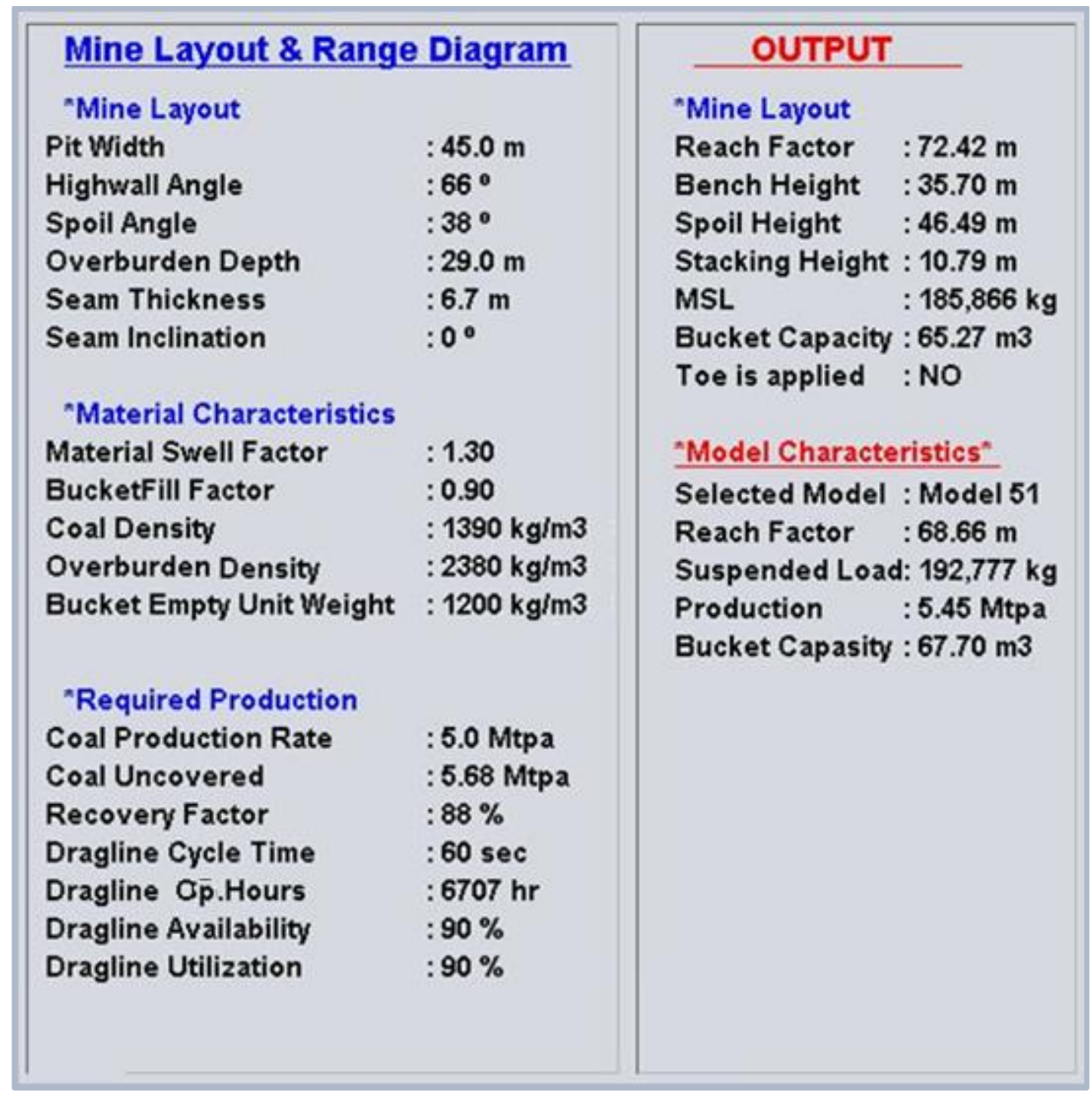

a)

b)

Figure 31. Working tab: a) Parameters block, b) Output block

Selection criterias are not default

Reach Factor of Selected dragline model is lower.

Suspended Load of selected dragline model is lower

Selected dragline model is not approwed by DragLayout.

Figure 32. Console block 


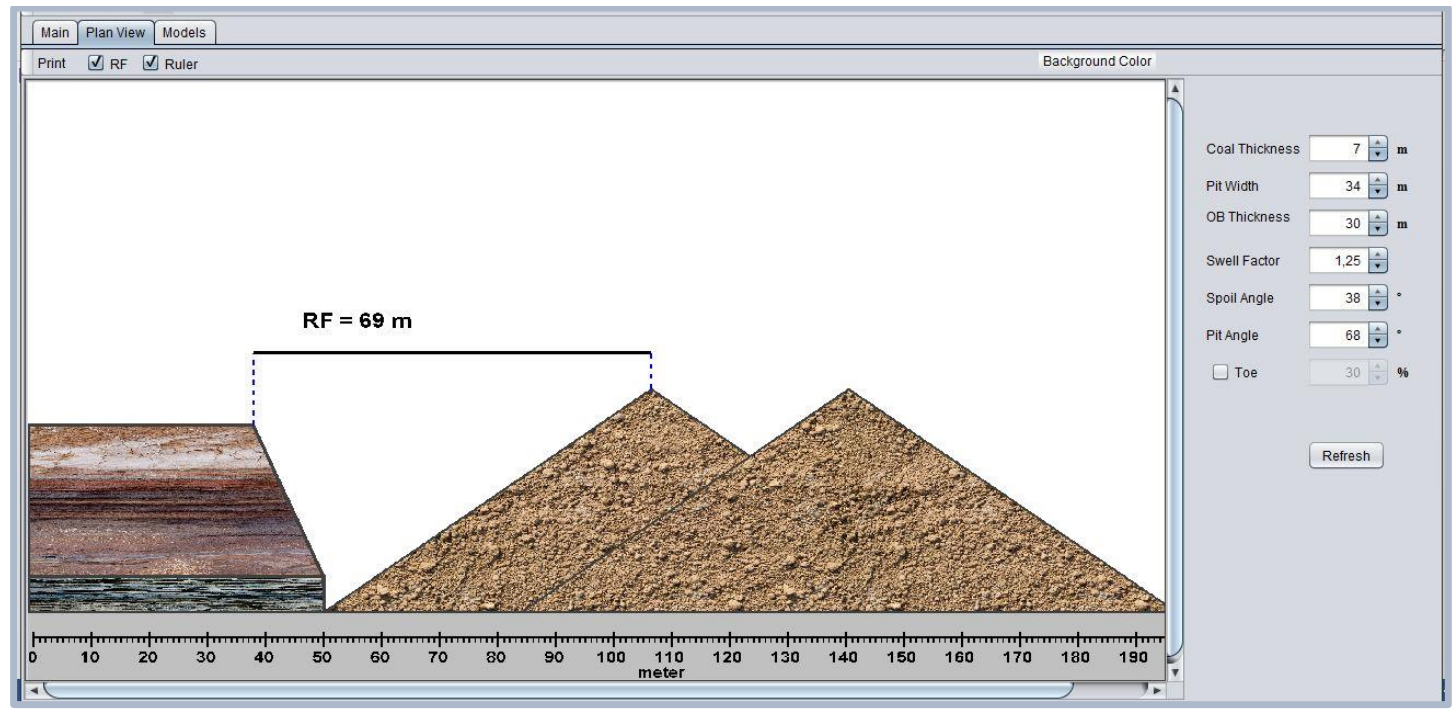

Figure 33. Plan view working tab

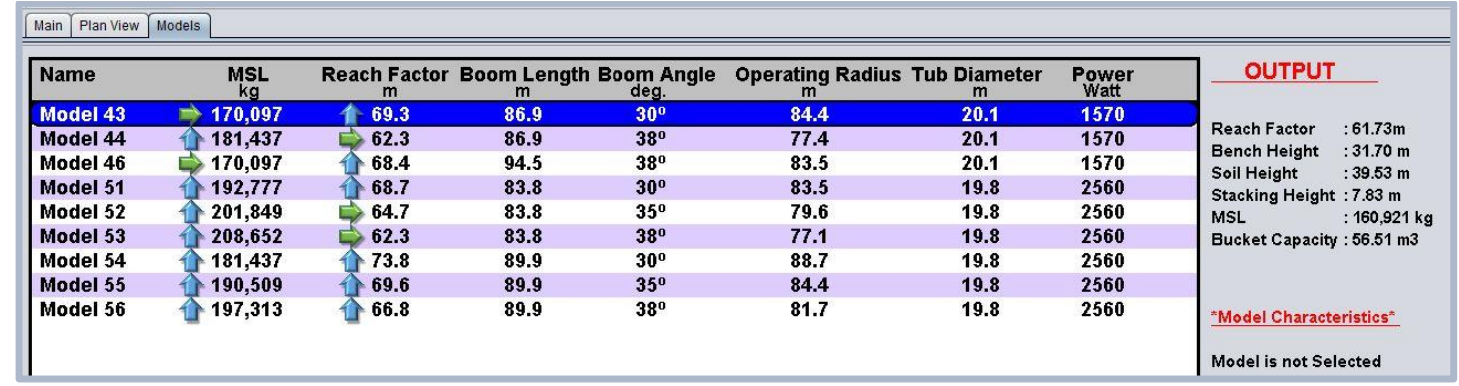

Figure 34. Models pane working tab

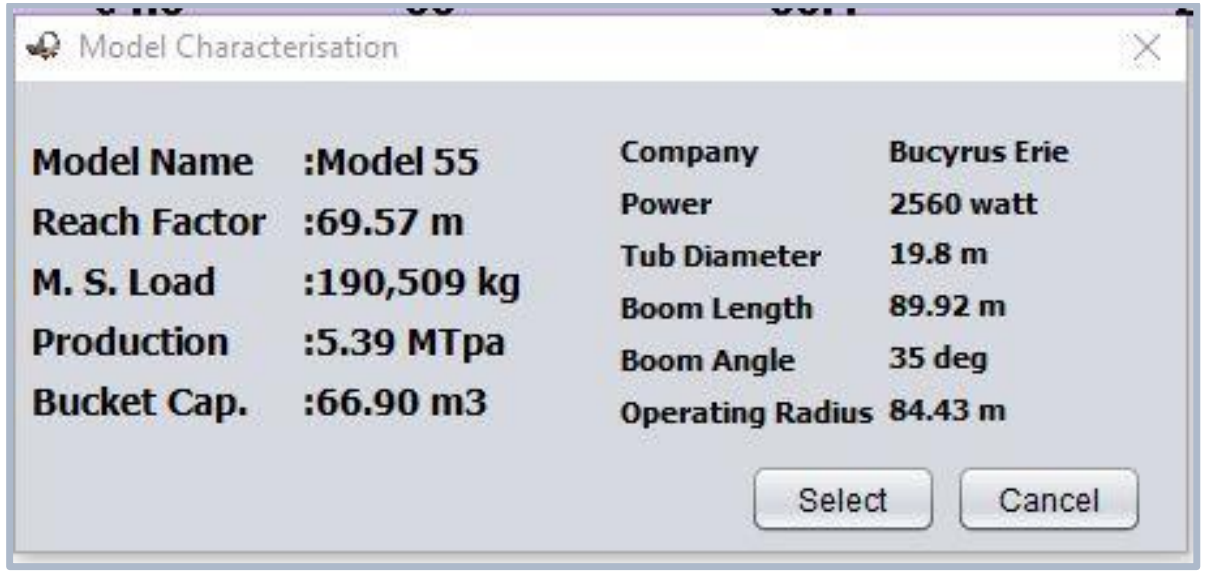

Figure 35. Model selection dialog 


\subsection{Program Flow Chart}

Program flow chart explains the working process of software (Figure 36). This section describes every step of the program flow algorithm step by step. There is some bridges between some of steps of flow where user can interact to the process and make some changes. Other steps are connected to each other automatized and do not allow user integration. Only when the order comes to the linked nodes Draglayout graphical interface allow user interaction. Dashed lines in the Figure 36 are showing bridges.

\subsubsection{Create New Draglayout Project}

Creating new projects starting by sufficient menus and buttons which leads to related input dialogs for data input. The data input process held in several steps with the sufficient options by graphical interface. It is possible to enter data in several unit standards (Can be variate by versions).

\subsubsection{Load Existing Draglayout Projects}

Program load all data from selected "Project $<$ file name $>$.dlp" file and lead to the next stage. With this option engineer can return to his work and continue selecting or change previous decisions at any time. Draglayout stores all project related information as input parameters, selected model, selection criteria, Draglayout project related settings (ex: Textures) in Draglayout project files (*.dlp).

\subsubsection{Input Data}

All necessary input data described in Chapter 3. Input parameters for planning section (Section 3.3.1). Input parameters for planning have to be entered in this stage of flow. Later, this data will be processed and calculated for software flow to proceed. Graphical interface provided by Draglayout gives to engineers' ability in changing this parameters in every phase of the process. 


\subsubsection{Processing Data}

The next step is processing data which process entered data to a single form in which are the calculations will be held. Data stores in the same form which will be further converted to sufficient unit standards for display and export result data.

\subsubsection{Loading Catalogues}

There are several catalogues provided by developer. In this phase Catalogue/ catalogues have been selected are loading for selection. Draglayout provides a graphical user interface for creating a new catalogues or loading supported ones from developer. Catalogues contain several parameters, such as:

- Model ID: individual ID number assigned number to model. This number will be used by Draglayout as a name of model if no any information about manufacturer or model series are available.

- MSL: Maximum suspended load is one of the important parameter for later selection. It describes the maximum load which can machine handle.

- RF: Reach factor is another important parameter for selecting dragline equipment. Reach factor value describes how far machine can reach and operate.

- Boom length: is the length of dragline arm.

- Boom angle: The maximum angle between boom and horizontal plane.

- Operating radius: the rotation radius in which machine can operate.

- Tub diameter: is the diameter of the machine leg or stand on the ground.

- Power: average energy support need for machine operate. 


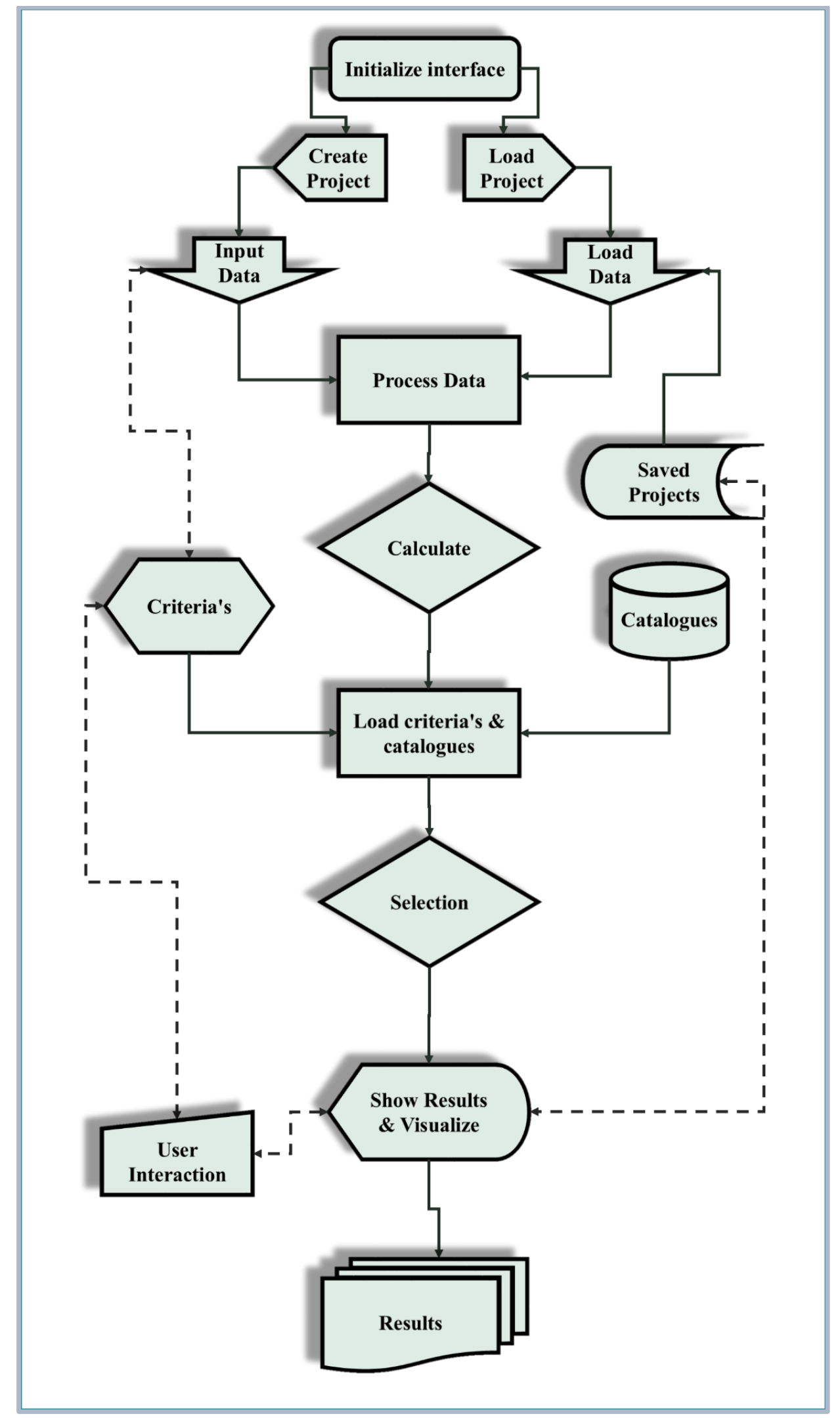

Figure 36. Draglayout software program flow 


\subsubsection{Loading Criteria}

Draglayout reads all default/selected criteria for further decisions. This phase is also provides a link to the main process cycle in user interaction case. In this stage, Draglayout loads selection criteria which were assigned to current project. Note that, selection criteria are stored in project itself. When project is created default selection criteria approved by Draglayout are assigning to the project file. It's available to change the criteria by graphical interface of Draglayout (see Selection Criteria dialog) but once the criteria are reached Draglayout default borders the Draglayout warns from console pane.

\subsubsection{Selection}

Selection takes place by sufficient decisions and calculations based on loaded criteria. First using relations between calculations output and the sufficient selection criteria Draglayout decide which models will pass to the compatible models list for selecting. These criteria are:

- Under Reach Factor: allows the models with reach ability less than project reach factor output amount.

- Above Reach Factor: allows the models with reach ability more than project reach factor output amount.

- Under Maximum Suspended Load: allows the models with maximum allowable load ability less than project output.

- Above Maximum Suspended Load: allows the models with maximum allowable load ability more than project output.

\subsubsection{Visualising}

This phase is actually always on processing also last phase of main process cycle where the visualization and plotting process is holding. Draglayout provides a 
link to the user interaction phase where it is possible to make changes on Selection criteria and other settings such as catalogue selection.

Once compatible models listed software is waiting user to review and select one of the models from list. In this phase all functions for user interaction is available. It's possible to go back and change all inputted data and parameters and run the calculations repeatedly. Model selection dialogs and information panels are good guide for this.

Also from console pane (see Console panel) it is possible to review if Draglayout approves the selected model. After user made decisions dragline model program proceeds to next stage of program flow

\subsubsection{Show Results}

By provided buttons/menus from graphical interface provided by Draglayout it is possible to plot results in several file formats supported/provided by Draglayout or direct send to the selected printer.

\subsection{Validation of the Developed Software}

Validation of the developed Draglayout software by sample data (Table 3) have been applied. Results were compared with conventional chart selection method and all related calculations are explained in the subsections below.

\subsubsection{Sample Data and Calculations}

With the given data (Table 3), range diagram has been drawn in Figure 37. From the given data volume of spoil pile for a unit width can be calculated by combining the Equations 2 and 3.

$$
V A_{s}=40 \mathrm{~m} \times 30 \mathrm{~m} \times 1.25 \times 1 \mathrm{~m}=1500 \mathrm{~m}^{3}
$$

Also using equation 6 the height of spoil pile can be calculated. 


$$
H=30 m \times 1.25+\frac{40 m}{4} \times \tan 38^{\circ}=45.31 m
$$

Table 3. Sample data

\begin{tabular}{ll}
\hline \multicolumn{1}{c}{ Input Parameter } & \multicolumn{1}{c}{ Value } \\
\hline Operation Time & $8030 \mathrm{hr} / \mathrm{yr}$ \\
Dragline Availability & $88 \%$ \\
Dragline Utilization & $90 \%$ \\
Ore Density (bank) & $1300 \mathrm{~kg} / \mathrm{m}^{3}$ \\
Ore Recovery & $85 \%$ \\
Ore Thickness & $7 \mathrm{~m}$ \\
Swell Factor & 1.25 \\
Bucket Fill Factor & $88 \%$ \\
Production & $5 \mathrm{M} \mathrm{t} / \mathrm{yr}$ \\
Cycle time & $60 \mathrm{sec}$ \\
Overburden Depth & $30 \mathrm{~m}$ \\
Overburden Density (bank) & $2100 \mathrm{~kg} / \mathrm{m}^{3}$ \\
Pit Width & $40 \mathrm{~m}$ \\
Pit Slope angle & $68^{\circ}$ \\
Spoil Pile angle & $38^{\circ}$ \\
Bucket Empty Unit Weight & $1100 \mathrm{~kg} / \mathrm{m}^{3}$ \\
Dragline Swing Angle & $120^{\circ}$ \\
\hline
\end{tabular}

By subtracting total bench height from calculated spoil pile height the stacking height of spoil pile will be obtained (Equation 7).

$$
S H=45.31 m-(30 m+7 m)=8.31 m
$$

Next, using equation 11 reach factor without toe is calculated.

$$
R F=\frac{30 m}{\tan 68^{\circ}}+\frac{30 m \times 1.25}{\tan 38^{\circ}}+\frac{40 m}{4}=70.12 m
$$

Later, the result of reach factor required converted from meter to feet for using in chart selection. 


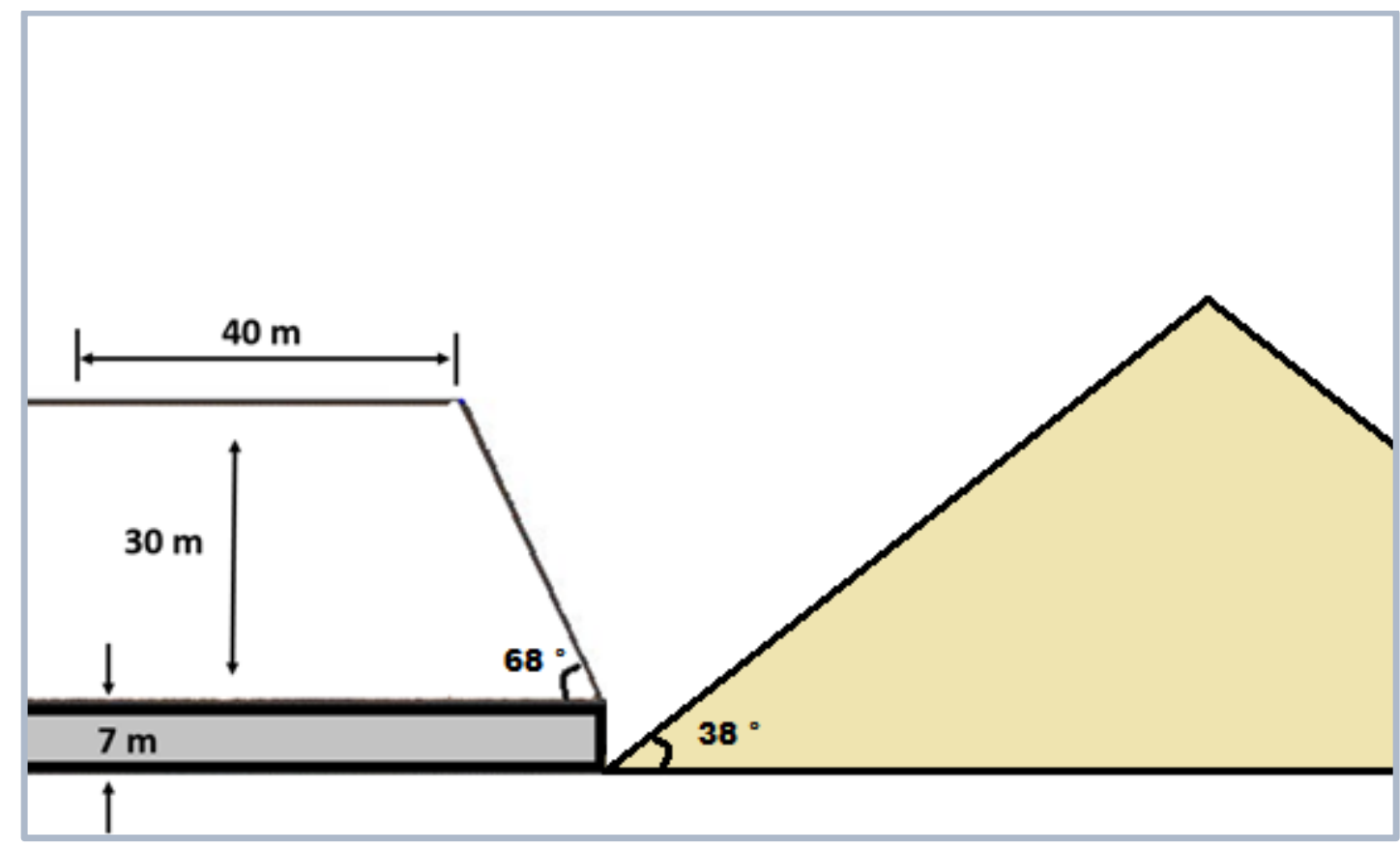

Figure 37. Range diagram for given sample data.

The other important parameter is required maximum suspended load (MSL) of dragline to complete the task as described in previous sections. The way of calculating MSL starts with calculating the total coal uncovered in a year. Calculation of coal uncovered is as follows (Equation 14):

$$
o_{U}=\frac{5 M t / y r}{0.85}=5.88 M t / y r
$$

The coal lost due to recovery is (Equation 15):

$$
O_{L}=5.88 M t / y r-5 M t / y r=0.88 M t / y r
$$

Next step is calculation of the areal extent of excavation (Equation 17):

$$
M A=\frac{5.88 M t / y r \times 10^{6}}{1.30 t / m^{3} \times 7 m}=646,153 m^{2} / y r
$$


According to this extent the length of excavation per year can be calculated (Equation 16).

$$
L=\frac{646,153 m^{2} / y r}{40 m}=16,153.82 m / y r
$$

Using equations 18 or 19 it is available to calculate the total overburden which will be excavated per year.

$$
\begin{gathered}
O B_{\text {Volume }}=646,153 \mathrm{~m}^{2} / y r \times 30 \mathrm{~m}=19.38 \mathrm{M} \mathrm{m}^{3} / y r(\text { bank }) \\
O_{L}=\frac{0.88 \mathrm{Mt} / \mathrm{yr}}{1.30 \mathrm{t} / \mathrm{m}^{3}}=0.67 \mathrm{M} \mathrm{m}^{3} / y r(\text { bank }) \\
O B_{T}=19.38 \mathrm{M} \mathrm{m}^{3} / y r+0.67=20.05 \mathrm{M} \mathrm{m}^{3} / y r(\text { bank })
\end{gathered}
$$

Next, total operation time in a year has to be calculated (Equation 20).

$$
O P=8030 h r / y r \times 0.88 \times 0.90=6360 h r / y r
$$

Inserting the calculated results in to equation 22 required bucket capacity (BC) of dragline is calculated.

$$
B C=\frac{20.05 \mathrm{M} \mathrm{m}^{3} / \mathrm{yr} \times 10^{6} \times 1.25 \times \frac{60 \mathrm{sec}}{3600 \mathrm{sec} / \mathrm{hr}}}{6360 \mathrm{hr} / \mathrm{yr} \times 0.88}=74.63 \mathrm{~m}^{3}
$$

MSL is the sum of two parameters as dead weight of bucket and pay load of bucket as described in previous sections. These two parameters can be calculated using equations 24 and 26 respectively.

$$
W_{D}=1100 \mathrm{~kg} / \mathrm{m}^{3} \times 74.63 \mathrm{~m}^{3}=82,093 \mathrm{~kg}
$$




$$
W_{L}=74.63 \mathrm{~m}^{3} \times 0.88 \times \frac{2100 \mathrm{~kg} / \mathrm{m}^{3}(\text { bank })}{1.25}=110,333 \mathrm{~kg}
$$

Then the sum of these parameters is required to calculate maximum suspended load (MSL) of dragline (Equation 23).

$$
M S L=82,093 \mathrm{~kg}+110,333 \mathrm{~kg}=192,426 \mathrm{~kg}
$$

\subsubsection{Use of Selection Chart}

Finally, all necessary data and calculated results essential for selection of optimum dragline are obtained and converted to the specified units for chart selection. With the obtained results of RF and MSL:

$$
M S L=192,426 \mathrm{~kg} \approx 423,337 \mathrm{lbs} \text { and } R F=70.12 \mathrm{~m} \approx 230 \mathrm{ft}
$$

Dragline selection can be done from chart (Figure 38). The crossed lines were drawn on chart to find best dragline model (Figure 38).

As it can be observed from the Figure 38 there is no direct match from chart but few models are near to cross point of lines (red and green coloured lines) referring RF and MSL values obtained, may be useful. It seems model 51 is close to match the example mine model requirements but the reach factor of model is lower than RF need. There is another model, model 55, having RF and MSL values close to the selected model. However, MSL of model $55(190,509 \mathrm{~kg})$ is less than the required MSL value $(192,426 \mathrm{~kg})$. Although RF of model 55 is greater than model 51 , it will not be selected due to its MSL value.

\subsubsection{Draglayout run for example}

By the sufficient menus and options data input of same example entered and new project created. Draglayout calculated all necessary parameters and offered 6 dragline models from catalogue (Figure 39). All program output results are almost 
same with calculations (Figure 40). It can be observed by range diagram panel as well (Figure 41). But when the same dragline model (Model 51) have been chosen program alerts from console pane that reach factor of selected model is lower (Figure 42). One of the solutions is shortening pit width to decrease the reach factor.

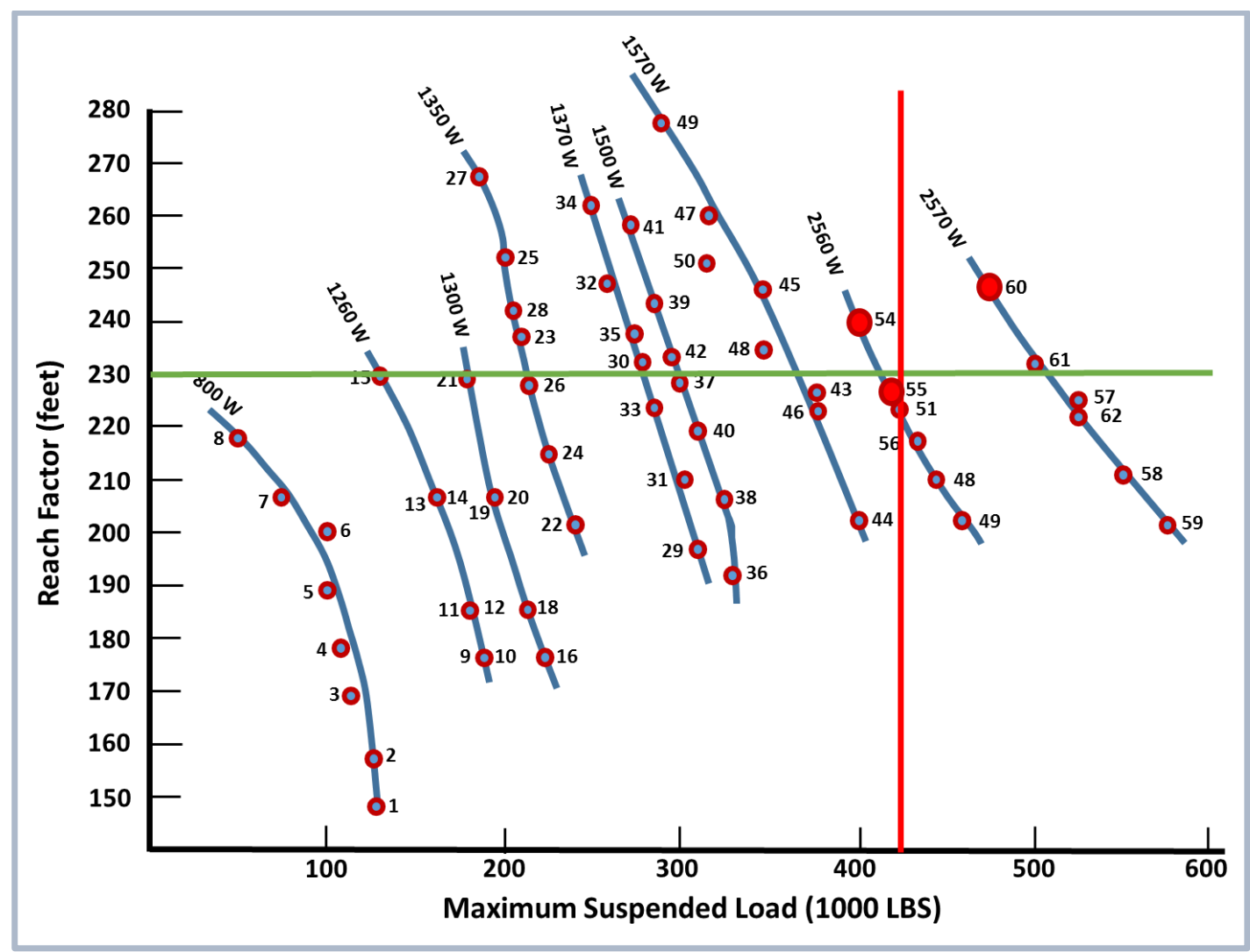

Figure 38. Selecting an appropriate model by their parameters from chart

Figure 38 showed dragline models and the details about most of these models are also listed in Table 4. Since Table 4 was developed using data obtained from available catalogue and it does not include all of the models given in Figure 38. 


\begin{tabular}{|c|c|c|c|c|c|c|c|}
\hline Name & MSL & Reach Factor & Boom Length & $\begin{array}{c}\text { Boom Angle } \\
\text { deg. }\end{array}$ & Operating Radius & Tub Diameter & $\begin{array}{l}\text { Power } \\
\text { Watt }\end{array}$ \\
\hline Model 51 & $\Rightarrow 192,777$ & $\Rightarrow 68.7$ & 83.8 & $30^{\circ}$ & 83.5 & 19.8 & 2560 \\
\hline Model 56 & $\Rightarrow 197,313$ & $\Rightarrow 66.8$ & 89.9 & $38^{\circ}$ & 81.7 & 19.8 & 2560 \\
\hline Model 57 & 238,136 & $\Rightarrow 69.3$ & 86.9 & $30^{\circ}$ & 86.3 & 22.6 & 2570 \\
\hline Model 60 & 215,456 & 75.7 & 94.5 & $30^{\circ}$ & 92.7 & 22.6 & 2570 \\
\hline Model 61 & 226,796 & $\Rightarrow 71.5$ & 94.5 & $35^{\circ}$ & 88.4 & 22.6 & 2570 \\
\hline Model 62 & 238,136 & $\Rightarrow 68.4$ & 94.5 & $38^{\circ}$ & 85.3 & 22.6 & 2570 \\
\hline
\end{tabular}

Figure 39. Model selection pane

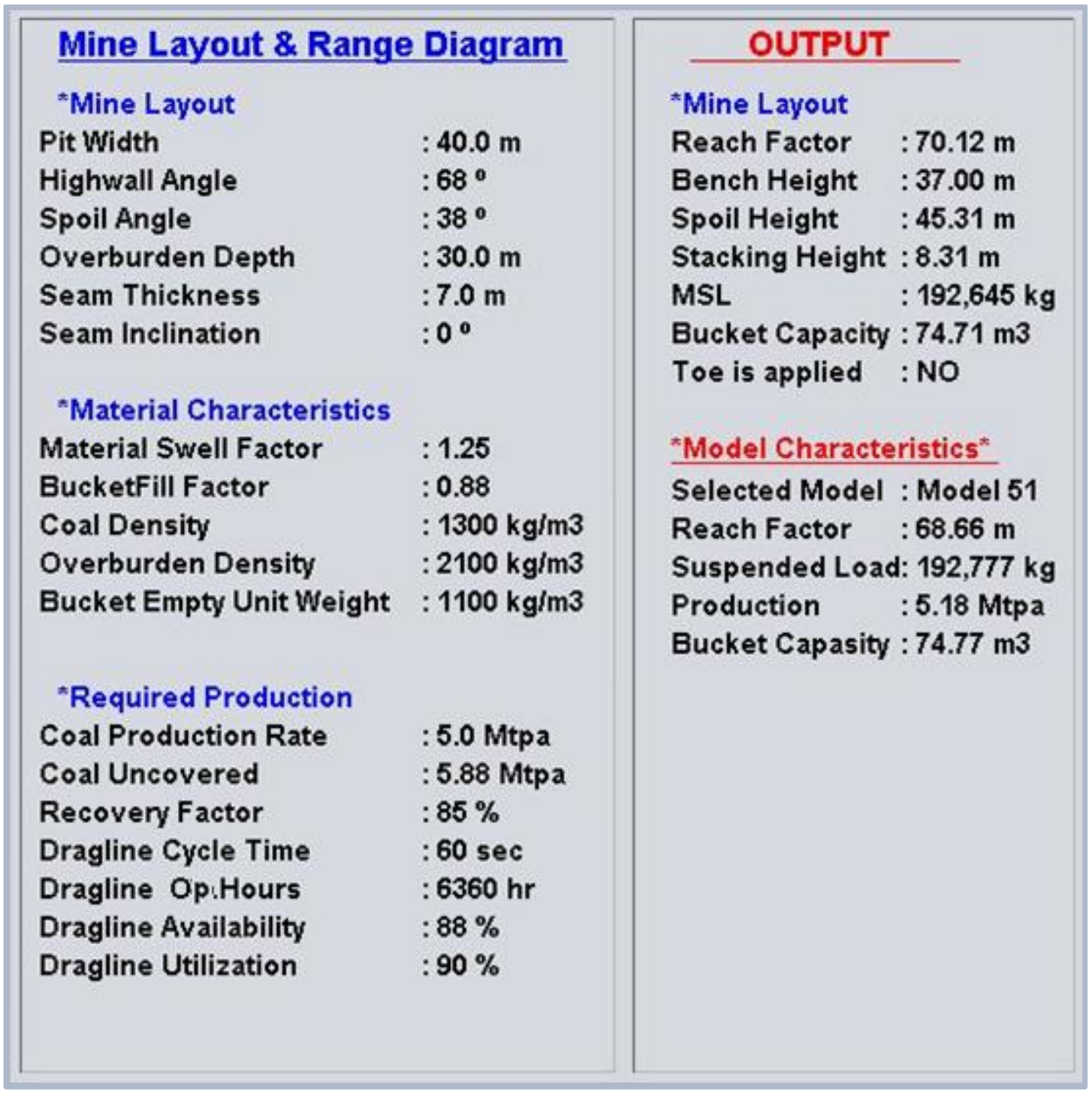

Figure 40. Results obtained for the example. 


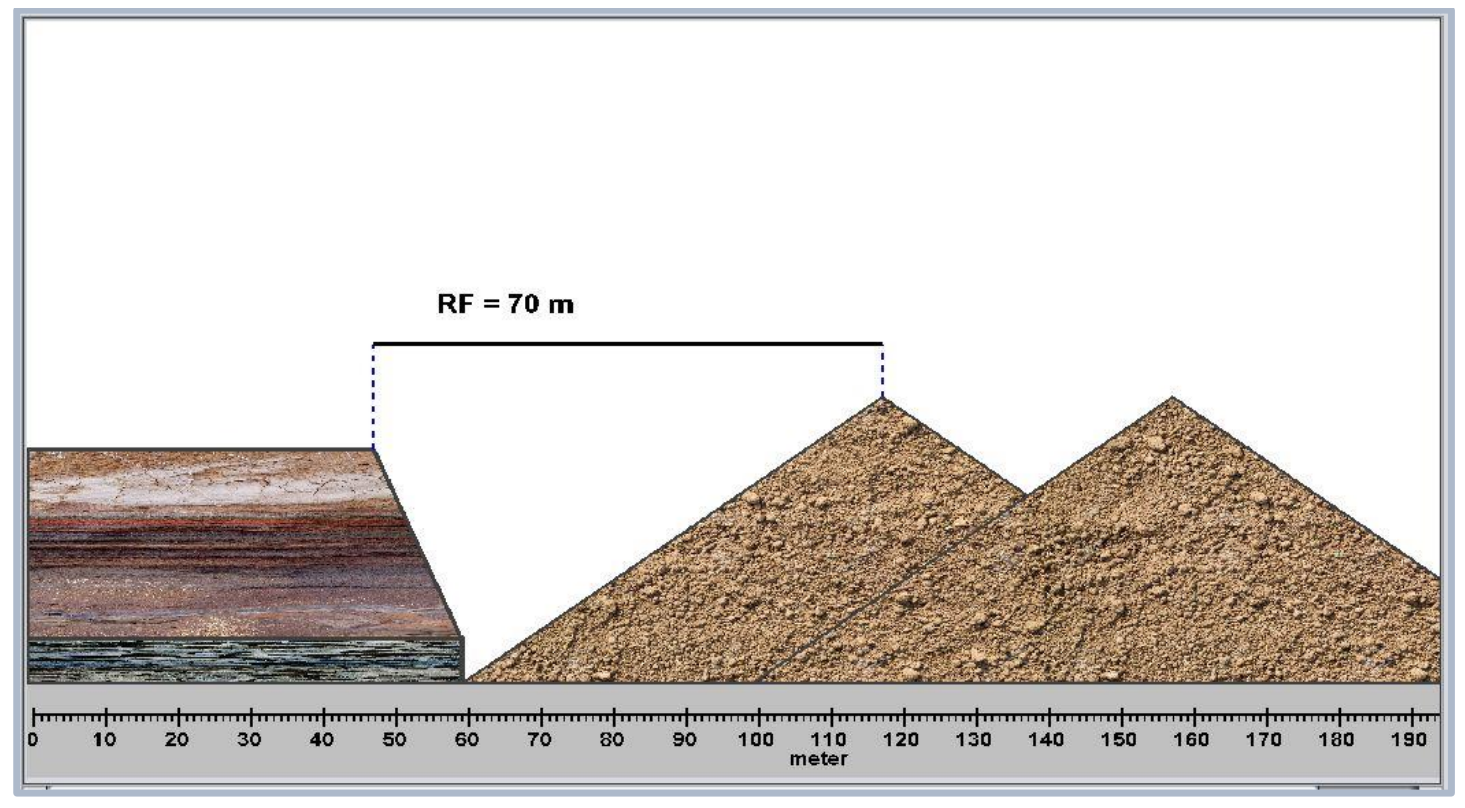

Figure 41. Example range diagram and RF

Reach Factor of Selected dragline model is lower. Selected dragline model is not approwed by DragLayout.

Figure 42. Draglayout - Console pane

Pit width have been changed from $40 \mathrm{~m}$ to $34 \mathrm{~m}$ to decrease reach factor needed. Related model is selected and passed approve test by Draglayout due to lower RF. New program output screen derived shown in Figure 43. 


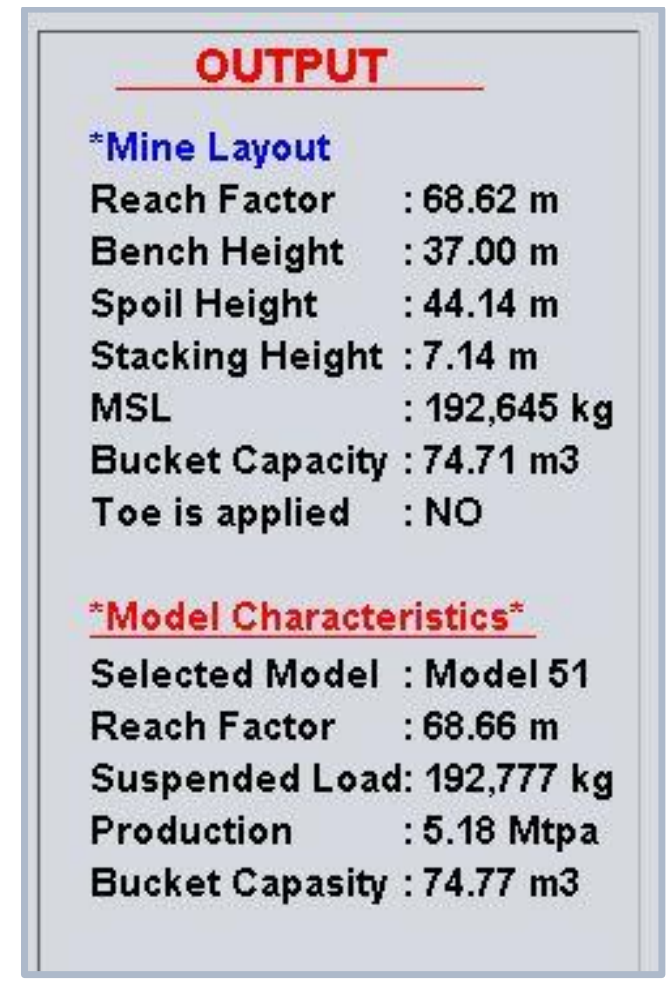

Figure 43. Draglayout output screen after changes on pit width and related model selected

\subsubsection{Production Calculations}

According to the selected dragline models parameters the approximate bucket capacity and the approximate production per year can be achieved with dragline model is calculated.

$$
\begin{gathered}
B C_{M}=\frac{192,777 \mathrm{~kg}}{1100 \mathrm{~kg} / \mathrm{m}^{3}+0.88 \times\left(\frac{2100 \mathrm{~kg} / \mathrm{m}^{3}(\text { bank })}{1.25}\right)}=74.76 \mathrm{~m}^{3} \\
O B_{t}=\frac{74.76 \mathrm{~m}^{3} \times 6360 \mathrm{hr} / \mathrm{yr} \times 0.88}{1.25 \times \frac{60 \mathrm{sec}}{3600 \mathrm{sec} / \mathrm{hr}}}=20.08 \mathrm{M} \mathrm{\textrm {m } ^ { 3 } / y r} \\
P_{M}=\frac{20.08 \mathrm{M} \mathrm{m} / \mathrm{yr}}{\frac{10^{6} \times 30 \mathrm{~m}}{1.3 \mathrm{t} / \mathrm{m}^{3} \times 0.85 \times 7 \mathrm{~m}}+\frac{1-0.85}{1.3 \mathrm{t} / \mathrm{m}^{3} \times 0.85}}=5.18 \mathrm{Mt} / \mathrm{yr}
\end{gathered}
$$


The calculations shows that with this model of dragline the production of mine can be increased up to $0.18 \mathrm{M} \mathrm{t} / \mathrm{yr}$ (Rehandle amount causing toeing is not taken in consideration).

Validation shows that, all calculated output results are approximately same with manually calculated results. Small differences on results observed because of rounding in manually calculating. Draglayout uses 8 bytes memory (13 digits) for storing each number which is a pretty big range, which makes results be more accurate. Moreover, Draglayout provide an easy graphical interface, fast calculation, menus to switch catalogues and ability to make changes in design and run calculations repeatedly.

\subsection{Software Library}

For this study only catalogue installed to the developed software is a catalogue presented by Bucyrus Erie Co. in 1977 (Table 4). For future developments and versions of Draglayout it is possible to add new catalogues.

Table 4. Dragline standard machine selection table (Bucyrus Erie Company, 1977)

\begin{tabular}{ccccccc}
\hline $\begin{array}{c}\text { Reference } \\
\text { Number }\end{array}$ & $\begin{array}{c}\text { Boom } \\
\text { Length }(\mathrm{m})\end{array}$ & $\begin{array}{c}\text { Boom } \\
\text { Angle }\left({ }^{\circ}\right)\end{array}$ & $\begin{array}{c}\text { Op. } \\
\text { Radius }(\mathrm{m})\end{array}$ & $\begin{array}{c}\text { Reach } \\
\text { Factor }(\mathrm{m})\end{array}$ & $\begin{array}{c}\text { Max. Sus. } \\
\text { Load }(\mathrm{kg})\end{array}$ & $\begin{array}{c}\text { Power } \\
(\text { watt })\end{array}$ \\
\hline 16 & 72 & 34 & 66 & 54 & 102,058 & 1300 \\
17 & 72 & 30 & 68 & 57 & 97,522 & 1300 \\
18 & 72 & 38 & 68 & 57 & 97,522 & 1300 \\
19 & 72 & 30 & 75 & 63 & 88,451 & 1300 \\
20 & 72 & 38 & 75 & 63 & 88,451 & 1300 \\
21 & 72 & 30 & 81 & 70 & 81,647 & 1300 \\
22 & 72 & 38 & 73 & 62 & 108,862 & 1350 \\
23 & 72 & 30 & 84 & 73 & 95,254 & 1350 \\
24 & 72 & 38 & 78 & 66 & 102,058 & 1350 \\
25 & 72 & 30 & 89 & 77 & 90,718 & 1350 \\
26 & 72 & 38 & 82 & 70 & 97,522 & 1350 \\
27 & 72 & 30 & 94 & 82 & 83,915 & 1350 \\
28 & 72 & 38 & 86 & 74 & 92,986 & 1350 \\
29 & 72 & 38 & 73 & 60 & 140,614 & 1370 \\
\hline
\end{tabular}


Table 5. Dragline standard machine selection table (Cont'ed.) (Bucyrus Erie Company, 1977).

\begin{tabular}{|c|c|c|c|c|c|c|}
\hline $\begin{array}{c}\text { Reference } \\
\text { Number }\end{array}$ & $\begin{array}{c}\text { Boom } \\
\text { Length }(\mathrm{m})\end{array}$ & $\begin{array}{c}\text { Boom } \\
\text { Angle }\left(^{\circ}\right)\end{array}$ & $\begin{array}{c}\text { Op. } \\
\text { Radius (m) }\end{array}$ & $\begin{array}{c}\text { Reach } \\
\text { Factor }(\mathrm{m})\end{array}$ & $\begin{array}{l}\text { Max. Sus. } \\
\text { Load (kg) }\end{array}$ & $\begin{array}{l}\text { Power } \\
\text { (watt) }\end{array}$ \\
\hline 30 & 72 & 30 & 84 & 71 & 127,006 & 1370 \\
\hline 31 & 72 & 38 & 78 & 64 & 138,346 & 1370 \\
\hline 32 & 72 & 30 & 89 & 76 & 117,934 & 1370 \\
\hline 33 & 72 & 38 & 82 & 68 & 129,274 & 1370 \\
\hline 34 & 72 & 30 & 94 & 80 & 113,398 & 1370 \\
\hline 35 & 72 & 38 & 86 & 73 & 124,738 & 1370 \\
\hline 36 & 72 & 38 & 73 & 59 & 149,685 & 1500 \\
\hline 37 & 72 & 30 & 84 & 70 & 136,078 & 1500 \\
\hline 38 & 72 & 38 & 78 & 63 & 147,418 & 1500 \\
\hline 39 & 72 & 30 & 89 & 75 & 129,274 & 1500 \\
\hline 40 & 72 & 38 & 82 & 67 & 140,614 & 1500 \\
\hline 41 & 72 & 30 & 94 & 79 & 122,470 & 1500 \\
\hline 42 & 72 & 38 & 86 & 72 & 133,810 & 1500 \\
\hline 43 & 72 & 30 & 84 & 69 & 170,097 & 1570 \\
\hline 44 & 72 & 38 & 77 & 62 & 181,437 & 1570 \\
\hline 45 & 72 & 30 & 91 & 76 & 156,489 & 1570 \\
\hline 46 & 72 & 38 & 84 & 68 & 170,097 & 1570 \\
\hline 47 & 72 & 30 & 95 & 80 & 142,882 & 1570 \\
\hline 48 & 72 & 38 & 87 & 72 & 156,489 & 1570 \\
\hline 49 & 72 & 30 & 100 & 85 & 129,274 & 1570 \\
\hline 50 & 72 & 38 & 92 & 77 & 142,882 & 1570 \\
\hline 51 & 72 & 30 & 84 & 69 & 192,777 & 2560 \\
\hline 52 & 72 & 35 & 80 & 65 & 201,849 & 2560 \\
\hline 53 & 72 & 38 & 77 & 62 & 208,652 & 2560 \\
\hline 54 & 72 & 30 & 89 & 74 & 181,437 & 2560 \\
\hline 55 & 72 & 35 & 84 & 70 & 190,509 & 2560 \\
\hline 56 & 72 & 38 & 82 & 67 & 197.313 & 2560 \\
\hline 57 & 72 & 30 & 86 & 69 & 238.136 & 2570 \\
\hline 58 & 72 & 35 & 82 & 65 & 249.476 & 2570 \\
\hline 59 & 72 & 38 & 79 & 62 & 260.816 & 2570 \\
\hline 60 & 72 & 30 & 93 & 76 & 215.456 & 2570 \\
\hline 61 & 72 & 35 & 88 & 71 & 226.796 & 2570 \\
\hline 62 & 72 & 38 & 85 & 68 & 238.136 & 2570 \\
\hline
\end{tabular}


Draglayout makes use of two main specifications of draglines for selection, these are reach factor (RF) and maximum suspended load (MSL). For this reason, all of the models in the models library (Draglayout models catalogue) should include their associated reach factor and maximum suspended load specifications. Also, it is important to note that Draglayout suggest other draglines having RF less than $5 \mathrm{~m}$ and greater than $35 \mathrm{~m}$ and enables user to analyse their corresponding productivities. This feature of the program was described in the sixth section of this chapter (Figure 26). Whereas, after selection of such models, selection will not be approved by the test and the program will alert the user from the console field. Reach factor criterion can be changed by selection criteria function by the user.

In order to have more options in the models pane working tab, in-build library of the program should be expanded and kept updated regularly with the recently developed draglines in market. 


\section{CHAPTER 5}

\section{CONCLUSIONS AND RECOMMENDATIONS}

\subsection{Conclusions}

This study is concentrated on simple side casting stripping method and the developed software and selection method is mostly convenient for this method, since this method describes the best selection criteria approach of this study. Toeing applied as an additional to the method to see the best picture if toeing is applicable and how minimum reach factor requirements can be decreased by toeing. Where, the Draglayout do not take in consideration amount of rehandle causing by toeing. It is important to notice that, production estimation of equipment calculated by Draglayout is not taking an account rehandle causing by toeing.

The result of this study introduces a new approach to the dragline selection process and the strip mine design. This thesis research is about automated dragline selection and developing computerized tool for this purpose, during the research process new convenient formulas and parameter were developed.

Developed formulas for production, helps to calculate the approximate production according to load ability of dragline and it is providing an idea in selecting a dragline and other equipment. The rehandle amount causing of toeing is not taken into consideration.

Developed Draglayout software is easy and useable tool for selecting dragline equipment. In order to make calculations easier, Draglayout provide to mining engineers working with different catalogues and gives ability in changing predesigned mine design. Also prove a friendly graphical interface to see full picture of designed mine layout. No doubt this ability will be improved in future and new 
useable functionalities will be added. Also it is possible interactively go back to mine design and redesign mine layout for proper selection and design.

\subsection{Recommendations}

For future improvements in software, it's important to add other conventional stripping methods to the software. Also rehandling calculations have to be added for best selection. More catalogues have to be added and the in-build library of the program should be updated on a regular basis for instance, once for every 2 year period. More information about characteristics of draglines such as clearance radius, clearance height, dumping height, digging depth, bearing pressure have to be added to the dragline catalogues for best choice. Also it is recommended to calculate real reach factor distance according to positioning of dragline and operating radius characteristics of equipment.

With the developing technologies in mining industry, the equipment selection methods will continue to develop and change. With the developing methods and new improvements in mine machinery technologies, computerized approaches also must be improved. More investment and attention must be put on computerised approaches in mining industry. The mine machinery and equipment providing companies have to get involved in to the process. The developed systems have to be tested with real parameters in the field.

No doubt software applications will increasingly continue to provide more convenience in all aspects of mining and mining engineering. It's important to support mining engineering graduates in software technologies and at least provide a knowledge about abilities of software programming. 


\section{REFERENCES}

Bucyrus Erie Company (1977), Dragline standard machine selection chart. Bucyrus Erie Co. Surface Mining Handbook. Bucyrus Erie Co.

Bucyrus Erie Company (2001), Bucyrus-Erie Company Handbook. Bucyrus Erie Co.

Erdem, B. and Çelebi, N. (1996), Development of an Expert System for Dragline and Stripping Method Selection in Surface Coal Mines. METU Thesis Collection, METU, Ankara.

Ford, Bacon and Davis Inc. (1975), Surface Coal Mining Machinery and Equipment, National Technical Information Service, Washington D. C.

Gibson, D. F. and Mooney, E. L. (1982), A Mathematical Programming Approach to the Selection of Stripping Technique and Dragline Size for Area Surface Mines, $17^{\text {th }}$ International symposium on the Application of Computers and Operations Research in the Mineral Industry, B. Johnson and R. J. Barnes (eds.), Society of Mining Engineers, AIME, New York.

Hamilton, B. W. (1990), Dragline Pit Design and Sensitivity Analysis, MSc Thesis Collection, Department of Mining, Metallurgical and Petroleum Engineering, University of Alberta, Canada.

Hill, K. J. (1989), A Review of BHP-Utah Coal Limited's Dragline Stripping Operations, Proceedings on Second Large Open Pit Mining Conference, The Australian Institute of Mining and Metallurgy, Victoria. 
Hrebar, M. J. (1990), Preliminary Dragline Selection for Surface Coal Mining Operations, Mine Planning and Equipment Selection. Singhal and Vavra (eds.), Balkema, Rotterdam.

Hrebar, M. J. and Dağdelen, K. (1979) Equipment Selection Using Simulation of Dragline Stripping Methods, $16^{\text {th }}$ International Symposium on the Application of Computers and Operations Research in the Mineral Industry, T. J. O'Neil (ed.), Society of Mining Engineers, AIME, New York.

Karpuz, C. and Demirel, N. (2016), Surface Mining, MINE 202 Lecture Notes, METU, Ankara.

Karpuz, C. and Hindistan, M. A. (2005). Açık İşletmelerde Üretim Yöntemleri. In: Eskikaya, Ş., Karpuz, C., Hindistan, M.A., and Tamzok, N. (eds.). Maden Mühendisliği Açık Ocak İşletmeciliği El Kitabı. Ankara. TMMOB Maden Mühendisleri Odas1, pp. 113-207.

Learmont, T. (1983), Productivity Improvement in Large Stripping Machines, Society of Mining Engineering, AIME.

McDonnell Douglas Co. (1978), Development of Operational Aids for Improved Dragline Utilization, Prepared for United States Department of Energy, Washington D. C.

Mirabediny, H. (1998), Dragline Simulation Model for Strip Mine Design and Development, University Wollongong Thesis Collection.

Morey, P.G. (1990), Surface Coal Mines, in Kennedy BA (ed.), Surface Mining. Society for Mining, Metallurgy, and Exploration, Inc., Englewood, pp. 499-500.

Nikforuk, P. N. and Zoerb, M. C. (1966), Analogue Computer Simulation of a Walking Dragline, Society of Mining Engineering, AIME, New York. 
Rai, P. (2004), Performance Assessment of Draglines in opencast mines, Department of Mining Engineering, Institute of Technology, Banaras Hindu University, Varanasi, India.

Rumfelt, H. (1961), Computer Methods for Estimating "Proper Machine Mass for Stripping Overburden”, Mine Planning and Equipment Selection 2000, Panagiotou G. N and Michalakopoulos T. N (eds).

Sadri, R. J. and Lee, C. D. (1982), Optimization of Single and Multiple Seam Dragline Mines Through Simulation, $17^{\text {th }}$ APCOM Symposium, Society of Mining Engineering, AIME, New York.

Sharma, D. K. and Singh, R. P. (1990), A Computer Model for Dragline Selection in Open Cast Mine Planning, Mine Planning and Equipment Selection. Singhal and Vavra (eds.), Balkema, Rotterdam.

Stefanko, R., Ramani, R. V., and Freko, M. R. (1973), An Analysis of Strip Mining Methods and Equipment Selection, Prepared for Office of Coal Research United State Department of Interior, The Pennsylvania State University.

Sweigard, R. J. (1992), Materials Handling, Loading and Haulage, SME Mining Engineering Handbook $2^{\text {nd }}$ edition, Colarado.

Zhang, Y. D., Yang, Y. R., and Li, K. M. (2003), Systems simulation for dragline selection in open cast mines, China University of Mining and Technology, Xuzhou, Jiangsu, China. 